\title{
Ergebnisse: Nach dem Studium
}

Spannend ist es zu sehen, welche Wege die (ehemaligen) Stipendiat*innen nach ihrem Studium gegangen sind. Sind sie nach Beendigung des Studiums in Deutschland in ihr Herkunftsland zurückgegangen oder sind sie in Deutschland geblieben bzw. in ein anderes Land weitergewandert? Die Feldforschungen in den fünf Untersuchungsländern haben vielfältige Antworten auf diese Frage zum Vorschein gebracht. Es ist deutlich geworden, dass (ehemalige) internationale Studierende in ganz vielfältiger Weise und in verschiedenen (Migrations-)Formen zur Entwicklung in ihren Herkunftsländern beitragen. Entsprechend des Designs unserer Studie wurde dies in Palästina insbesondere im Gesundheitssystem, in Indonesien im Technologie- und Wirtschaftssystem, in Ghana im Umwelt- und Landwirtschaftssektor, in Georgien im Rechtssystem sowie in Kolumbien im politischen System, speziell in der Friedens- und Demokratieentwicklung, aufgezeigt. Dabei wurde auch deutlich, dass es sich nicht um einen einseitigen Transfer von Nord nach Süd, sondern eher um einen zirkulären Austausch von Know-how und Gütern handelt, angestoßen und umgesetzt durch das Engagement der Alumni, die, so viel sei vorweggenommen, sowohl in ihr Herkunftsland zurückgekehrt als auch in Deutschland geblieben sind. In den ersten Teilen dieses Abschnitts wollen wir ein genaueres Bild der verschiedenen Engagementformen in den fünf Fallstudienländern zeichnen und darstellen, welche Auswirkungen die Migration der internationalen Studierenden auf die verschiedenen Gesellschaftsbereiche in ihren Herkunftsländer hatte. Im abschließenden Teil geht es dann um übergreifende Befunde, die für alle Fallstudienländer gelten. Hier geht es um Beiträge im Wissenschaftssystem, aber auch um Probleme bei der Wiedereingliederung und schließlich um Sichtweisen der Studierenden und Alumni auf das Thema „Entwicklung“ selbst.

S. Krannich und U. Hunger, Studierendenmigration und Entwicklung, https://doi.org/10.1007/978-3-658-32048-5_5 


\subsection{Stabilisierung und Differenzierung des Gesundheitssystems in Israel/ Palästina}

Palästina ist zwar ein international von vielen Staaten anerkannter, aber kein völlig unabhängiger Staat. Vielmehr hängt er in vielen wesentlichen Bereichen von den Entscheidungen des israelischen Staats ab und verfügt deswegen nur über einen begrenzten Haushalt und kann nur sehr eingeschränkt staatliche Aufgaben übernehmen. Zudem kann jederzeit ein Krieg zwischen Israel und Palästina ausbrechen, der auch das palästinensische Wirtschaft und Gesellschaft schwer schädigen könnte, wie dies zuletzt im Gaza-Krieg 2015 geschehen ist. Auch der palästinensische Gesundheitssektor hängt aufgrund der schwierigen und unsicheren Situation der palästinensischen Autonomiebehörde sehr stark von privaten und internationalen Initiativen ab. ${ }^{12}$

Aufgrund der beschränkten Studien- und Forschungsmöglichkeiten an den Universitäten in den Palästinensischen Autonomiegebieten gehen viele palästinensische Studierende, wenn sie es sich leisten können, zum Studium ins Ausland. Dies gilt insbesondere für Mediziner*innen, da man bis zu Beginn der 2000er Jahre in Palästina Medizin gar nicht studieren konnte. Inzwischen kann man zwar zumindest an zwei palästinensischen Universitäten Medizin studieren, an den Universitäten An-Najah National in Nablus und al-Quds in Ostjerusalem, viele Interessierte gehen aber weiterhin ins benachbarte Ausland, wie z. B. nach Jordanien oder Israel (wenn dies möglich). Noch zu Zeiten des Kalten Krieges zog es viele zudem in die Sowjetunion oder nach Rumänien. ${ }^{13}$

Nach 1990 sind viele Palästinenser*innen zum Medizinstudium ins westliche Ausland gegangen, vor allem nach Westeuropa und in die USA. Zum Ärger der palästinensischen Autonomiebehörde sind viele von ihnen nach dem Studium nicht zurückgekehrt, sondern haben sich als Ärt $^{*}$ innen im Ausland niedergelassen. Anfang der 2000er Jahre wurde geschätzt, dass fast die Hälfte aller palästinensischen Medizinstudent*innen im Ausland geblieben ist (Palestinian Health Ministry 2004).

Entsprechend schwierig gestaltet sich die Situation im palästinensischen Gesundheitssystem. Ein Indikator hierfür ist die Anzahl der Krankenhausbetten pro 1.000 Einwohner. In Deutschland liegt dieser Wert im Schnitt bei 8,3, in den palästinensischen Gebieten im Durchschnitt bei 1,1, laut der letzten offiziell be-

12 Dazu gehören vor allem die Hilfswerke der UN, staatliche Fördereinrichtungen wie USAid und private Stiftungen sowie christliche Hilfswerke und andere NGOs.

13 Fast alle unserer Interviewpartner, die nicht vom KAAD gefördert wurden und bereits vor 1990 studierten, taten dies in der Sowjetunion, Rumänien oder Jordanien. Dort konnten sie zumeist kostenlos studieren, weil die Sowjetunion im Kalten Krieg Palästina unterstütze. Demgegenüber wurde Israel überwiegend von den westlichen Staaten unterstützt (Khouri 1985). 
kannten Veröffentlichung des palästinensischen Gesundheitsministeriums aus dem Jahr 2004. Dabei fallen auf staatliche Krankenhäuser nur rund 20 Prozent der Krankenhausbetten (vgl. Palestinian Health Ministry 2004), auf private dementsprechend 80. Der private Gesundheitssektor ist damit in Palästina deutlich besser ausgestattet und bedeutsamer als staatliche Einrichtungen, was vor allem mit den vielen Spendengeldern in der Region zusammenhängt. ${ }^{14}$ So finanzieren etwa die katholische und evangelische Kirche in der Region um der heiligen Stadt Bethlehem viele Einrichtungen, so dass die Region auch die größte Krankenhausbettendichte in Palästina aufweist (Palestinian Health Ministry 2004). Zudem leiden die staatlichen Krankenhäuser an einer personellen Unterbesetzung und einem Mangel speziell an Fachärzt ${ }^{\star}$ innen. Viele der an staatlichen Krankenhäusern beschäftigten Ärzt*innen haben ihre Ausbildung an den schlecht ausgestatteten Universitäten in Jordanien oder, sofern sie schon älter sind, in ehemaligen Sowjetländern zu Zeiten des Kalten Krieges erhalten. Private Krankenhäuser verfügen demgegenüber nicht nur über mehr Geld, sondern auch über die entsprechenden Fachärzt*innen, die zumeist in westeuropäischen Ländern oder den USA studiert haben.

Auch aus Sicht in unserer Studie Interviewten ist die Gesundheitsversorgung in der Region immer noch unzureichend:

„In diesem Land herrscht vor allem ein Mangel an Ärzten in allen medizinischen Gebieten. Es gibt zu wenig Herzchirurgen, Onkologen, Handchirurgen, Spezialärzte für Verbrennungen und so weiter. Deswegen werden häufig allein schon falsche Diagnosen gegeben und falsche Behandlungen durchgeführt. Deswegen haben in diesem Land viele Leute kein Vertrauen in die ärztliche Behandlung. Dies gilt vor allem für staatliche Krankenhäuser. Dort gibt es keine Fachleute für komplizierte Behandlungen von besonderen Krankheiten" (Interview mit einer palästinensischen Alumna in Deutschland, Skype, 2016).

Vom KAAD wurden seit 1984 insgesamt 243 Stipendiat ${ }^{\star}$ innen aus Israel und den Palästinensischen Autonomiegebieten gefördert. ${ }^{15}$ Knapp die Hälfte davon hat im Bereich Medizin/Gesundheitswesen - d.h. Medizin, Zahnmedizin, Pharmazie, Gesundheitswissenschaft oder Psychologie - studiert oder in diesen Bereichen einen Forschungsaufenthalt in Deutschland gemacht. Die Rückkehrquoten der

14 Aufgrund der Nähe zu den historischen und religiösen Stätten spenden viele christliche Organisationen große Geldsummen an Krankenhäuser und soziale Einrichtungen.

15 Palästinensische Studierende und Forscher wurden jedoch schon seit der Gründung des KAAD im Jahr 1958 gefördert. Insgesamt waren es wahrscheinlich über 400 palästinensische Stipendiat*innen (Interview mit einer Vertreterin des KAAD, Bonn, 2016). 
palästinensischen Stipendiat ${ }^{\star}$ innen nach dem Studien- und Forschungsaufenthalten ist mit ca. 65 Prozent relativ gering (KAAD-interne Dokumente).

Die zurückkehrenden KAAD-Stipendiat ${ }^{\star}$ innen haben sich u. a. in dem Verein „AUDA - Vereinigung Rückkehrender Akademiker aus Deutschland“ zusammengeschlossen. Sie finden vor allem in privaten Krankenhäusern eine Arbeit oder lassen sich als selbstständige Ärzt*innen nieder, was im Übrigen auch für viele andere Ärzt ${ }^{\star}$ innen gilt, die in anderen westeuropäischen Ländern oder den USA studiert haben. Ein herausragendes Beispiel für eine erfolgreiche Rückkehrerin ist eine ehemalige KAAD-Stipendiatin, die heute als Chefärztin das größte und am besten ausgestattete Kinderkrankenhaus in Palästina, das Caritas Baby Hospital in Bethlehem, leitet, und die 2007 vom KAAD für ihre Erfolge als Klinikleiterin mit dem Peter-Hünermann-Preis ausgezeichnet wurde. ${ }^{16}$ Unter ihrer Leitung werden jedes Jahr mehr 50.000 Patient*innen behandelt. In ihrer täglichen Arbeit greift sie dabei nicht nur auf ihr in Deutschland erworbenes Wissen zurück, sondern auch auf ein breites Netzwerk von Kolleg*innen in Deutschland und Palästina. So tauscht sie sich nach eigenen Angaben regelmäßig mit Mediziner*innen in Freiburg, Tübingen und Hamburg über seltene Kinderkrankheiten aus. Dabei werden z. B. Röntgenbilder für ein Konsil nach Deutschland geschickt. Dadurch konnte schon das „eine oder andere Menschenleben“ gerettet werden, wie die Klinikleiterin berichtet. „Dies wäre nicht möglich gewesen, wenn ich nicht in Deutschland studiert hätte“, sagt sie. Dabei bezieht sie sich nicht nur auf die angesprochenen Kontakte in Deutschland, sondern auch auf das in Deutschland erworbene Fachwissen, das, so die ehemalige KAAD-Stipendiatin, in Palästina bis heute nicht erworben werden könne, aber dringend benötigt werde. Nur sie selbst und wenige Kolleg*innen, die selber im Ausland studiert hätten, würden das Fachwissen aber jetzt an jüngere Kolleg*innen in Palästina weitergeben. ${ }^{17}$

Während auf der einen Seite KAAD-Alumni Karriere als Angestellte in privaten Krankenhäusern machen, die von internationalen Hilfsorganisationen gefördert werden, haben sich auf der anderen Seite Alumni selbstständig gemacht und eigene

16 Die Alumna studierte in den 1990er Jahren an der Ludwig-Maximilians-Universität Medizin und promovierte dort zum Thema „Neue therapeutische Ansätze in der Behandlung von Frühgeborenen“ und wurde danach mit Unterstützung eines KAAD-Stipendiums zur Fachärztin an der Universität Würzburg ausgebildet. Nachdem sie für ein paar Jahre nach Bethlehem zurückkehrte, um als Fachärztin am Caritas Baby Hospital zu arbeiten, ging sie 2003 erneut mit einem KAAD-Stipendium nach Deutschland, um sich in den Bereichen Intensivmedizin und Ultraschalldiagnostik weiterzubilden (KAAD 2008: 86).

17 Im Jahr 2015 wurde sie für ihr Engagement mit dem Preis der „KAAD-Stiftung Peter Hünermann" ausgezeichnet (KAAD 2015). 


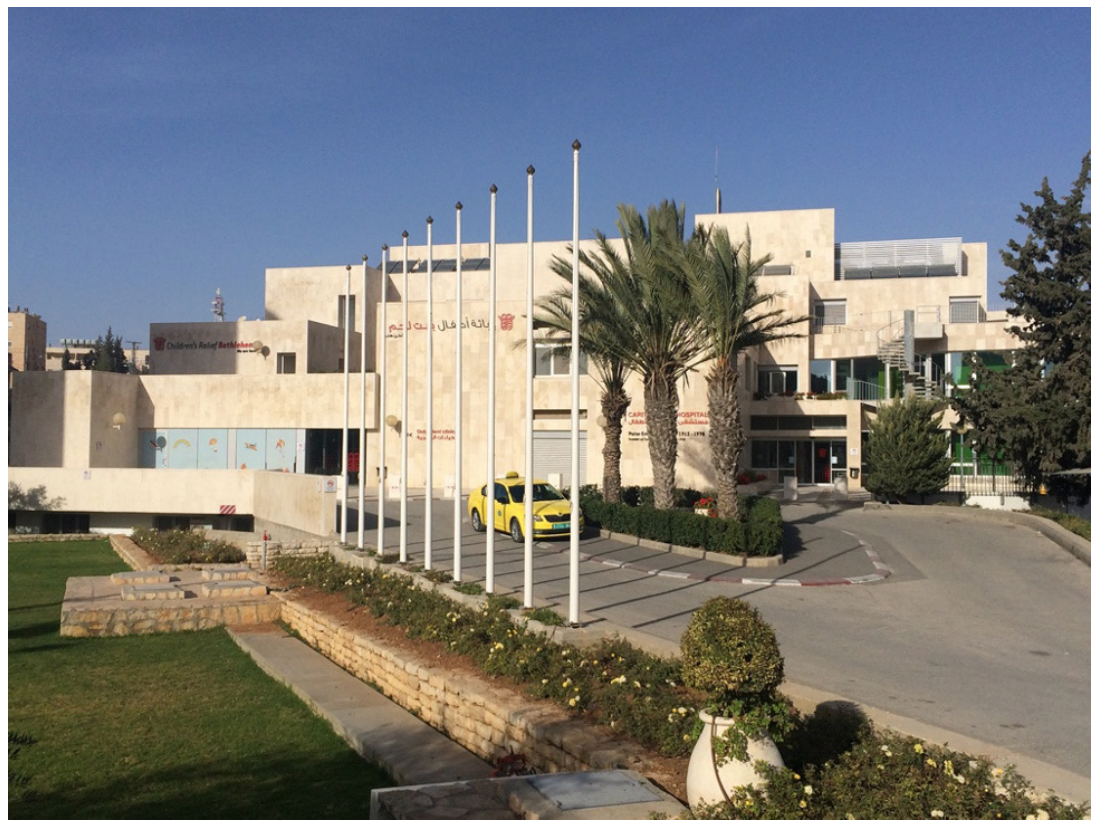

Aufnahme 1 Caritas Baby Hospital Bethlehem

Quelle: Eigene Aufnahme

Privatpraxen oder -kliniken in Palästina nach der Rückkehr aus Deutschland eröffnet. Dazu gehört z. B. ein KAAD-Alumnus, der 1999 mit einem KAAD-Stipendium einen dreimonatigen Weiterbildungskurs als Orthopäde an einer Klinik in Kirchberg/Sachsen machte und 2002 seine eigene Klinik Al Shifa in Beit Sahour, einem Nachbarort von Bethlehem, eröffnete. In der Klinik sind mittlerweile knapp 40 Ärzt*innen bzw. Pflegekräfte beschäftigt, darunter Spezialist*innen aus Radiologie, Orthopädie und Physiotherapie. Viele von ihnen haben ebenfalls in westeuropäischen Ländern studiert. Die Patient*innen kommen mittlerweile aus allen Teilen Palästinas, weil sich die qualitativ hochwertige Behandlungsweise herumgesprochen hat und die Klinik über die neuesten Geräte verfügt. Diese hat der Gründer im Übrigen mit Hilfe von Krediten, die er während seiner Weiterbildungsaufenthalte in Italien (2006 und 2010) und den USA (2007) aufgenommen hat, finanziert. Ein Schwerpunkt der Klinik besteht in der Diagnose seltener Krankheiten, für deren Erkennung ein spezielles Know-how notwendig ist. Er sagte dazu: 
„Wir haben uns auf Diagnosen spezialisiert, weil es wichtig ist erst einmal die richtige Krankheit zu erkennen bevor man operiert. In palästinensischen Krankenhäusern fehlt den Ärzten häufig die Expertise und sie fangen an zu operieren, obwohl sie die falsche Krankheit diagnostiziert haben. Zudem gibt es keine Kontrolle der Ärztearbeit in staatlichen Krankenhäusern. Menschen können aufgrund falscher Behandlungen sterben, und es gibt keine Konsequenzen für die Ärzte. Das ist ein großes Problem in Palästina" (Interview mit einem palästinensischen Alumnus in Beit Sahour, Palästina, 2016).

Nach erfolgreicher Diagnose werden die Patient*innen an Krankenhäuser überwiesen, die über die notwendigen Operationsgeräte und Krankenbetten verfügen. Hierbei handelt es sich zumeist ebenfalls um private Krankenhäuser, wie dem Caritas Baby Hospital oder der Dips Clinic in Bethlehem, in denen oftmals Fachärzt*innen praktizieren, die im Ausland studiert haben und über das entsprechende Fachwissen verfügen. Die Diagnosen in seiner Klinik sind im Vergleich zu anderen privaten Kliniken günstig, z. B. kostet eine Röntgen-Untersuchung 50 Schekel (12,50 Euro) oder eine MRT-Behandlung 500 Schekel (125 Euro). Da die meisten Patient ${ }^{\star}$ innen nicht privat versichert sind und die Kosten von der staatlichen Krankenversicherung nicht übernommen werden, müssen die Patient*innen meistens aus der eigenen Tasche in bar bezahlen.

Interessant ist auch der Fall von zwei palästinensischen Schwestern (64 und 68 Jahre alt), die in ihrer eigenen Wohnung in Ramallah eine kleine Kinderklinik eröffnet haben. Beide wurden während ihrer sechsmonatigen medizinischen Weiterbildungen 2004 bzw. 2009 in Deutschland vom KAAD gefördert. Bereits zuvor hatten beide in den 1970er Jahren in Deutschland studiert und in den 1980er Jahren promoviert. Nach dem Studium ist die ältere Schwester sofort wieder zurück nach Palästina gegangen, um sich gegen die medizinische Unterversorgung von Kindern zu engagieren. Die jüngere Schwester arbeitete nach dem Studium noch bis 1986 als Neurochirurgin in Kiel, bevor sie ebenfalls nach Palästina zurückkehrte. Dort konnten beide keine Anstellung in einem staatlichen Krankenhaus bekommen, so dass beide lange als Krankenschwestern arbeiten mussten. Diese Zeit fiel ihnen sehr schwer:

"Ich habe mich oft gefragt: Warum habe ich so viel und lange in Deutschland studiert, wenn man hier keine Beachtung findet und keinen Beruf. Das liegt natürlich daran, dass ich eine Frau und Christin bin in einer muslimisch dominierten Welt" (Interview mit einer palästinensischen Alumna in Ramallah, Palästina, 2016).

Jedoch hatten sie über die Jahre genügend Geld angespart, um 1983 eine kleine Kinderpraxis in ihrer Privatwohnung im Zentrum von Ramallah zu eröffnen, wo sie 
ihrer Arbeit nachgehen können. Dafür haben sie gebrauchte Untersuchungsgeräte von einem bekannten Kollegen in Deutschland gekauft und haben sie alleine mit ihrem Auto nach Ramallah gefahren. ${ }^{18}$

Während die ältere Schwester sich ausnahmslos um die Kinderarztpraxis kümmerte, schaffte es die jüngere Ende der 1980er Jahre eine Stelle als Neurochirurgin an einem staatlichen Krankenhaus in Ramallah zu bekommen. Sie war damit erst die zweite praktizierende Neurochirurgin in Palästina. In ihrer Funktion als Chefärztin trug sie wesentlich dazu bei, die Neurochirurgie in Palästina mit aufzubauen. Zurzeit behandeln die beiden Schwestern bis zu 50 Kinder pro Woche in ihrer kleinen Privatpraxis, wobei sie, weil die meisten Patient*innen keine Privatversicherung haben, nur bis zu 60 Schekel (15 Euro) für eine Behandlung nehmen, oder, wenn die Eltern dies auch nicht zahlen können, es auch kostenlos machen. Zudem engagieren sich beide ehrenamtlich für kirchliche Einrichtungen und soziale NGOs (Interview mit den beiden Alumnae in Ramallah, Palästina, 2016).

Eine andere KAAD-Alumna hat eine private Zahnarztpraxis in Ramallah gegründet, die stark nachgefragt wird. Die Praxiseinrichtung hat sie vor zehn Jahren von einem niederländischen Zahnarzt mit allen Instrumenten und Geräten gekauft, nachdem sie dort für 2 Jahre als angestellte Zahnärztin arbeite. Zuvor führte sie mit Unterstützung des KAAD im Jahr 2002/03 einen dreimonatigen Weiterbildungskurs in Köln durch. Dieses Wissen war so noch nicht in Palästina vorhanden. Ihr Beruf macht ihr großen Spaß, jedoch hat sie mit einer täglichen Herausforderung zu kämpfen: Da sie in Ostjerusalem wohnt, muss sie tagtäglich die Grenze zwischen Jerusalem und Ramallah mit dem Auto überqueren, um zu ihrer Zahnarztpraxis nach Ramallah zu kommen. Aufgrund der strengen Grenzkontrollen und je nach Sicherheitslage kann das bis zu drei Stunden pro Weg dauern. Das kostet viel Kraft und Zeit, die sie eigentlich für die Patient*innen in Ramallah benötigt (Interview mit einer palästinensischen Alumna, Skype, 2017).

Nicht nur in der West Bank haben KAAD-Alumni eine Anstellung in einem privaten Krankenhaus bekommen, sondern auch in Israel, obwohl dies aufgrund der Minderheitenstellung und Benachteiligung von Palästinenser*innen in der israelischen Gesellschaft, auch wenn sie selbst israelische Staatsbürger sind, schwieriger ist. Eine KAAD-Alumna hat es geschafft eine Stelle als Gesundheitsberaterin an einem privaten Krankenhaus in Jerusalem zu bekommen. Das Krankenhaus wird von palästinensischen und israelischen Ärzt*innen geleitet und von einer

18 Dabei gab es jedoch große Probleme mit den israelischen Zollbeamten, die einige der Geräte konfiszieren wollten. Mit ein wenig Verhandlungsgeschick gelang es ihr jedoch die meisten der Geräte nach Ramallah zu bringen (Interview mit einer palästinensischen Alumna in Ramallah, Palästina, 2016). 
israelischen NGO unterstützt. Dort ist sie als eine Art Krankenpflegerin für die Betreuung der Patient ${ }^{\star}$ innen zuständig, aber auch in der Krankenhausverwaltung und im Management tätig. Sie wuchs als Muslimin mit israelischer Staatsbürgerschaft in dem arabischen Ort Um El Fahem an der Nordwestgrenze zur West Bank auf, erwarb einen Bachelor im Studiengang Nursing an der renommierten Hebrew University in Jerusalem und machte mit Unterstützung des KAAD einen einjährigen Master in International Health an der Universität Heidelberg (2014/15) (Interview mit einer palästinensischen Alumna in Tel Aviv-Jaffa, Israel, 2016).

Ferner tragen auch Alumni zur Stabilisierung des Gesundheitswesens in Palästina bei, die nicht Medizin studiert haben und somit nicht als Ärzt*innen tätig sind, sondern als Apothekerinnen, Psycholog*innen, Lebensmittelchemiker ${ }^{\star}$ innen oder Arzneimittelhersteller ${ }^{*}$ innen beschäftigt sind. So arbeitete ein Alumnus als Lebensmittelchemiker für ein privates Unternehmen und das Gesundheitsministerium in Ramallah. Dabei war er für die Untersuchung der Lebensmittel-, Wasser- und Medikamentenqualität zuständig. Er sagte, dass immer noch zu viele Lebensmittelchemiker*innen in Palästina fehlen. Er studierte von 1999 bis 2005 Lebensmittelchemie an der Universität Münster, von 1999 bis 2002 hatte er ein Stipendium vom KAAD (Interview mit einem palästinensischen Alumnus in Bethlehem, Palästina, 2016).

Ein weiterer KAAD-Alumnus hilft im Rahmen seiner Tätigkeit als Regionaldirektor des Vereins Christen helfen Christen im Heiligen Land e. V. ${ }^{19}$ Bedürftigen einen Zugang zum Gesundheitssystem zu verschaffen, wie z. B. durch die Erstattung von Arzt- und Medikamentenkosten. Er studierte mit einem KAAD-Stipendium von 2005 bis 2010 Betriebswirtschaftslehre an der Universität Augsburg und arbeitete seit seiner Rückkehr auch in den Auslandsbüros der Konrad-Adenauer-Stiftung (KAS, Ramallah), der Friedrich-Naumann-Stiftung (FNS, Amman/Jordanien) und der Gesellschaft für Internationale Zusammenarbeit (GIZ, Ramallah) (Interview mit einem palästinensischen Alumnus in Bethlehem, Palästina, 2016).

Eine weitere KAAD-Alumna aus Nazareth setzt sich im Rahmen ihrer Arbeit für die NGO Al Tufula Nazareth Institute ${ }^{20}$ für die Gesundheit von Kleinkindern

19 Christen helfen Christen im Heiligen Land e. V. ist ein gemeinnütziger Verein mit Hauptsitz in Regensburg leistet materielle und ideelle Direkthilfe für notdürftige Menschen in Palästina, beispielsweise durch Zahlung von Schulgeld, Erstattung von Arzt- und Medikamentenkosten. Ferner unterstützt der Verein gezielt Christ*innen in der Region Bethlehem, da sich diese in einer Minderheitenrolle befinden und der internationalen Unterstützung von Christ*innen im Ausland bedürfen (Interview mit Elias Awad, Bethlehem, 22. November 2016). Der Verein finanziert sich vor allem durch Spenden in Deutschland (vgl. Christen helfen Christen 2017).

20 Die NGO Al Tufula Nazareth Institute wurde 1984 von palästinensischen Frauen in Israel gegründet. Die Arbeit der NGO konzentriert sich auf die Bildung und Gesundheit 
und Mütter ein, vor allem durch Aufklärung in Workshops zu gesunder Ernährung und Lebensweise sowie zu Mutterschaftsberatung in der Schwangerschaft und frühkindlichen Erziehung. Während ihres Psychologiestudiums in Deutschland hat sie zahlreiche Kontakte aufgebaut, von denen sie bei ihrer Arbeit heute noch profitiert. Darauf sind auch die engen Kooperationsbeziehungen zwischen dem $\mathrm{Al}$ Tufula Nazareth Institute und Misereor bzw. Caritas, die verschiedene Frauenprojekte des Vereins fördern, zurückzuführen (Interview mit einer palästinensischen Alumna in Nazareth, Palästina, Skype, 2016).

Unsere Interviews in Deutschland haben deutlich gemacht, dass Alumni auch von Deutschland aus zur Entwicklung des palästinensischen Gesundheitssystems beitragen können. Ein Paradebeispiel hierfür ist ein Alumnus, der an der Universität Regensburg mit einem KAAD-Stipendium bis 2011 Humanmedizin studierte und seitdem als Facharzt an einem Krankenhaus in Essen arbeitet. Er hat zusammen mit einer Klinik in Palästina ein Austauschprogramm aufgebaut, in dessen Rahmen jedes Jahr palästinensische Ärzt ${ }^{\star}$ innen zu einer sechsmonatigen Fortbildung nach Deutschland kommen. Dabei können die eingeladenen Ärzt*innen sich in allen medizinischen Fachbereichen weiterbilden, insbesondere an Geräten und Instrumenten, die es in palästinensischen Krankenhäusern (noch) nicht gibt oder die es erst seit kürzerer Zeit gibt, aber für die noch nicht das ausreichende Know-how und die Erfahrungen vorhanden sind. Dabei sind auch mehrere deutsche Ärzt*innen involviert, die ihr Fachwissen an die Gastärzt ${ }^{*}$ innen weitergeben. Somit erwerben die palästinensischen Ärzt*innen wertvolles Know-how für ihre Arbeit in den palästinensischen Krankenhäusern. Für die palästinensischen Ärzt*innen ist die Weiterbildung kostenlos.

Indem das Wissen durch die Ärzt*innen immer wieder nach Palästina zurückgetragen wird, würde seiner Meinung nach eine viel größere Wirkung erzielt als durch seine eigene (einmalige) Rückkehr:

„Diese Weiterbildungsmaßnahmen haben einen Multiplikatoreffekt. Die Ärzte eignen sich wertvolle Kenntnisse an, die sie aufgrund der schlechten Ausstattung in Palästina nicht bekommen können, und geben diese an ihr Team von vier, fünf Mitarbeitern weiter. Dadurch unterstütze ich insgesamt über 20 Ärzte und Pflegekräfte. Würde ich zurückgehen, würde ich nur mein Team unterstützen, wenn ich überhaupt eine Stelle als Arzt finden würde" (Interview mit einem palästinensischen Alumnus in Deutschland, Skype, 2016).

sowie das Empowerment von sozial benachteiligten Frauen und Kindern in Israel und Palästina (vgl. Al Tufula Nazareth Institute 2016). 
Zudem verdient der Arzt in Deutschland nach eigener Auskunft ein Vielfaches von dem, was er in Palästina verdienen würde. Mit einem Teil seiner monatlichen Ersparnisse finanziert er die volle Rente seiner Eltern, die in einem kleinen Dorf in der West Bank leben. Seine Eltern könnte er nicht unterstützen, wenn er in Palästina arbeiten würde, weil das monatliche Einkommen dort nicht dafür reichen würde (Interview mit einem palästinensischen Alumnus in Deutschland, Skype, 2016).

Gegen eine Rückkehr nach Palästina spricht für ihn zudem - neben der dort existierenden politischen Unsicherheit - auch die medizinische Eignungsprüfung für im Ausland ausgebildete Mediziner*innen, die vom palästinensischen Staat angeordnet ist und von Vertreter*innen des Gesundheitsministeriums durchgeführt werden. Ein Medizinabschluss von einer deutschen Universität (oder von anderen westeuropäischen Ländern) wird vom palästinensischen Staat nicht automatisch anerkannt. Diese Regelung wurde von dem Regionalbeauftragten des palästinensischen Gesundheitsministeriums für Bethlehem - der selbst Medizin in Russland in den 1980er Jahren studierte - folgendermaßen begründet:

„Wir akzeptieren in Palästina nur die Medizindiplome aus den Ländern, die auch unsere Medizindiplome anerkennen. Deutschland tut das nicht. Deswegen müssen auch Palästinenser, die in Deutschland ihren Abschluss gemacht haben, hier zuerst eine Prüfung ablegen, bevor sie hier als Arzt arbeiten dürfen. Das gilt nicht nur für staatlichen Krankenhäuser, sondern auch für private" (Interview mit dem Regionalbeauftragten des palästinensischen Gesundheitsministeriums in Bethlehem, Palästina, 2016).

Dieser Prüfung müssen sich auch palästinensische Ärzte unterziehen, wenn sie im Ausland Medizin studiert haben und an einem staatlichen Krankenhaus in Palästina arbeiten wollen. Die Prüfung ist, so der Alumnus, enorm schwer, und viele rückkehrende Ärzt ${ }^{*}$ innen bestehen die Prüfung nicht:

„Die Prüfung macht überhaupt keinen Sinn. Wir sind besser ausgebildet als die meisten Ärzte in Palästina. Die meisten von uns würden die Prüfung auch locker bestehen, aber es werden Fragen gestellt, die häufig mit unserem Fach nichts zu tun haben, und viele lässt man absichtlich durchfallen. Außerdem kann man die Prüfung nur auf Englisch machen, was es für die erschwert, die mehr Deutsch oder Arabisch sprechen. Ich vermute, dass man uns nicht im Land haben will, weil wir als Konkurrenz zu den Ärzten an staatlichen Krankenhäusern angesehen werden. Die haben Angst, dass wir ihre Jobs wegnehmen, weil wir eben besser ausgebildet sind" (Interview mit einem palästinensischen Alumnus in Deutschland, Skype, 2016). 
Auch ein weiterer Alumnus beklagt die fehlende Unterstützung und Wertschätzung seiner in Deutschland erworbenen Fähigkeiten, die er auch für die Entwicklung in Palästina einsetzen könnte. Jedoch sieht er als promovierter Psychologe und aktueller Postdoktorand an der Universität Regensburg keine Zukunft in Palästina, und zwar aus dem einfachen Grund, weil es dort kaum praktizierende Psycholog*innen, geschweige denn entsprechende Forschungseinrichtungen gibt. In ganz Palästina gibt es nur drei Universitäten, die einen Bachelorstudiengang in Psychologie anbieten, und das erst seit ein paar Jahren. Promotionsstudiengänge im Fach Psychologie gibt es keine (British Psychological Society 2016). Daher kann er sich nur vorstellen, von Deutschland aus zur Entwicklung und Etablierung der Psychologie in Palästina beizutragen. Zurzeit konzentriert er sich allerdings auf seine Forschungsarbeiten in Deutschland zu Therapie- und Handlungsmethoden von verschiedenen Angstformen. Daneben behandelt er auch Kriegsflüchtlinge aus Syrien und anderen arabischen Ländern in Regensburg, die aufgrund ihrer Kriegs- und Fluchterfahrungen traumatisiert sind. Er betont, dass seine Arbeit unverzichtbar ist, weil er der einzige arabisch sprechende Therapeut in Regensburg sei und die Kultur der Geflüchtete kenne (Interview mit einem palästinensischen Alumnus in Deutschland, Skype, 2017).

Ein weiterer Kollege forscht und lehrt als Psychologe an der Ludwig-MaximiliansUniversität und sieht seine Zukunft ebenfalls in Deutschland, obwohl er gerne nach Haifa zurückkehren würde. Die schlechten Berufsaussichten und die mangelnden Aufstiegschancen für Araber*innen an israelischen Hochschulen lassen für ihn keine Rückkehr zu. Er promovierte mit Unterstützung eines KAAD-Stipendiums (von 2002 bis 2005) in München und forscht jetzt im Bereich Arbeits- und Organisationspsychologie. Er will versuchen über Wissenschaftsnetzwerke zur Entwicklung einer psychologischen Forschung in Israel und Palästina beizutragen. Wie dies konkret gestaltet werden kann, ist ihm allerdings noch unklar, da es in Palästina, wie eben erwähnt, kaum Forscherinnen gibt, die als Kooperationspartnerinnen in Frage kommen. Einen konkreten Entwicklungsbeitrag leistet er aber bereits jetzt: Er pflegt regelmäßigen Kontakt zu Familienmitgliedern und Freundinnen in Haifa und schickt regelmäßig Geld an seine Eltern, die darauf angewiesen sind ((Interview mit einem palästinensischen Alumnus in Deutschland, Skype, 2017).

Ein anderer ehemaliger KAAD-Stipendiat hat sich im Saarland als Hausarzt niedergelassen, nachdem er von 1999 bis 2006 an der Universität des Saarlandes Medizin studiert hatte. Seine Arztpraxis in Homburg hat er 2013 von einem Kollegen, mit dem er zuvor ein Jahr zusammenarbeitete, mit kompletter Ausstattung übernommen. Neben seiner ärztlichen Tätigkeit in Homburg hat er zusammen mit seinem Bruder, der ebenfalls Arzt ist und im Gazastreifen wohnt, ein transnationales Hilfsnetzwerk zwischen dem Gazastreifen und Deutschland aufgebaut. 
So haben beide ein Patenschaftsprogramm für bedürftige Kinder im Gazastreifen ins Leben gerufen. ${ }^{21}$ Patient ${ }^{*}$ innen in Deutschland übernehmen dabei die Kosten für die Behandlung von kranken Kindern im Gazastreifen. Bisher wurden über 50 solcher Patenschaften abgeschlossen. Teilweise würden Arztrechnungen von „bis zu 200 Euro" für die Patenkinder in Palästina übernommen. Dabei spielte sicher auch das über Jahre aufgebaute Vertrauensverhältnis zu seinen Patient ${ }^{*}$ innen eine Rolle, so dass die Patenschaften "mit einem guten Gefühl für eine gute Sache“ übernommen werden können.

Zudem spendete der ehemalige KAAD-Stipendiat mehrfach Geld oder medizinische Gerätschaften, zuletzt eine Summe von knapp 10.000 Euro für den Transport von Untersuchungsinstrumenten und Medikamenten aus dem Saarland nach Gaza-Stadt. Die Spenden wurden von seinem Bruder entgegengenommen und an verschiedene kleinere Praxen und Krankenhäuser in der Region verteilt. Der Alumnus ist überzeugt:

"Ich kann viel mehr helfen, weil ich in Deutschland lebe. Hier habe ich ein höheres Einkommen, mehr Sicherheit und den schnellen Zugang zu den Arbeitspartnern. Von Gaza aus könnte ich die Hilfsprojekte für Mediziner dort nicht verwalten. Keinem wäre damit geholfen, wenn ich zurück nach Gaza gehen würde. Hier habe ich auch mehr Ressourcen, das heißt schnelles Internet, Telefon und eine gute Infrastruktur. Das ist alles nicht der Fall in Gaza"(Interview mit einem palästinensischen Alumnus in Deutschland, Skype, 2017).

Gelegentlich arbeitet er dabei mit der GIZ zusammen, die vor allem die Transporte der Instrumente mitfinanziert. Oder auch mit der deutschen Krankenversicherung AOK, die mehrere Rollstühle gestiftet hatte. Einmal kooperierte er auch mit der palästinensischen Regierung. Das würde er aber nicht wieder machen, weil einige Gelder und Instrumente dabei verschwunden sind. Überhaupt sieht er seine Arbeit aufgrund der extrem unsicheren Lage und der Isolation des Gazastreifens in permanenter Gefahr. Allein die Bombenangriffe der israelischen Armee in den letzten drei Jahren zerstörten einige der Arztpraxen, die er mit seinem Bruder unterstützt hat. Ein weiteres Problem ist der unsichere Transport der Gegenstände nach Gaza. Es gab schon Fälle, bei denen ein Liefercontainer über ein Jahr an der ägyptischen

21 Im Gazastreifen, dem anderen Teil des Palästinensischen Autonomiegebietes südwestlich von Israel, engagieren sich ebenfalls Alumni für die Entwicklung des Landes. Da viele Alumni nach dem Studium aufgrund der extrem unsicheren Lage im Gazastreifen nicht zurückkehren konnten, versuchen sie von Deutschland aus über Kontakte und Netzwerke die Situation für die palästinensische Bevölkerung im Gazastreifen zu verbessern. 
Grenze stand, weil ihn die israelischen Grenzsoldaten nicht nach Gaza hinein transportieren lassen wollten.

Auch ein weiterer KAAD-Alumni aus Palästina, der heute als Apotheker in Deutschland arbeitet, schickt regelmäßig Container voll mit Labor- und Untersuchungsgeräten, Büchern und anderen Sachen nach Gaza. Nachdem er in den 1990er Jahren mit einem KAAD-Stipendium Pharmazie an der Universität Würzburg studiert hatte, ging er sofort nach Gaza-Stadt zurück, um eine Forschungsstelle an der dortigen Universität zu übernehmen. Dabei nutzte er seine in Deutschland geknüpften Kontakte, um Ende der 1990er Jahre das erste Institut für Pharmazie in Gaza aufzubauen. Dieses leitete er bis 2009, als er sich dazu entschied der Wissenschaft den Rücken zukehren und mit seiner Familie wieder nach Deutschland zu gehen. In München arbeitete er zunächst für ein halbes Jahr in einer Apotheke, bevor er seine eigene Apotheke eröffnete. Die Kontakte nach Gaza sind nicht abgebrochen. Im Gegenteil: Er schickt regelmäßig Arznei- und Pflegeprodukte nach Gaza, die dort nicht erhältlich sind. In diesem Rahmen liefert er jährlich auch Pflegeprodukte im Wert von bis zu 200.000 Euro an verschiedene kleine Drogerien in Gaza. Der Alumnus sagt, dass er durch diese Kooperationen über 20 Arbeitsplätze in Gaza geschaffen habe (Interview mit einem palästinensischen Alumnus in Deutschland, Skype, 2017).

Im Gegensatz dazu möchte ein anderer KAAD-Alumnus aus Rheinland-Pfalz sofort in seine Heimatstadt in Gaza zurückkehren, wenn sich die politische Lage entspannt hat und der Frieden sicherer ist. Er hat mit einem Stipendium des KAAD von 2008 bis 2009 an der Universität Mainz Medizin studiert und danach sofort eine Arbeit als Facharzt für Orthopädie und Unfallchirurgie an einer Klinik in Bad Kreuznach bekommen. Seit vier Jahren arbeitet er nun als Wirbelsäulenchirurg in einem Krankenhaus in Koblenz. Trotz seines sicheren und gut bezahlten Jobs plant er seine Rückkehr nach Gaza. Er hat bereits genügend Geld gespart, um eine kleine Arztpraxis für Orthopädie in seinem Heimatort in Gaza aufzubauen. Eine solche Praxis gibt es dort bisher noch nicht. Seinen Bruder, der in Gaza lebt, hat er bereits damit beauftragt Materialien einzukaufen, die er für den Bau einer Praxis benötigt und die rechtzeitig beschafft werden müssen, weil in Gaza Baumaterial und Rohstoffe knapp sind. Dafür schickt er seinem Bruder in regelmäßigen Abständen Geld. Da sein Vater bereits vor Jahren gestorben ist, unterstützt er auch seine Mutter finanziell. Wann er jedoch zurück nach Gaza zieht, kann er noch nicht absehen. Es hängt alles von der politischen Situation und der Sicherheitslage in Gaza ab (Interview mit einem palästinensischen Alumnus in Deutschland, Skype, 2017).

Insgesamt kann man also sagen, dass die palästinensischen Alumni eine wichtige Rolle für ihr Heimatland spielen. So wurden durch die ehemaligen Studierenden neue Diagnose- und Therapieansätze nach Palästina gebracht, die es hier vorher 
noch nicht gab bzw. die teilweise noch nicht bekannt waren. Hierzu zählen auch differenzierte Diagnose- und Therapieansätze in der Dermatologie, Onkologie, Orthopädie oder Urologie, die von Deutschland aus über die Alumni nach Palästina gekommen sind. Das Wissen, das die Alumni im Ausland erworben haben, wird dabei, wie wir gesehen haben, nicht nur in die Herkunftsländer transferiert, sondern auch multipliziert.

\subsection{Innovation und Vernetzung des Technologiesektors in Indonesien}

Indonesien gehört neben Korea und Indien zu den frühen Schwerpunktländern des KAAD im asiatischen Raum, wobei bereits in den 1950er Jahren erste Kontakte mit zivilgesellschaftlichen Vertretern in Indonesien geknüpft wurden (Interview mit dem Leiter des KAAD-Asienreferats). Seitdem haben zahlreiche indonesische Studierende an den Stipendienprogrammen des KAAD teilgenommen, so dass es mittlerweile mehrere Alumni-Generationen gibt. Wie bereits ausgeführt, wurde Indonesien aber hauptsächlich deswegen als Fallstudienland herangezogen, weil viele Indonesier*innen im MINT-Bereich vom KAAD gefördert wurden. In den letzten 15 Jahren waren dies rund 60 Prozent aller indonesischen Stipendiat*innen (interne KAAD-Dokumente).

Indonesien ist mit über 260 Mio. Menschen das viertbevölkerungsreichste und das größte muslimisch geprägte Land der Welt, dessen Bevölkerung sich in den letzten 30 Jahren verdoppelt hat. Der südostasiatische Inselstaat hat ein BIP/ Kopf in KKP von 11.600 US-Dollar und ist in den letzten 20 Jahren mit einem Wirtschaftswachstum von bis zu 10 Prozent sehr stark gewachsen. Indonesien ist zudem seit 2008 ein G-20-Mitgliedsstaat. Mit derzeit über 4.600 privaten und staatlichen Institutionen im Bereich der tertiären Ausbildung hat Indonesien eines der größten Hochschulsysteme der Welt. Die meisten Universitäten befinden sich in der 30 Millionen Hauptstadt Jakarta und wurden nach der Unabhängigkeit von den Niederlanden 1949 gegründet (DAAD 2018a: 9).

Seit den 2000er Jahren sind ca. zwei Drittel von den durch den KAAD geförderten Stipendiat*innen nach ihrer Förderung wieder nach Indonesien zurückgekehrt. Damit weist Indonesien wie Israel/Palästina eine durchschnittliche Rückkehrquote auf. Die Alumni haben bereits einen KAAD-Alumniverein in Jakarta gegründet (Ikatan Alumni KAAD di Indonesia), dessen Arbeit sich hauptsächlich auf religiöse Themen konzentriert und dabei insbesondere auf die Situation von christlichen Minderheiten in einem überwiegend muslimisch dominierten Land 
eingeht. Daneben bilden berufliche Themen einen weiteren Schwerpunkt. So führt der Verein vielfältige Netzwerkaktivitäten durch und organisiert Bildungsangebote, u. a. in Kooperation mit einer anderen KAAD-Alumni-Gruppe (KONTAK), deren Mitglieder sich größtenteils aus der in Deutschland gegründeten Katholischen Indonesischen Studierendenfamilie KMKI zusammensetzen, und der Atma JayaUniversität in Jakarta, wo auch das Partnerkomitee des KAAD („,KAAD Committee Indonesia") angesiedelt ist und u. a. Informationsveranstaltungen zu einem Studium in Deutschland angeboten werden.

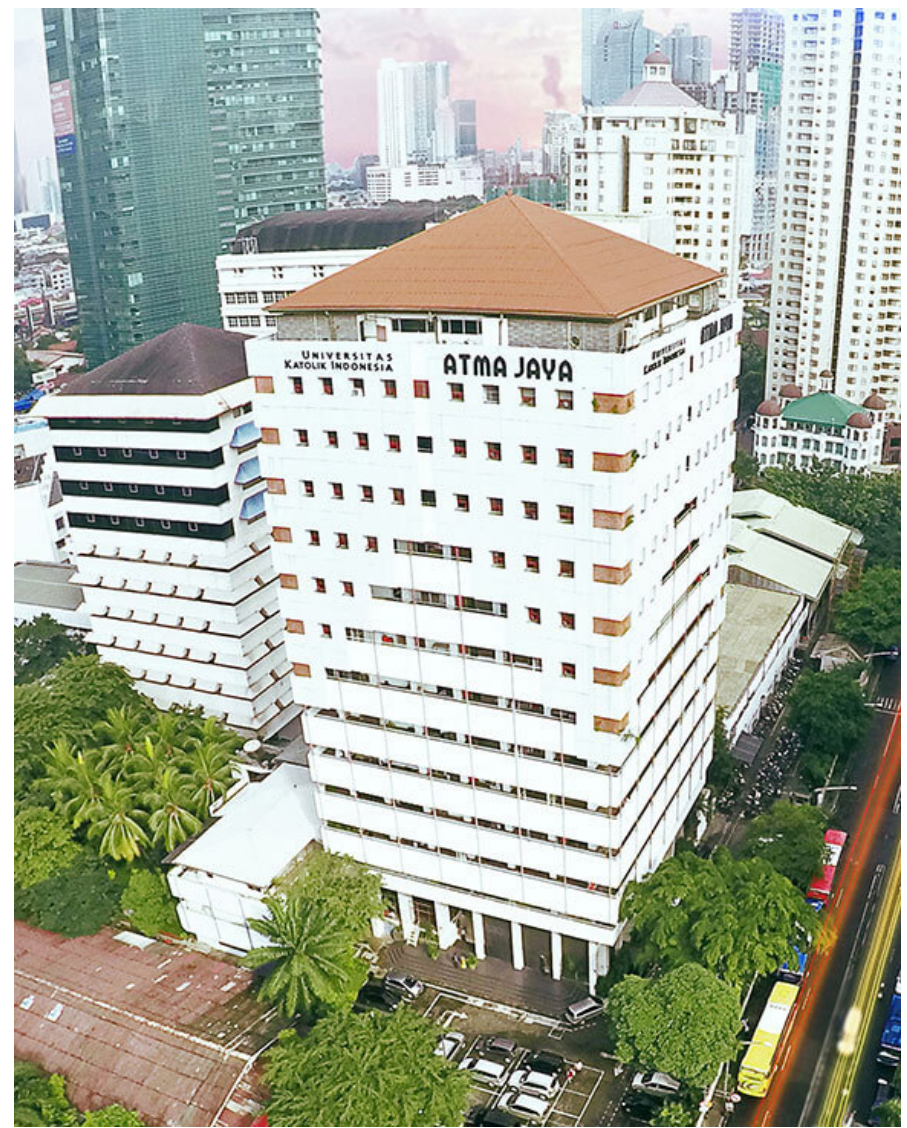

Aufnahme 2 Atma Jaya-Universität in Jakarta

Quelle: Atma Jaya Universität Jakarta. 
Die nach Indonesien zurückgekehrten KAAD-Alumni - die vor allem Mathematik, Informatik, Naturwissenschaften, Technik und/oder Wirtschaft in Deutschland studiert haben - sind vielfach in führenden Positionen der indonesischen Wirtschaft tätig bzw. haben selbst Unternehmen gegründet. Man kann sagen, dass sie nicht ganz unmaßgeblich an der positiven Entwicklung des dynamischen Technologiesektors beteiligt waren. Ein herausragendes Beispiel ist der Gründer eines Technologie-Unternehmens „Triputra Group“ zur Herstellung von Werkzeugen und Haushaltsgeräten. Der Gründer hatte bereits in den 1980er Jahren Architektur in Mainz und Braunschweig studiert und sich nach seiner Rückkehr im Jahr 1989 in Indonesien selbstständig gemacht. Seine neue, umweltfreundliche Produktionsmethode zur Herstellung von Werkzeugen und Haushaltsgeräten hatte er aus Deutschland mitgebracht und erfolgreich in Indonesien eingeführt. Noch heute nutzt das Unternehmen seine Deutschlandkontakte dazu, Nachwuchs für das Unternehmen zu akquirieren, indem Absolvent*innen von MINT-Studiengängen aus Deutschland rekrutiert werden. Teilweise handelt es soich bei den Absolvent ${ }^{\star}$ innen selbst um Indonesier*innen, die in Deutschland studiert haben. Über die Jahre hat sich das Unternehmen von einem Vier-Mann-Unternehmen zu einem der zehn größten Unternehmen des Landes entwickelt. Das Unternehmen beschäftigt heute viele Hundert Mitarbeiter*innen, darunter noch weitere KAAD-Alumni, die Maschinenbau oder andere Ingenieurwissenschaften in Deutschland studiert haben. Ein KAAD-Alumnus, der über das KAAD-Netzwerk des Unternehmens rekrutiert wurde und seit 2014 in diesem Unternehmen tätig ist, hat dabei maßgeblich an der Entwicklung einer neuen Schlagbohrmaschine mit Diamant- und Edelstahlkopfaufsätzen mitgewirkt, die Bohrungen in Steinen und im Mauerwerk deutlich erleichtern. Die Expertise für diese neue Entwicklung erwarb er während seines Studiums an der RWTH Aachen, im Bereich Automatisierungstechnik:

„In Deutschland habe ich fast alles über Automatisierungstechnik gelernt. Nur damals war mir noch nicht so bewusst, dass Deutschland auch die besten Bohrmaschinen der Welt herstellt. Das habe ich erst hier begriffen in Indonesien. Man denke nur an Bosch, das sind sehr gute Bohrmaschinen, die man auch in Indonesien kaufen kann, aber die viel zu teuer hier sind. Deswegen entwickeln wir jetzt unsere eigenen Bohrmaschinen, die man auch bezahlen kann. Dabei wende ich fast eins zu eins mein technisches Know-how an, das ich in Aachen gelernt habe. Dazu gehören vor allem die Details und Präzession für die Bohrmaschine. Das ist nicht ganz leicht, aber unsere Modelle werden immer besser. Noch nicht ganz auf Bosch-Niveau, aber ich glaube, das Beste in Indonesien bis jetzt" (Interview mit einem indonesischen Alumnus in Pontianak, Indonesien, 2017). 
Ein weiterer KAAD-Alumnus, der von dem Unternehmen eingestellt wurde, arbeitet mittlerweile an der Entwicklung eines neuen Produktionsprozesses, der eine effizientere und klimafreundlichere Werkzeugproduktion ermöglichen soll. Dabei stimmt er sich auch eng mit dem Alumnus ab, der die Schlagbohrmaschine mitentwickelt hat, deren Herstellung ebenfalls in diesen neuen Produktionsprozess integriert werden soll.

Auch in anderen Wirtschaftsbereichen sind KAAD-Alumni innovativ tätig. So ist z. B. ein Alumnus - der Architektur in einem Masterstudiengang am Karlsruher Institut für Technologie studiert hat und sich in Jakarta als Architekt selbstständig gemacht hat - zurzeit wesentlich am Bau der größten Kirche im Norden Jakartas mit über 2.000 Plätzen beteiligt. Da sein kleines Unternehmen mit zwei Angestellten selbst nicht über ausreichende Kapazitäten verfügt, arbeitet er mit drei anderen Architekturunternehmen an diesem Kirchenbauprojekt. Er hat dabei den Grundriss für die Kirche entworfen und beaufsichtigt die Bauarbeiten dazu. Das Projekt soll im Jahr 2022 abgeschlossen werden. Allerdings gibt es auch Probleme bei der Projektrealisierung:

„Dabei war es schwierig, eine Baugenehmigung von der Stadt Jakarta zu bekommen, weil aufgrund der zunehmenden Islamisierung immer schwieriger wird Kirchen in Indonesien zu bauen, vor allem wenn es große Kirchen werden sollen, die andere Gebäude wie Moscheen überragen. Aber wir hatten Glück, dass wir die Genehmigung bekommen haben" (Interview mit einem indonesischen Alumnus in Jakarta, Indonesien, 2017).

Bereits während seines Studiums in Deutschland hat er im Austausch mit anderen deutschen und indonesischen Studierenden einen Sinn für's Unternehmertum entwickelt und ein Netzwerk mit anderen indonesischen Unternehmer*innen aufgebaut:

\begin{abstract}
"Gerade das Netzwerk unter Indonesiern in Deutschland ist sehr wichtig. Dort sind wir sehr gut vernetzt und bauen unsere Kontakte dort aus und nutzen sie auch weiterhin in Indonesien. Die Indonesier, die in Indonesien geblieben sind, haben das nicht gelernt und machen das auch kaum. Das ist ein großes Plus, das wir in Deutschland gelernt haben, weil dort mussten wir uns vernetzen. Diese Netzwerke nutze ich jetzt für meine Arbeit als Unternehmer in Indonesien" (Interview mit einem indonesischen Alumnus in Pontianak, Indonesien, 2017).
\end{abstract}

Eine andere KAAD-Alumna, die zusammen mit ihrem Mann während ihres Masterstudiums im Fach Global Production Engineering an der TU Berlin Ende 
der 1990er Jahre vom KAAD gefördert wurde, gründete direkt nach der Rückkehr eine Consulting-Firma im Bildungssektor in Jakarta. Die Idee zur Selbstständigkeit entwickelte sie bereits während ihres Studiums. Mit der Firmengründung setzte sie ihre oben zitierte Masterarbeit „Private Owned Business Sector in Education“ direkt in die Praxis um. Zentrales Ziel der Firma ist es, indonesische und koreanische Schüler*innen und Studierende an englischsprachige Schulen, Sprachschulen und Universitäten in den USA, Kanada, Großbritannien, Australien und Neuseeland zu vermitteln. Dabei arbeitet die Firma eng mit Partnerunternehmen in Südkorea zusammen. Die Alumna über die Aufgaben ihrer Firma:

"You can say, we bring rich students, boys and girls, abroad to study there or to learn a new language there. They mostly come from rich families in Indonesia, who are able to pay for the tuition fees at the universities, and who can afford living costs for their children abroad. Many of the parents live and work in Jakarta, and have a good education background. Most of them want to go to the United States, but not all of them can go there. So, they also go to England or Australia. We also want to expand to Germany, and I want to use my experiences and contacts there, but it is difficult to get into Germany, because most education institutions are state owned, and not private owned. It is difficult to cooperate with them, and sometimes even impossible" (Interview mit einer indonesischen Alumna in Jakarta, Indonesien, 2017).

Die meisten der vermittelten Schüler*innen und Studierenden müssen Collegeoder Universitätsgebühren zahlen, um dort studieren zu dürfen. Die Colleges und Universitäten zahlen dann wiederum Vermittlungsgebühren an die Firma der Alumna. Mit diesem Geschäftsmodell wird sie von Jahr zu Jahr erfolgreicher. Seit der Gründung im Jahr 2008 beschäftigt sie mittlerweile 17 Angestellte. Sie sieht in ihrer Arbeit, ähnlich wie der KAAD, auch einen Beitrag zur Entwicklung Indonesiens:
"I want to help to educate students by taking them abroad. I think they need education and expertise from abroad to bring Indonesia forward when they come back. That is very important. Because the universities in Indonesia are still no so good like the ones in the United States, England, or Australia. They have to study there, come back, and bring Indonesia forward with their knowl- edge. It is a bit like the KAAD. [...] And the most of them really come back" (Interview mit einer indonesischen Alumna in Jakarta, Indonesien, 2017)..

Ihr Mann, der ebenfalls ein KAAD-Alumnus ist, arbeitete zunächst für verschiedene Unternehmen im Energiesektor nach der Rückkehr, bevor er eine Führungsposition 
in dem indonesischen Energieunternehmen Puri Energi Kencana im Jahr 2010 annahm. Mittlerweile ist er dort zum Direktor aufgestiegen. Das Unternehmen konzentriert sich auf nachhaltige Energieversorgung im Großraum Jakarta mit einem Schwerpunkt auf Wasserenergie. Das Unternehmen hat über 120 Mitarbeitende. Das größte aktuelle Projekt ist die Entwicklung eines neuen Wasserkraftwerks in Jakarta, das Wasser kostengünstiger, effizienter und in größeren Mengen für die Stadt zur Verfügung stellen soll. Er sagte dazu:

„Die Bevölkerung in Jakarta wächst unglaublich schnell, aber die Wasserversorgung kann vor allem in den Stadträndern, wo immer mehr Menschen vom Land hinziehen, nicht sichergestellt werden. Es ist jetzt unsere Aufgabe, dass wir jetzt auch dort Wasser hintransportieren können. Dafür hat uns jetzt die Stadt Jakarta beauftragt. Insgesamt passiert da jetzt sehr viel, neben der Wasserversorgung auch die Verkehrsinfrastruktur wie der Bau eines Metrosystems. Das gehört alles zusammen und bringt die Entwicklung unserer Stadt jetzt wesentlich voran. [...] Aber es muss auch noch viel gemacht werden" (Interview mit einem indonesischen Alumnus in Jakarta, Indonesien, 2017).

Auch ein anderer KAAD-Alumnus hat sich in Jakarta selbstständig gemacht. Nach seinem Ingenieurstudium an der RWTH Aachen im Jahr 1996 arbeitete er allerdings erst sechs Jahre für verschiedene Unternehmen in Indonesien, darunter für Motorola und Softwarehouse, um erst einmal Berufserfahrung als Angestellter zu sammeln, jedoch hatte er schon während seines Studiums das Ziel sich selbstständig zu machen:

„Während meines Ingenieurstudiums in Aachen habe ich kein BWL-Seminar besuchen können. [...] Weil keine angeboten werden im Ingenieurstudium. Das ist nicht gut, und vielen Ingenieuren, die ein Unternehmen gründen wollen, fehlen dann die unternehmerischen Kenntnisse ein Unternehmen gut zu führen, wie Buchhaltung, Marketing und so weiter. [...] Dieses Wissen musste ich mir erst in Indonesien aneignen, als ich mein Unternehmen gegründet habe. Das hat mir am Anfang viel Zeit gekostet und auch viel Geld" (Interview mit einem indonesischen Alumnus in Pontianak, Indonesien, 2017).

Im Jahr 2002 gründete er ein Telekommunikationsunternehmen, das Prepaid-Telefoneinheiten in über 40.000 Geschäften in Indonesien verkauft. Mittlerweile hat er über 20 Angestellte. In Zukunft möchte er sein Unternehmen weiter ausbauen und auch in den Handymarkt einsteigen. 
Eine Alumna, die Anfang der 2000er Jahre BWL an der Universität Hamburg studierte, arbeitet mittlerweile als Entwicklungsmanagerin bei einem der größten Chemie-Unternehmen in Indonesien, wo sie für die Einführung von neuen Herstellungsprozessen für Farben zuständig ist. Die Stelle wurde ihr bereits durch eine Zusammenarbeit zwischen ihrem Doktorvater und einem führenden deutschen Chemiekonzern, bei dem sie zu der Zeit neben ihrer Promotion in Deutschland arbeitete, vermittelt. Sie ist davon überzeugt, dass sie die Stelle in Indonesien ohne diese Vermittlung nie bekommen hätte. Die beruflichen Verbindungen zu dem deutschen Unternehmen bestehen weiterhin, wovon auch ihr Unternehmen profitiert.

Aber ähnlich wie in Palästina sind KAAD-Alumni auch aus Deutschland heraus entwicklungsrelevant aktiv. Ein KAAD-Stipendiat der TU Dresden arbeitet zurzeit im Rahmen seiner Promotion an der Entwicklung einer neuen Bautechnik für Hochhäuser, die nicht nur aus Beton und Stahl hergestellt werden, wie es in Indonesien bisher üblich ist, sondern auch aus Holz und Kunststoffen. Diese neue Bauweise soll Hochhäuser im erdbebengefährdeten Indonesien sicherer machen und vor schnellen Einstürzen schützen. Durch die Anwendung von Holz und Kunststoff werden die Gebäude stabiler und flexibler bei Erdbeben und brechen nicht so schnell ein, vielmehr schwingen sie bei Erderschütterungen mit. Das Thema wird zunehmend wichtiger in der Region, da Indonesien immer wieder von Erbeben und den darauffolgenden Tsunamis heimgesucht wird, wie das verheerende Erdbeben Weihnachten 2014 gezeigt, bei dem über 200.000 Menschen auf Sumatra starben. Auch die Entscheidung des indonesischen Präsidenten Joko Widodo im August 2019, den Regierungssitz und Hauptstadtstatus von Jakarta auf der Insel Java aufgrund der akuten Erdbebengefahr in den Osten der Insel Borneo zu verlegen, zeigt, wie dramatisch die Erdbebengefahr in Indonesien ist.

Dabei arbeitet er nicht nur mit Kolleg*innen von der TU Dresden zusammen, sondern auch vom Bandung Institute of Technology, die diese neuen Techniken und Verfahren in Kooperation mit indonesischen Unternehmen in Indonesien umsetzen wollen. Der KAAD-Stipendiat sagt dazu:

„Die Forschung und Holzverarbeitung in Deutschland ist führend weltweit. Wir wissen in Indonesien noch nicht viel davon, aber wir lernen in diesem Projekt sehr viel. Hochhäuser mit Holz zu bauen, daran hat man in Indonesien bisher noch nicht gedacht. Wir können durch diese neue Herstellungsmethode dazu beitragen, das Leben in Indonesien sicherer zu machen" (Interview mit einem indonesischen Stipendiaten, Skype, 2017).

Zudem sieht der Alumnus die Holzbauweise, entgegen landläufiger Meinungen, als eine Art Öko-Bauweise, oder Green Building, da Holz in Indonesien leicht zu 
beschaffen ist und Bäume bereits nachhaltig in größeren Mengen angebaut werden. Zudem würde die Holzbauweise die $\mathrm{CO}_{2}$-Emissionen verringern, die bei der Stahl- oder Zementproduktion für konventionelle Hochhäuser in großen Mengen ausgestoßen werden. Er sagt, dass die Holzbauweise sogar für den Bau von Hochhäusern über 30 Stockwerken angewendet werden kann. Sein Forschungsleiter an der Universität Bandung empfahl ihm nach Deutschland zu gehen, weil es wenig Forschungsmöglichkeiten in diesem Bereich in Indonesien gibt. Deswegen entschied er sich an der Technischen Universität Dresden zu bewerben, auch weil die TU Dresden einen Schwerpunkt in diesem Forschungsfeld hat. Er möchte diese Technik auch in Indonesien an die Forschung weitergeben und in seinen Seminaren vermitteln, um diese Technik langfristig in die indonesische Praxis zu implementieren. Bisher wird dazu noch wenig Forschung an der Universität Bandung betrieben. Mittlerweile gibt es auch ständige Besuche, Vorträge und Konferenzen zwischen den beiden Partnerinstituten. Die intensive Forschungszusammenarbeit beschreibt er folgendermaßen:

"Some of my colleagues in Bandung have done that already sometimes. This is good for our research exchange and it takes care of our partnership with Dresden. We are permanently in contact with our partners in Dresden, over the Internet, and we work together in different research projects. We also visit each other permanently. And I represented my first findings already in Bandung. So, we learn from each other, the Institute in Bandung learns from the colleagues in Dresden about how to use new research methods, and the colleagues in Dresden learn from us about how to implement the research findings on the ground. So, Indonesia can be an experimental ground for new sciences. And they learn about wood kinds they do not have in Europe. And how we see the wood building results based on our experiences with earthquakes and real wood buildings" (Interview mit einem indonesischen Stipendiaten, Skype, 2017).

Eine weitere KAAD-Alumna aus Indonesien arbeitet als Maschinenbauingenieurin in einem Münchner Beratungsunternehmen, bei dem sie schon während ihres Studiums in Teilzeit tätig war. Damals erkannte das Unternehmen bereits, dass es die damalige Studentin für mögliche Projekte in der Zukunft in Indonesien einsetzen könnte. Direkt nach ihrem Studienabschluss wurde sie von dem Unternehmen gefragt, ob sie in Vollzeit bei dem Unternehmen arbeiten möchte und wurde sofort eingestellt. Im Interview berichtet sie uns:

„Der Job war sehr wichtig neben meinem Studium, weil ich dadurch eine feste Stelle nach dem Studium bekommen habe. Sonst hätte ich die nicht bekommen. 
Da habe ich schon viel über die deutsche Bürokratie und deutschen Gesetze gelernt und auch über die Arbeitsweise in Deutschland. Das habe ich später im Beruf auch alles wieder gebraucht. Das Unternehmen hat aber auch viel von mir gelernt, vor allem über die Menschen und die Kultur in Indonesien. Das ist auch sehr wichtig, wenn man dort arbeiten will" (Interview mit einer indonesischen Alumna in Deutschland, Skype, 2017).

In diesem Rahmen ist sie regelmäßig für mehrere Wochen oder Monate in Indonesien tätig. Für ein Projekt auf der indonesischen Insel Sumatra war sie ein ganzes Jahr vor Ort, um ein indonesisches Unternehmen bei der Konstruktion und beim Bau eines Evakuierungsgebäudes in einem Tsunamigebiet auf Sumatra zu beraten. Dabei konzentriert sie sich auf die Sicherheitsrichtlinien, die Konstruktion der Notausgänge (die u. a. behindertengerecht und barrierefrei sein sollten), Beschilderungen und Wegweiser. Dabei hat sie viel von den Richtlinien in Deutschland gelernt, die sehr genau und gut entwickelt sind. In Indonesien gibt es solche Sicherheitsbestimmungen größtenteils noch nicht. Zudem sind die meisten Gebäude auf Sumatra nicht erbeben- bzw. tsunamisicher gebaut worden, obwohl dieses Problem schon seit Beginn der ersten Siedlungen dort besteht. Das war bisher vor allem ein Kostenproblem. Das Projekt wurde von der indonesischen Regierung und verschiedenen Organisationen in Deutschland und Österreich finanziell unterstützt.

Ein anderer Alumnus, der ein Consultingunternehmen für interkulturelles Training und Management in Jakarta gegründet hat, ist nach wie vor regelmäßig beruflich in Deutschland unterwegs, um Unternehmen, die in Südostasien Fuß fassen wollen, in interkulturellen Managementstrategien zu beraten. Die Unternehmen werden dabei im Umgang mit den politischen, sozialen und kulturellen Gegebenheiten in Indonesien geschult, nicht zuletzt in Bezug auf die vorherrschende Unternehmenskultur, die sich in Indonesien grundsätzlich von der in Deutschland unterscheide. Der Alumnus erklärte, dass die indonesische Unternehmenskultur wesentlich von der javanesischen Harmonieethik ${ }^{22}$ geprägt sei, bei der man in der Kommunikation eher zurückhaltend argumentiert und man Konflikten eher aus dem Weg geht. Demgegenüber ist die deutsche Kultur eher von direkter Konfrontation und klaren Problemlösungsansätzen geprägt. In der indonesischen Kultur gehe es demnach mehr um das persönliche Wohlbefinden der Mitarbeiter, demgegenüber in der deutschen eher um das Erreichen eines Unternehmensziels. Der zentrale Unterschied bestehe demnach in dem "harmonischen“ Kompromiss auf der einen Seite und der effizienten Zielerreichung auf der anderen.

Hierzu sagte er:

22 Zur javanesischen Harmonieethik vgl. Magnis-Suseno (2015). 
„Ich bin für die deutschen Firmen sehr interessant, weil ich ihnen klar machen konnte, was mein Mehrwert ist. In Deutschland habe ich gelernt, wie ich Indonesiern erklären kann, was Deutsche wollen. Und ganz wichtig: Ich habe auch gelernt, was Indonesier von den Deutschen wollen. Und ich helfe dabei, wie die beiden sich gegenseitig ihre Interessen erklären und ein Übereinkommen finden" (Interview mit einem indonesischen Alumnus in Pontianak, Indonesien, 2017).

Inzwischen ist seine Firma auch in China, Singapur und Malaysia tätig.

\subsection{Entwicklung von Umweltschutz und Landwirtschaft in Ghana}

Ghana stellt als zentralwestafrikanisches Land eines der Schwerpunktländer des KAAD in Afrika dar, aus dem über die letzten Jahrzehnte besonders Stipendiat ${ }^{\star}$ innen gefördert wurden, die sich zum Zeitpunkt ihrer Bewerbung noch in Ghana aufhielten. Ghana wurde 1957 als erstes afrikanisches Land von Großbritannien unabhängig. Seitdem unterliegt das Land ständigen politischen und sozialen Veränderungen und wurde zwischenzeitlich immer wieder von Diktatoren regiert. Heute gilt Ghana als eines der sichersten und politisch stabilsten Länder Afrikas. In dem zentralwestafrikanischen Land leben gegenwärtig 28 Millionen Einwohner*innen (überwiegend englischsprachig), die ein Bruttoinlandsprodukt pro Kopf in Höhe von 4.300 US-Dollar (in KKP) erwirtschaften. Jedoch leidet das Land, ähnlich wie in vielen anderen afrikanischen Ländern, unter einem starken Brain Drain von hochqualifizierten Akademiker*innen, insbesondere Wissenschaftler*innen, Ingenieur*innen und Ärzt*innen, die in vielen Regionen des Landes fehlen (Ghanaian Government 2017). Die Universitätslandschaft ist erst in den letzten 50 bis 60 Jahren seit der Unabhängigkeit von Großbritannien entstanden und konzentriert sich vor allem in den größeren Städten Accra, Kumasi und Tamale. Viele Führungspersönlichkeiten des Landes haben im Ausland studiert und wurden dabei finanziell von Stipendienprogrammen unterstützt. Dazu gehören der ehemalige UNO-Generalsekretär Kofi Annan und die beiden ghanaischen Ex-Präsidenten John Evans Atta Mills, der von 2009 bis 2012 Präsident Ghanas war, und Kofi Abrefa Busia, von 1969 bis 1972 Präsident Ghanas, die beide durch das US-amerikanische FulbrightProgram gefördert wurden (Fulbright 2018).

Ghana ist nach wie vor ein überwiegend agrar- und fischereiwirtschaftlich geprägtes Land. Fast 60 Prozent der Bevölkerung sind in der Land-, Forst- oder 
Fischereiwirtschaft tätig. Das spiegelt sich auch in der Kooperation mit anderen Ländern wider. So konzentrieren sich viele Entwicklungsprojekte in Ghana auf den Agrarsektor. Dabei geht es vor allem um Maßnahmen, die Landwirtschaft in Ghana effektiver zu gestalten, wie z.B. durch eine bessere Wasserversorgung, bessere Transportmöglichkeiten für Agrarprodukte (v. a. aus dem Süden in den trockenen Norden des Landes) oder eine bessere Anpassung der Landwirtschaft an klimatische Veränderungen (Ghanaian Government 2017).

Auch der Schwerpunkt der Förderung des KAAD liegt in den Bereichen Landwirtschaft, Energie und Umwelt, die auch aus Sicht der Studierenden eine herausragende Bedeutung besitzen. Ein interviewter KAAD-Alumnus sagte uns dazu:

"Landwirtschaft ist das wichtigste Thema für Ghana. Wenn man Ghana nach haltig entwickeln will, muss man sich auf die Landwirtschaft dort konzentrieren. Dabei ist auch ein Punkt entscheidend: Durch die Unterstützung der Landwirtschaft werden auch die lokalen Strukturen und die kommunalen Einrichtungen unterstützt, weil eben fast alle Menschen, die auf dem Lande in Ghana leben von der Landwirtschaft abhängig sind. Sie gewinnen nicht nur ihre eigene Nahrung daraus, sondern verdienen auch ihr Geld damit. In Ghana ist alles von der Landwirtschaft abhängig" (Interview mit einem ghanaischen Alumnus in Kumasi, Ghana, 2018).

Auch andere Alumni betonten die herausragende Bedeutung der Landwirtschaft für die Entwicklung Ghanas:

"Agriculture and processing of agricultural products should be a focus in development policies in Ghana. Because we have comparative advantages in cocoa or palm oil to other countries. We have the best soil and best climate. However, we export too many raw products. We should improve our processing, so that we can export more quality products that were actually produced in Ghana" (Interview mit einem ghanaischen Alumnus in Accra, Ghana, 2018).

„Entwicklung heißt für mich, wenn es den Menschen heute insgesamt besser geht als gestern. In Ghana kann man Entwicklung nur über eine bessere Förderung der Landwirtschaft erreichen. Die Landwirtschaft bei uns ist bisher noch nicht mechanisiert, es wird noch viel mit der Hand angebaut und geerntet. Deswegen kann man bis jetzt noch nicht viel Entwicklung in der Landwirtschaft sehen, das muss verbessert werden. Die Farmer bekommen noch nicht das zurück was sie investieren"(Interview mit einem ghanaischen Stipendiaten, Bonn, 2017). 
In Ghana arbeiteten viele zurückgekehrte Alumni - die Rückkehrquote der aus Ghana Geförderten lag in den 2000er Jahren bei überdurchschnittlichen 85 Prozent (interne KAAD-Dokumente) - entsprechend in den Bereichen Landwirtschaft und Umweltschutz. Viele ehemalige Geförderte haben dabei ebenfalls oftmals Führungspositionen erreicht.

Ein hervorstechendes Beispiel ist hier der zweimalige ghanaische KAAD-Stipendiat Stephen Nana Ato Arthur, der 2013 als erster KAAD-Alumnus in ein afrikanisches Nationalparlament einzog und sich intensiv in der internationalen Entwicklungszusammenarbeit zwischen Deutschland und Ghana engagiert (KAADJahresbericht 2013). Er promovierte im Jahr 2012 mit einem KAAD-Stipendium im englischsprachigen Studiengang Development Studiesan der Universität Bonn und kehrte unmittelbar nach seinem Abschluss nach Ghana zurück. In seiner Doktorarbeit beschäftigte er sich mit Dezentralisierung und Kommunen in Ghana; der Titel seiner Arbeit lautete „The unfinished business of decentralisation: political accountability of local government in Ghana". Dabei kam er zu dem Ergebnis, dass einzelne Kommunen in Ghana mehr politische Verantwortung übernehmen könnten, wobei die meisten Kommunen noch demokratische Defizite aufweisen, vor allem in Bezug auf die transparente Darstellung von politischen Entscheidungsprozessen. Von 2001 bis 2005 setzte er seine theoretischen Erkenntnisse als Deputy Central Regional Minister in die Tat um. 2017 wurde er Head of the Local Government Service. ${ }^{23}$ In dieser Funktion betreut er die Umsetzung von nationalen Richtlinien für die kommunale Verwaltung in Ghana.

Einige Alumni und auch nicht vom KAAD geförderte Rückkehrer*innen, die im Bereich Umweltschutz und Landwirtschaft tätig sind, arbeiten heute für internationale NGOs, die ghanaische Groß- und Kleinbauern darin unterstützen, neue, umweltfreundlichere Produktionsweisen in Ghana einzuführen. Dabei greifen sie teilweise auf Technologien zurück, die von KAAD-Alumni an deutschen und ghanaischen Universitäten entwickelt wurden. Ein Alumnus an der Universität Kumasi entwickelte z. B. ein neues Bewässerungssystem für den Anbau wasserintensiver Pflanzen in der Trockenzeit. Das Bewässerungssystem zeichnet sich dadurch aus, dass es relativ einfach zu installieren und zu bedienen und zudem sehr kostengünstig in der Unterhaltung ist, da es im Wesentlichen nur aus einer unter dem Erdboden befindlichen Wasserpumpe und einem Wasserspeicher besteht. Dadurch ist es speziell für Kleinbauern erschwinglich und einfach anzuwenden. Aber auch größere Agrarunternehmen nutzen das System mehr und mehr.

23 Kompletter Lebenslauf unter https://www.modernghana.com/news/766213/dr-ato-arthur-takes-office-as-head-of-local-gover.html. 
Ein anderer KAAD-Alumnus, der von 2000 bis 2002 Biologie und Aquatic Tropical Ecology an der Universität Bremen sowie von 2002 bis 2004 Waldwirtschaft an der TU München studiert hat, hat sich in seiner Abschlussarbeit mit dem Thema "Researching the Organisms at the Bottom of the Lagoons at the Ghanaian Coast" beschäftigt. Dabei kam er zu dem Ergebnis, dass die verschmutzten Lagunen in Ghana mehr Mikroorganismen aufweisen als die diejenigen, die nicht verschmutzt sind, was eine Belastung für das Biotop darstellt. Heute ist er an der Universität in Kumasi tätig ist und leitet dort ein Forschungsprojekt zur Verbesserung der Wasserqualität in den Flüssen Ghanas. Die Verschmutzung der Flüsse ist seit Jahrzehnten ein großes Problem. Abwässer, Fäkalien und Müll werden bis heute häufig direkt in die Flüsse entsorgt. Viele ghanaische Städte und Dörfer entlang der Küste werden daher auch als „größte Müllhalden Westafrikas" bezeichnet, wie kürzlich in der Neuen Zürcher Zeitung (NZZ 2016). Weiter heißt es dort: „In Accra kippen über zweihundert Tanklaster jeden Tag Tausende Tonnen Jauche
auf den Strand. Bis zu 85 Prozent der Fäkalien werden gegenwärtig nicht ordent-
lich eingesammelt, 26 Prozent werden in offenen Erdlöchern versorgt. «Das ist eine
Schätzung», sagt der Mann, lächelt. Es gibt noch ältere Broschüren, stolz erklärt das
Umweltministerium, dass zwischen 2006 und 2008 die Rate der open defecation von
24,4 auf 23,1 Prozent gesunken sei. Dies bedeutet, dass etwas weniger Bewohner der
Hütten ihre Ausscheidungen direkt dort versorgen, wo sie schlafen und essen. Wenn
man den Behördenmann nach diesen Zahlen fragt und nachschiebt, auch gerne
wissen zu wollen, wie sie erhoben würden, lächelt er weiter. Und findet noch einen
Satz, der so klingt, als habe er lange darüber nachgedacht: «Man kann in Accra und
vielleicht überhaupt in Ghana von einer funktionierenden Kontrolle nicht sprechen“
(NZZ 2016). ${ }^{24}$

Die Verschmutzung hat aber in den letzten Jahren noch Mal deutlich zugenommen, weil Goldsucher - entweder Privatleute, kleine oder größere Unternehmen, vor allem aus China - versuchen, Gold in den Flüssen zu finden. Dabei wühlen sie durch ihre Schürfungen große Teile des Flussbodens auf, was die Flüsse enorm verdreckt. Zudem benutzen sie Blei, um das Gold schneller zu finden, wodurch dem Wasser Giftstoffe hinzugeführt werden und war zu einem großen Pflanzen- und Fischsterben führt. Damit fallen die Flüsse auch als Trunkwasserreservate weg. Ja, selbst zum Wäschewaschen ist das Wasser oftmals nicht mehr sauber genug. Die großen Goldsuchunternehmen benutzen keine umweltfreundliche Technik, weil sie Geld sparen wollen; die kleinen Unternehmen oder Privatleute sind sich

24 In einem Bericht der UN heißt es zudem: „Statistics today show that fewer than two in five Ghanaians drink safe water, two out of every five schools are without toilets, and three out of every five schools are without water supplies“ (UN 2017: 14). 
der Verschmutzung nicht mal bewusst, könnten sich aber auch finanziell keine modernen Goldsuchinstrumente leisten. In seinem aktuellen Forschungsprojekt „Wasserqualität der Flüsse Ghanas" untersucht der Alumnus die Auswirkungen der Wasserverschmutzung auf Menschen, Tiere und Pflanzen und versucht herauszufinden, wie man die Giftstoffe wieder aus dem Wasser herausfiltern kann, um es für die Landwirtschaft wieder nutzbar zu machen: „Ich kann jetzt schon sagen, dass die Wasserqualität für die Landwirtschaft verbessert werden muss, denn der hohe Bleigehalt im Wasser kann die Ernte vernichten und sehr schädlich für den Menschen sein, der den Mais oder die Bohnen isst" (Interview mit einem ghanaischen Alumnus in Kumasi, Ghana, 2018).

In einem anderen Forschungsprojekt beschäftigt er sich mit der Nutzung von Purgiernüssen in der Luftfahrt. Auch die Lufthansa führte schon Tests dazu durch (FAZ 2011). Viele internationale Konzerne wollen verstärkt darin investieren und versuchen von den Bauern und Chiefs Land zu kaufen, um mehr Pflanzen für die Ölgewinnung anzubauen, um es dann in Europa verkaufen zu können. Hierbei kommt es regelmäßig zu Konflikten zwischen ghanaischen Bauern und Chiefs auf der einen und größeren internationalen Konzernen (wie z. B. aus Dänemark oder Israel) auf der anderen Seite:

"For instance, a chief got very angry, because he sold land to someone he never saw through a middleman. He never knew what they did with his land, or what they are planning to do with his land. When he decided to sell the land, he thought he would negotiate with the company directly, and would get to know the new landowner. When he realized that there are no direct negotiations between him and the company, it was too late, his land was already sold" (Interview mit einem ghanaischen Alumnus in Kumasi, Ghana, 2018).

Eine andere Alumna - die ihren Master im Fach Landwirtschaft an der Universität Den Haag machte, am Zentrum für Entwicklungsforschung (ZEF) der Universität Bonn mit einem KAAD-Stipendium im Jahr 2011 über über Bewässerungssysteme in Nordghana promovierte $e^{25}$ und zurzeit Senior Researcher am Institute of Statistical, Social, and Economic Research (ISSER) (ISSER) der Legon Uni in Accra ist - arbeitet ebenfalls zu den sozialen Auswirkungen der Veränderungen in der Landwirtschaft in Ghana. In einem aktuellen Projekt untersucht sie aus einer Genderperspektive

25 Thema der Doktorarbeit: „Marketing and Market Queens - A Study of Tomatoe Female Farmers in the Upper East Region of Ghana“ (vgl. oben Punkt 3. 2 „Während des Studiums"). 
die soziale und ökonomische Situation von Frauen im Sheanusshandel. ${ }^{26}$ In diesem Projekt geht es um den Anbau von Sheanüssen in Nordghana und ihren Absatz in Europa, vor allem im Dänemark. Die Frauen sammeln die wildgewachsenen Sheanüsse im Wald und verkaufen sie an größere Händler*innen in Ghana und Europa, die diese dann weltweit vermarkten. Der Anteil der Farmerinnen an dem globalen Handel ist äußerst gering, so dass sie in der Armut verhaftet bleiben. Die Produkte aus Sheanüssen, wie z. B. Kosmetik der Marke „Body Shop“, sind gleichwohl teuer. Die Sheanüsse sind also nicht fair gehandelt. In ihrem Projekt interviewt die Alumna Frauen in Ghana gleichermaßen wie Händler in Dänemark. Sie arbeitet auch im Ph.D.-Programms zum Thema "nachhaltige Landwirtschaft" mit, das in Kooperation mit dem ZEF von ISSER durchgeführt wird (es wurde auch vom ZEF aufgebaut), sie hat dabei als Kontaktperson des ZEF am ISSER beim Aufbau des Programms mitgeholfen - mittlerweile sind weitere Forschungskooperationen mit Universitäten in den USA und Großbritannien dazu gekommen; zurzeit arbeiten fünf ghanaische Doktorand*innen im Rahmen des Programms.

Ein weiterer Fall ist eine ghanaische Alumna, die für ein deutsches Wald- und Landvermessungsunternehmen in Ghana tätig ist und zurzeit ein Projekt zur Erstellung von virtuellen Landkarten für landwirtschaftliche Nutzflächen leitet. Direkt nach ihrem Masterstudium der Geoinformatik und Fotogrammetrie (Luftbildvermessung) von 2008 bis 2010 an der Universität Stuttgart absolvierte sie ein halbjähriges Praktikum in dem Unternehmen. Im Rahmen dieser Tätigkeit machte sie das Unternehmen auf Marktchancen in Ghana aufmerksam. Bis dato gab es noch keine Unternehmen dieser Art in Ghana. Das deutsche Unternehmen hätte ohne die Kontakte der Ghanaerin zum ghanaischen Innenministerium und zu lokalen Verwaltungseinrichtungen nicht in Ghana Fuß fassen können. Nicht ohne Stolz macht sie deutlich:

„Ohne mich wäre das deutsche Unternehmen nicht in Ghana. Ich habe sie auf diese Möglichkeit hier, auf die Ausschreibung des ghanaischen Ministeriums, aufmerksam gemacht, und sie bei der Bewerbung beraten, also auf welche Dinge man in Ghana achten muss, was dem Ministerium wichtig ist, welche besonderen Umweltbedingungen es in Ghana gibt, die Herausforderungen bei der Landvermessung in Ghana und mit welchen Partnern man hier gut zusammen arbeiten kann. Das wusste ich alles schon ganz gut durch meine Kollegen hier und meine Kontakte zu ghanaischen Behörden" (Interview mit einer ghanaischen Alumna in Accra, Ghana, 2018).

26 Das Forschungsprojekt wird von der Volkswagenstiftung finanziert und in Kooperation mit ZEF in Bonn durchgeführt. 
Auch ein anderer KAAD-Alumnus half einem europäischen Unternehmen auf dem ghanaischen Markt Fuß zu fassen. So unterstütze ein Alumnus, der mit Unterbrechungen von 1989 bis 1998 Food Science an der TU Berlin studierte, ein schweizerisches Agrarunternehmen darin, die Wildpflanze Griffonia aus Ghana nach Europa zu exportieren. Dabei nutzte er seine Kontakte zu den ghanaischen Behörden. Seit 2010 fing er an für die GIZ zu arbeiten und übernahm später die Leitung des Centrums für Internationale Migration (CIM) in Accra. Im Rahmen seiner CIM-Arbeit ist er sowohl Chefkoordinator des Reintegrationsprogramms als auch Leiter des "German Ghanaian Center for Jobs and Reintegration“, das im Dezember 2017 von Bundespräsident Frank-Walter Steinmeier festlich in Accra eingeweiht wurde (Der Spiegel 2017). Das Center soll insbesondere Rückkehrer*innen bei ihrer Arbeitssuche und Re-Integration helfen. ${ }^{27}$ Nach zwei Jahren soll das German Ghanaian Center von ghanaischer Seite alleine unterhalten werden. Unter den Geförderten waren in der Vergangenheit auch immer KAAD-Rückkehrer*innen. ${ }^{28}$

Die KAAD-Alumni haben inzwischen ein breites Netz an Alumni-Vereinen aufgebaut. So besteht an der Partneruniversität Kwame Nkrumah University of Science and Technology (KNUST) in Kumasi das Partnerkomitee „Regional KAAD Partner Committee for West Africa“ (KASWA), das auch mit verschiedenen zivilgesellschaftlichen Kooperationspartner ${ }^{\star}$ innen vor Ort zusammenarbeitet. Das Ziel der Vereinigung ist es KAAD-Alumni zusammenzuführen und sich im Rahmen von Seminaren über Entwicklungsthemen in Ghana auszutauschen, Dabei spielen auch Religion und soziale Themen eine Rolle. KASWA ist in drei sog. Chapter eingeteilt: das Nordghana-Chapter, das Mittelghana- und das Südghana-Chapter. Alle Chapter haben einen eigenen Vorsitzenden, und alle Chapter haben ihre eigenen Schwerpunkte mit regionalen Programmen und Seminaren. Alle Mitglieder der drei Chapter treffen sich einmal pro Jahr in einem ghanaweiten, überregionalen Jahresseminar, zu dem auch der KAAD eingeladen wird. Das Jahrestreffen rotiert

27 Seit 1994 wurden insgesamt über 900 ghanaische rückkehrende Fachkräfte gefördert. Allein im Jahr 2018 sind 70 Ghanaer*innen im Programm.

28 So hat z. B. ein KAAD-Alumnus bereits zwei Mal eine CIM-Förderung bekommen, einmal nach seiner Rückkehr nach dem Masterabschluss in Deutschland und einmal nach seinem Ph.D.-Abschluss. Die Rückkehrerinnen mit einem Masterabschluss bekommen 300 bis 600 Euro CIM-Förderung monatlich und die Rückkehrer*innen mit einem Doktorabschluss 700 bis 900 Euro zusätzliche Förderung zum monatlichen Arbeitslohn. Die jeweilige Förderhöhe hängt vom monatlichen Verdienst ab. Je weniger man monatlich verdient, desto höher ist der CIM-Zuschuss. Grundvoraussetzung ist eine Jobzusage in Ghana bereits vor der Rückkehr. Weitere Kriterien für die Zuschussvergabe durch CIM sind, dass der Job entwicklungsrelevant sein muss und die Förderung in Absprache mit der ghanaischen Regierung erfolgt. Zudem werden Rückkehrerinnen gefördert, die sich gerade erst selbstständig gemacht haben. 
zwischen den einzelnen Chaptern und findet jedes Jahr in einer anderen Region statt, meistens in Kumasi, Tamale oder Accra. Die größten Erfolge von KASWA in den letzten Jahren waren der stetige Zuwachs an Mitgliedern auf mittlerweile über 100 Mitglieder, wovon $60 \mathrm{sehr}$ aktiv sind. Zudem ist es KASWA gelungen, einen engen Austausch mit den katholischen Bischöfen in Ghana zu etablieren, wobei es vor allem um die großen Themen in Ghana wie nachhaltige Entwicklung oder friedliche Koexistenz der Religionen geht.

Weitere zentrale KASWA-Themen sind Bildung und Gesundheit. So wird in den KASWA-Veranstaltungen diskutiert, ob die mehrfach verabschiedeten Bildungsreformen in Ghana ausreichend waren und den Bedürfnissen der Universitäten entsprechen. Dabei ging es z. B. um die Frage, ob die sekundäre Schulbildung drei oder vier Jahre dauern sollte. Die meisten Politiker plädieren für drei Jahre. KASWA fordert mindestens vier Jahre, weil die Schüler*innen sonst zu jung und unerfahren seien, wenn sie an die Universitäten kommen. Auch im Gesundheitssystem sieht KWASA großen Reformbedarf. Es fehlen weiterhin Ärzt*innen und Pflegekräfte im Land. Im Jahr 2004 wurde zwar eine gesetzliche Krankenversicherung eingeführt, jedoch werden hierdurch bei weitem noch nicht alle Behandlungen abgedeckt (Oxfam 2011).

Auch der Zusammenhang von Entwicklung und Flucht wird unter den KAADAlumni in Ghana intensiv diskutiert. Ein langjähriges Mitglied des Alumnivereins sagte dazu folgendes:

"Insgesamt ist es wichtig, und darin sehe ich auch einen wesentlichen Teil meines Jobs, die Ghanaer vor der Flucht aufzuklären, damit sie erst gar nicht die gefährliche Flucht nach Europa antreten. Die meisten von ihnen werden dort nie ankommen. Durch die Wüste zu kommen, ist bereits der gefährlichste Teil der Flucht. Viele sterben bereits vor oder in der Wüste. Sie haben keine Ahnung von der gefährlichen Reise, sie wissen nichts über die Skrupellosigkeit der Schleuser und die Hitze und Gefahren der Wüste. Und danach kommen noch das Mittelmeer und die Alpen. Davon haben viele arme Ghanaer vom Dorf noch nie etwas gehört. Darüber müssen wir sie aufklären. Europa ist nicht das gelobte Land und selbst ein schlecht bezahlter, aber sicherer Job in Ghana kann eine Alternative zu dem gefährlichen Reiseprojekt ins Ungewisse oder in den Tod sein" (Interview mit einem ghanaischen Alumnus in Accra, Ghana, 2018).

Dabei versucht er auch potenzielle Migrant*innen (aber auch Rückkehrer*innen) an NGOs zu vermitteln, die ihnen bei der Jobsuche helfen können. Dabei arbeitet er auch mit deutschen Organisationen wie MISEREOR oder dem Raphaelswerk 
zusammen, die Arbeitsstellen an Rückkehrer*innen vermitteln können. Zudem sieht er sich auch als Vermittler für ghanaische Studierende, die nach Deutschland wollen und informiert sie über Fördermöglichkeiten des DAAD, der FES oder eben des KAAD. Er betonte in dem Interview:

„Durch diese Aufklärungs- und Vermittlungsarbeit können wir junge Menschen davon überzeugen, hier in Ghana zu bleiben, oder eben auch aus dem Ausland zurückzukommen, also ihnen eine Jobperspektive hier in Ghana zu zeigen. Damit können sie zur Entwicklung hier beitragen und somit auch die Fluchtursachen verringern. Wenn junge Menschen Jobperspektiven bekommen, dann müssen sie auch nicht mehr flüchten und können dabei mithelfen, das Land zu entwickeln" (Interview mit einem ghanaischen Alumnus in Accra, Ghana, 2018).

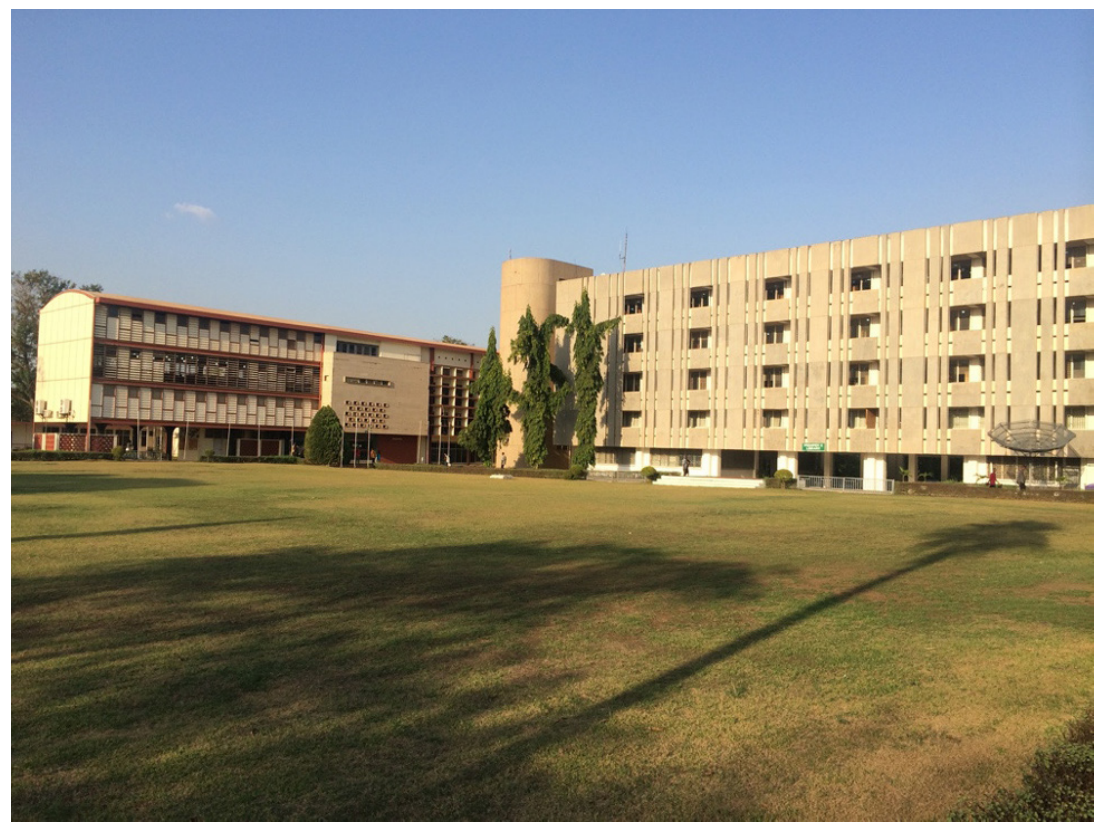

Aufnahme 3 Campus der Universität in Kumasi

Quelle: Eigene Aufnahme. 
Auch ghanaische KAAD-Alumni, die nach dem Studium in Deutschland geblieben sind, setzen sich beruflich für eine nachhaltige ökologische Entwicklung in Ghana ein. So arbeitet z. B. ein Alumnus im Rahmen eines Dreijahresprojekts bei der internationalen NGO „Local Governments for Sustainability“ in Bonn, die sich für nachhaltige Politik in Kommunen weltweit einsetzt (ICLEI 2018), inklusive Ghana. Speziell für Accra wird im Rahmen des Projekts eine Strategie entwickelt, um die Emissionsraten (v.a. durch Autos verursacht) zu drosseln. Die Strategie besteht hauptsächlich aus einer Kombination von mehr öffentlichen Verkehrsmitteln und eine verkehrsreduzierende Infrastruktur. Dabei kooperieren das Projekt mit den zuständigen Behörden in Accra und verschiedenen Bundesministerien und Organisationen, wie dem Gesundheitsministerium oder dem Ghana Health Service. Er sagte dazu:

"The goal of the project reflects my personal philosophy that development and sustainable change has to come from below. This means supporting and developing communities. [...] And educating and supporting local community leaders. They are the change agents and driver of development" (Interview mit einem ghanaischen Alumnus in Deutschland, Bonn, 2018).

Die Grundlagen und die ersten Ideen dafür sammelte er bereits während seines Studiums. In seiner viel beachteten Masterarbeit im Studiengang „Geography of Environmental Risks and Human Security ${ }^{\text {“29 }}$ beschäftigte er sich mit den Auswirkungen des Klimawandels auf die Kakaoproduktion in Ghana und entwickelte einen ökologischen Ansatz zur Erntesteigerung im Kakaoanbau. Seine Arbeit zeigt, dass viele Bauern noch keine adäquaten Mittel gefunden haben, um den sich durch steigende Temperaturen und geringere Niederschläge verändernden Kakaowachstum zu begegnen. Viele Bauern wissen zwar, dass sie die Pflanzen stärker bewässern müssen, haben aber nur sehr eingeschränkte Möglichkeiten um ausreichend Wasser zu beschaffen. In seiner MA-Arbeit empfiehlt er deshalb einen umweltschonenden und gemeindebezogenen Ansatz, der zu einer Erntesteigerung und somit zu einem Einkommenszuwachs unter den Bauern führen kann.

Die einseitige Ausrichtung auf die Landwirtschaft in Ghana wird jedoch zunehmend kritisch gesehen. Ein Alumnus, der in Deutschland geblieben ist, bemerkt dazu:

"We have to focus on high technology in Ghana. I think we can do that now, we learned about that in the last years. I learned about that in Germany. But

29 Fachbereich Agrar-, Forst- und Ernährungswissenschaft der der Universität Bonn und der Universität der Vereinten Nationen in Bonn. 
in Ghana, everyone just talks about agriculture. That was right 20 years ago, but now we are further, we should do the next steps towards a higher development. We should develop from an agricultural to an industrial country, and here we should focus on technical products. [...] Another big challenge for start-up companies in Ghana is to get a credit at the beginning. No bank is giving a loan. They don't trust the young people, and don't believe in their knowledge and ability to form a company. If a bank gives a credit, then it can cost up to 50 percent interest rate. No one can pay for that." (Interview mit einem KAAD-Alumnus aus Ghana)

Deswegen hat er sich auch selbstständig gemacht: Neben seinem Studium in Leipzig hat er im Jahr 2016 einen Online-Schuh-Store namens „KOLIKOWEL. com" gegründet. In diesem Online-Store verkauft er Schuhe, die aus gebrauchten und recycled Kleidungsstücken aus Deutschland hergestellt wurden. Er kauft die Kleidungsstücke in Second-Hand-Kleidungsläden in Accra auf und schickt sie an einen Angestellten in Ghana, der sich zusammen mit sechs Angestellten (alles Ghanaer) um die Schuhherstellung kümmern. Bei den Second-Hand-Kleidungsstücken handelt es sich um Kleidung, die aus den USA oder Europa nach Ghana geschickt werden. Die Schuhe werden für eine junge Zielgruppe hergestellt (sowohl Frauen als auch Männer): „Dabei stellen wir coole Schuhe her, die junge Leute in Ghana gerne tragen, auch junge Leute in Deutschland würden diese tragen, aber die Konkurrenz ist hier zu groß. Das sind Schuhe wie Sneakers und Sportschuhe. Die werden auch schon ganz gut von den jungen Leuten in Accra gekauft." Dieses kleine Unternehmen, gegründet und geleitet von einem KAAD-Alumnus, ist ein gutes Beispiel für ein kleines transnationales Unternehmen, durch das auch Arbeitsplätze für junge Menschen (aktuell sieben, alle zwischen 20 und 24 Jahre alt) in Ghana geschaffen werden.

Dabei ist es entscheidend für ihn, dass er die ghanaische Arbeitskultur kennt und auch die ghanaischen Mitarbeitenden in Accra selbst, denn sonst würde das Unternehmen seines Erachtens nicht funktionieren, weil er die Ghanaer*innen braucht, um auf dem ghanaischen Markt Fuß zu fassen und die Bedürfnisse und Vorlieben der jungen Leute in Ghana zu verstehen. Er zahlt überdurchschnittliche Gehälter, von denen die Angestellten gut leben und ihre Familien versorgen können. Er hat die Angestellten sozusagen „auf der Straß" gesucht; alle waren arbeitslos und suchten händeringend nach Arbeit. Nur so konnte er sich überhaupt erst einmal leisten, sie einzustellen und das Unternehmen zu gründen. Seit das Unternehmen gut läuft und die Verkaufszahlen gestiegen sind, wurden auch höhere Löhne gezahlt. Die Löhne sollen weiter mit dem Unternehmen wachsen: 
"I got the idea to found this company in Germany. I had no money, but only knowledge. That's why, I came up with this idea to start this company. Wouldn't I have studied in Germany I maybe would have got this idea, but not the skills to actually realize the idea" (Interview mit einem ghanaischen Alumnus in Deutschland, Skype, 2018).

Bei der Führung dieses kleinen Online-Unternehmens kann er Know-how einbringen, das er sich in seinem BWL-Studium an der Universität Leipzig angeeignet hat. Gerade ist er dabei, seine Doktorarbeit zum Thema „Tech Start-Up Companies in Ghana" abzuschließen. Dabei untersucht er die Gründungslandschaft für HighTech-Unternehmen in Ghana und geht der Frage nach, warum junge Menschen in Ghana ein Tech-Unternehmen gründen, was ihre Ziele dabei sind und welchen Herausforderungen sie begegnen. Dabei konzentriert er sich vor allem auf die beiden großen Wirtschaftszentren in Ghana, Accra und Kumasi. Gerade dort gibt es seiner Meinung nach einen neuen Gründergeist unter jungen Leuten, die oftmals im Ausland studiert haben und ihr Wissen nutzen wollen, einen neuen Wirtschaftssektor in Ghana aufzubauen. ${ }^{30}$ Dabei scheint es ihnen wichtig zu sein, von der „alten Entwicklungsphilosophie“ der landwirtschaftlichen Förderung wegzukommen und mehr in Zukunftstechnologien wie Internet und Maschinenbau zu investieren. Hierzu fehlen seiner Meinung nach aber häufig noch die materiellen Ressourcen, und deswegen sollte man sich auf High-Tech im Internet konzentrieren, weil man dazu nicht viel Startkapital und Material benötige, sondern nur Wissen als Startkapital und Produktionsfaktor. Dies hätten viele junge Akademiker*innen in Accra und Kumasi erkannt und möchten Entrepreneurs werden. In Accra gebe es ein „Boom wie in Berlin“. Sein Online-Schuh-Store gehört ebenfalls dazu. Nun komme es nur darauf an, eine Nische auf dem ghanaischen Markt (und vielleicht auch auf dem Weltmarkt) zu finden. Die Doktorarbeit und den Job zusammen unter einen Hut zu bringen: „Das ist die größte Herausforderung. Es ist sehr schwierig die Doktorarbeit schriftlich abzuschließen und sich nebenbei um das Unternehmen zu kümmern. Mit dem Unternehmen verdiene ich meinen Lebensunterhalt. Trotzdem versuche ich noch dieses Jahr [2018] meine Doktorarbeit abzuschließen“ (Interview mit einem ghanaischen Alumnus in Deutschland, Skype, 2018).

30 Bisher ist der Tech-Sektor in Ghana allerdings noch unterentwickelt und macht nur einen Bruchteil der ghanaischen Wirtschaftsleistung aus, und der industrielle Sektor nur rund ein Drittel des Wirtschaftsvolumens (BMZ 2018). 


\subsection{Förderung und Konsolidierung des Friedensprozesses in Kolumbien}

Wie in Palästina, Indonesien und Ghana verfügt der KAAD auch in Kolumbien über eine lange Stipendientradition. Das besondere Engagement des KAAD in Lateinamerika geht auf den ehemaligen Präsidenten des KAAD, Peter Hünermann zurück, der während einer längeren Reise in Lateinamerika in den 1960er Jahren zahlreiche Kontakte zu Universitäten und staatlichen Einrichtungen knüpfte und 1968, zusammen mit Bernhard Welte ${ }^{31}$, das Stipendienwerk Lateinamerika-Deutschland aufbaute, auf das auch heute noch viele Netzwerke des KAAD in Lateinamerika zurückgehen (Eckholt 2011: 13; Interview mit Peter Hünermann, Bonn, 2017). Jedoch war Kolumbien schon seit der Gründung des KAAD 1958 ein Förderland.

Kolumbien ist ein überwiegend katholisch geprägtes Land (über $70 \%$ der Einwohner sind römisch-katholisch, ca. $20 \%$ gehören evangelischen und evangelikalen Religionsgemeinschaften an und weitere $10 \%$ anderen kleineren Religionsgruppen). Mit fast 50 Millionen Einwohnern ist es zudem das zweitbevölkerungsreichste Land Lateinamerikas nach Brasilien. Dreiviertel der Bevölkerung leben in urbanen Ballungsgebieten, allein ein Sechstel in der Hauptstadt Bogotá. In ländlichen Gebieten leben vor allem indigene Gruppen, deren Lebens- und Dorfstrukturen rechtlich geschützt sind, was aber häufig missachtet wird, und zwar sowohl vom kolumbianischen Staat, Unternehmen und anderen Gruppen. Überhaupt herrscht in Kolumbien eine starke soziale Ungleichheit, wobei vor allem indigene Gruppen auf der untersten Ebene der sozialen Rangordnung zu finden sind. ${ }^{32}$ Diese starke soziale Ungleichheit prägte Kolumbien seit der Unabhängigkeit von Spanien im Jahr 1810 und führte immer wieder zu sozialen Konflikten und Bürgerkriegen in den letzten zwei Jahrhunderten, darunter der Bürgerkrieg in der Granada-Konföderation von 1860 bis '62, der zur Gründung der Vereinigten Staaten von Kolumbien führte, und der „Krieg der tausend Tage“, der in Folge des Kaffeebooms zu einer Aneignung kleinflächigen Kleinbauernland durch Großgrundbesitzer (Latifundistas) führte. Es wird geschätzt, dass über 100.000 Menschen in diesem

31 Bernhard Welte war von 1952 bis 1973 Professor für Christliche Religionsphilosophie an der Albert-Ludwigs-Universität in Freiburg und ein Förderer des akademischen internationalen Austausches, vor allem mit Hochschulen in Lateinamerika (Eckholt 2011: 16).

32 Der Gini-Koeffizent beträgt ca. 54, was für eine hohe ungleiche Verteilung des Reichtums spricht. Das Bruttoinlandsprodukt pro Kopf betrug im Jahr 2017 rund 7.600 US-Dollar. Damit belegte Kolumbien Platz 87 weltweit (vgl. Internationaler Währungsfonds 2018). Auch der Human Development Index war 2016 mit 0,747 relativ niedrig (Platz 90 weltweit) (UNDP 2018). 
Krieg starben (vgl. König 2008). Auch der letzte und über 50 Jahre andauernde bewaffnete Konflikt (1964-2016) zwischen dem kolumbianischen Staat auf der einen Seite und verschiedenen Terror- und Guerillagruppen auf der anderen Seite, erforderte viele Opfer und konnte erst Ende November 2016 mit dem Friedensvertrag zwischen der kolumbianischen Regierung und der größten Guerillagruppe, der FARC-EP, beendet werden.

Bei diesem Konflikt handelt es sich um eine komplizierte Gemengelage von Interessen verschiedener Konfliktparteien. Grundsätzlich geht es in dem Konflikt um die Verteilung von Land, Rohstoffen und Gütern. Die Latifundas und internationale Unternehmen versuchen weiterhin Land von Kleinbauern und indigenen Gruppen für geringe Preise zu kaufen, um Ölpalmen oder Kaffee anzubauen bzw. Bergbau zu betreiben. Dabei werden die Kleinbauern und indigenen Gruppen vom kolumbianischen Staat nur unzureichend geschützt. Daher versuchen linksgerichtete Guerillagruppen (darunter die beiden größten Gruppen FARC-EP und ELN) - die v. a. aus Linksintelektuellen, der Landbevölkerung und Indigenen bestehen - die Interessen der Kleinbauern und indigenen Gruppen gegenüber dem Staat und rechten Paramilitärs (bestehend aus rechten Militärs und Bürgermilizen) zu verteidigen. Insgesamt hat der Konflikt in den letzten 50 Jahren über 300.000 Menschen das Leben gekostet und über 8 Millionen Menschen wurden von ihrem Land vertrieben, die innerhalb Kolumbiens und teilweise ins Ausland flüchteten (Adveniat 2018). Unter den Leidtragenden sind auch viele Landminenopfer und Friedensaktivisten.

Der Konflikt wurde aber mit dem Friedensabkommen nicht vollständig gelöst, sondern wird noch in vielen ländlichen Gebieten und sozialen Bereichen des Landes teils gewalttätig weitergeführt. Zudem wurde der Friedensvertrag von einigen Guerillagruppen nicht anerkannt. Überhaupt offenbarten sich in dem Konflikt enorme demokratische Defizite in Kolumbien. Das zeigt sich vor allem in dem fehlenden Schutz der Landbevölkerung vor den Paramilitärs und Guerillaorganisationen sowie die zum Teil enge Verwicklung von Politiker*innen und Richter*innen in den Drogenhandel, Korruption und die Ausbeutung natürlicher Ressourcen durch Großkonzerne und die damit einhergehende Umweltverschmutzung. Kolumbien wird in der Politikwissenschaft als ,unvollständige Demokratie“ bezeichnet und liegt im weltweiten Vergleich des Demokratieindexes auf Platz 51 (The Economist 2019).

Ein Schwerpunkt der Förderung des KAAD in Kolumbien liegt, wie oben bereits dargelegt, auf den Rechts-, Wirtschafts-, Geistes-, Kultur- und Sozialwissenschaften. Über zwei Drittel aller kolumbianischen KAAD-Stipendiat*innen waren in den letzten 15 Jahren in diesen Fächern eingeschrieben. Im Gegensatz zu Alumni aus den anderen Fallstudienländern weisen kolumbianische KAAD-Alumni eine relativ geringe Rückkehrquote auf. So gehen in der Regel weniger als die Hälfte aller ko- 
lumbianischen KAAD-Alumni nach ihrer Förderung in Deutschland wieder zurück nach Kolumbien (46\% in den 2000er Jahren). Die meisten Rückkehrer*innen leben und arbeiten in der Hauptstadt Bogotá. Auch in dieser Fallstudie konnten wir aber wieder Beispiele von ehemaligen Stipendiat*innen finden, die nicht zurückgekehrt sind, sich aber für ihr Herkunftsland engagieren. Das Engagement konzentriert sich dabei in erster Linie auf die Bewältigung der zahlreichen innerkolumbianischen Konflikte sowie auf die Förderung des Demokratieprozesses im Allgemeinen, an den seit dem Friedensabkommen 2016 viele Hoffnungen geknüpft sind. In diesem Zusammenhang engagieren sich auch viele KAAD-Alumni, indem sie die kolumbianische Politik bei der Konfliktaufarbeitung und beim Friedensdialog beraten oder sich für die Rechte und Interessen der Opfer des Konflikts einsetzen.

So berät z. B. ein KAAD-Alumnus, der in Deutschland im Fach Philosophie promoviert hat, kolumbianische Politiker ${ }^{\star}$ innen beim Friedensdialog mit indigenen Gruppen. Dabei stützt er sich auf ein von ihm im Rahmen seiner Promotion entwickeltes Modell des interreligiösen Dialogs zwischen indigenen Weltanschauungen und dem Christentum in Lateinamerika, das auf gegenseitigem Respekt, interkultureller Offenheit, Solidarität und kommunikativer Sensibilität basiert. Dieses Modell ist inzwischen in Teilen vom kolumbianischen Staat übernommen worden und wird erfolgreich im Dialog mit indigenen Gemeinden im Norden Kolumbiens angewendet, die besonders stark unter gewalttätigen Auseinandersetzungen im Bürgerkrieg gelitten haben, sich mittlerweile aber weitgehend selbst verwalten und mit der kolumbianischen Nationalregierung kooperieren.

Eine andere KAAD-Alumna, die Soziologie an der Universität Heidelberg und Universität Frankfurt studierte und inzwischen Professorin für Soziologie an der Universidad del Rosario in Bogotá ist, berät die Politik in ihrem Umgang mit Guerilla- und paramilitärischen Organisationen auf lokaler Ebene. Dabei versucht sie, einen partizipativeren Ansatz zu vermitteln, als dies bisher in Kolumbien üblich war, und der darüber hinaus stärker die Interessen der Guerillas und Paramilitärs in Entscheidungsprozesse einbezieht:

„Und ich bin Teilnehmerin von verschiedenen Forschungsnetzwerken in der Friedens- und Konfliktforschung. Das ist mit deutschen Institutionen und mit meiner Uni Universidad del Rosario. Meine Uni ist Mitglied im Instituto Colombo-Aleman Para la Paz. Bei diesem Instituto Colombo-Aleman para la Paz bin ich die Vertreterin der Universidad del Rosario. Das Instituto ist angesiedelt an der Universidad Nacional, Universidad del Rosario, Universidad de los Andes, Universidad Javeriana und Universidad Externado in Kolumbien. In Deutschland sind es die Universitäten Gießen, Göttingen, das Lateinamerikanische Institut an der Freien Universität Berlin, das Friedens- 
institut in Frankfurt am Main und die Universität Freiburg. [...] Es geht vor allem um die Untersuchung des Konflikts in Kolumbien, aber auch Post-conflict und peace building in Kolumbien. Mein Forschungsschwerpunkt in diesem Rahmen ist die Beziehung zwischen Zivilgesellschaft und dem Staat. Aber auch um Staatsbürgerschaft. Die Rolle von Citizenship im Friedensprozess und die neuen Beziehungen zwischen Staat und Citizenship. Ich habe ein Buch dazu publiziert, ein Handbuch bei Routledge. Das ist ein Buch des Transformation of Citizenship, zusammen mit einem Professor in Potsdam geschrieben. Dabei geht es um Forschungsergebnisse, die ich in der kolumbianischen Karibik gemacht habe. In einer kleinen Stadt in der Karibik über die politische Partizipation von Leuten in einer Stadt, die von Paramilitärs kontrolliert wird. Das ist sehr interessant, weil es um eine kleine Gemeinde namens Magangué geht. Die liegt bei Cartagena in der Karibik. Diese Kleinstadt wurde mehr als 20 Jahre von Paramilitärs kontrolliert. Sie kontrollieren alles - durch Angst. Aber sie haben so viel Geld durch Geldwäsche und Drogenhandel. Ein Bürgermeister hat die Wahlen 2011 gewonnen, er ist von einer linken Partei. Und meine Frage war, was passiert hier? Und ich war in Magangey und habe Interviews gemacht. Meine Kontakte in diese kleine Stadt war die katholische Kirche und ich hatte diesen Kontakt durch den KAAD. Das ist sehr gut, ein richtig gutes Netzwerk. Ehemalige KAAD-Stipendiaten haben Kontakte zu Caritas in Kolumbien und zur Bischofskonferenz in Bogotá und sie haben sich für meine Arbeit interessiert. Und sie sagten mir, dass ich in Magangey forschen kann. Und ich arbeite mit denen in verschiedenen Workshops, Treffen mit Leuten. Und dank dieser Kontakte konnte ich meine Forschung machen. Das war wunderbar. Und die Ergebnisse sind sehr kompliziert, nicht so einfach zu erklären. Viele Leute in Magangey, wie viele Leute in verschiedenen Orten in Kolumbien, können ihre Wahl verkaufen und andere handeln mit dieser Wahl. Normalerweise kostet das 20 Euro. In Magangey kostet es 30 Euro. Was passiert? Viele Leute haben die Wahl verkauft, aber viele haben einen anderen Kandidaten gewählt. Sie glauben nicht an die Paramilitärs, aber bekommen ihr Geld. Das ist eine besondere Rationalität. Aber das Wichtigste ist, ich konnte die Forschung in Magangey zusammen mit den Kirchen machen. [...] Der neue Bürgermeister, der Sozialist, war auch korrupt und hatte zu viel Probleme mit den Paramilitärs. Und in 2015 der neue Bürgermeister hat noch Leute von den Paramilitärs. Die Paramilitärs kontrollieren immer noch die Stadt. Es ist eine besondere Konstellation. Es ist nicht so öffentlich, aber die Paramilitärs kontrollieren noch viele Regionen in Kolumbien. [...] Ja, ich finde, vielen Leute geht es gut. Ich weiß nur nicht, ob es Resignation ist, aber viele Leute haben eine komische Beziehung zu den Paramilitärs zwischen Liebe und Hass. Aber 
es funktioniert. Zum Beispiel, die Leute bitten um eine neue Schule und die Paramilitärs bauen die neue Schule. Manchmal ja und manchmal nicht, aber es gibt keine anderen guten Optionen auch. [...] Ja, aber meine Frage für die nächsten Jahre ist, was passiert, zum Beispiel, mit den Regionen, die von den Guerillas kontrolliert worden. Also die Guerillas sind nicht mehr da, also regieren nicht mehr in den Regionen und was passiert dann? Also gibt es eine neue Bürgerschaft oder neue Akteure, die die Kontrolle ausüben und es bleiben mehr oder weniger dieselben alten Beziehungen, und dieselbe Ungleichheit zwischen Bürger und dem Staat. Aber wir verstehen Staat nicht in klassischen Sinn, sondern bei uns kann Staat sein, die Guerilla oder die Paramilitärs, oder andere Gruppen. Es ist kompliziert" (Interview mit einer kolumbianischen Alumna in Bogotá, Kolumbien, 2017).

Im Rahmen ihrer Arbeit kooperiert sie regelmäßig mit der Friedrich-Ebert-Stiftung in Kolumbien (FESCOL):

„Die FESCOL hat eine lange Tradition in der Friedensvermittlung in Kolumbien. Sie organisieren jeden Monat ein Treffen zwischen Bürgermeistern, Politikern, NGOs und Wissenschaftlern. Dabei geht es um verschiedene Themen wie Demokratie, Sicherheit, Gender-Studien und Konfliktbewältigung. Und jeder diskutiert dort aus seiner eigenen Perspektive. Dazu werde ich häufig eingeladen. Dort hatte ich die Möglichkeit, meine Positionen der FESCOL, den Bürgermeistern und Politikern vorzustellen. Aber normalerweise haben diese Politiker eine große Distanz zu der Universität. Sie denken: Ihr schreibt eure Bücher und wir arbeiten. Das ist die Konzeption. Die FESCOL sieht sich dabei als neutraler Ort, an dem verschiedene Konfliktparteien ihre Positionen austauschen können. Und ich bringe meine wissenschaftliche Perspektive ein" (Interview mit einer kolumbianischen Alumna in Bogotá, Kolumbien, 2017).

„Andere kolumbianische Alumni kümmern sich um die rechtliche Aufarbeitung der Konflikte, wie ein Jurist, der Jura an den Universitäten in Marburg und Mainz studiert und im Jahr 1995 zum Thema Optionsanleihen und Wandelschuldverschreibungen im europäischen Bankenrecht an der Universität Mainz promoviert hat. Nach seiner Rückkehr und ein paar Jahren als Professor an der Universidad Nacional in Bogotá gründete er 2002 eine Kanzlei, die mittlerweile zu den größten und renommiertesten Kanzleien in ganz Kolumbien gehört. Zurzeit beschäftigt er in seiner Großkanzlei zwölf Anwälte und über 30 weitere Angestellte. Die Kanzlei arbeitet in den Bereichen des Bankenrechts, Umweltrechts, Energierechts, Infrastrukturrechts und Vergaberechts. Unter 
seinen Mandaten sind auch viele Deutsche, die in Kolumbien wohnen. Die Kontakte hat er vor allem wegen seiner guten Deutschkenntnisse und guten Beziehungen nach Deutschland aufgebaut. Im Rahmen seiner Anwaltstätigkeit kümmert er sich auch ehrenamtlich um die rechtlichen Belange von Opfern des Konflikts, insbesondere Sehbehinderte. Dieses Engagement geht vor allem darauf zurück, dass er selbst unter einer Sehbehinderung leidet und dadurch die Belange und Bedürfnisse von Blinden aus eigenen Erfahrungen sehr gut kennt. Dabei nimmt er kein Geld von den Opfern, weil diese überwiegend aus armen ländlichen Kommunen kommen und sich keine Beratung oder Verteidigung leisten können. Auch von staatlicher Seite wird diese Gruppe nicht unterstützt, „weil sie einfach keine Lobby hat", so der KAAD-Alumnus. Viele von ihnen wurden Opfer von Schießereien auf offener Straße, meistens durch reinen $\mathrm{Zu}$ fall, weil sie die Straße überqueren wollten, aber die Auseinandersetzungen auf der Straße aufgrund ihrer Sehbehinderung nicht rechtzeitig sahen. Zudem hat er ihnen dabei geholfen einen eigenen Verband zur Interessenvertretung in Bogotá zu gründen, bei dem er auch Mitglied geworden ist. Das hat ihn auch erleichtert, ihre Interessen vor Gericht zu vertreten, weil er eine Organisation in seiner Arbeit hinter sich hat und auch in ihrem Namen sprechen kann" (Interview mit einem kolumbianischen Alumnus in Bogotá, Kolumbien, 2017).

Eine in Deutschland promovierte Juristinn ${ }^{33}$, die seit ihrer Rückkehr im Jahr 2017 als wissenschaftliche Assistentin im Fach Jura an der Universidad Externado in Bogotá arbeitet, setzt sich für die Entschädigung und gesellschaftliche Reintegration von Landminenopfern ein. In Kolumbien gibt es nach Afghanistan die meisten Landminenopfer weltweit. Laut der kolumbianischen Kommission für Frieden sind es 11.460 Landminenopfer seit 1990, 80 Prozent davon waren Zivilist*innen. Ca. 20 Prozent sind an den Folgen gestorben, die meisten in dem Bundesstaat Antioquia (Oficina del Alto Comisionado para la Paz 2019). ${ }^{34}$ Die Minen wurden von der Guerillaorganisation FARC-EP gelegt, um das kolumbianische Militär zu bekämpfen.

33 In ihrer Doktorarbeitet beschäftigte sie sich mit dem Thema „Einfluss von Staatszielbestimmungen auf die Rechtsauslegung“. Dabei ging es darum, wie ein Richter die Staatszielbestimmungen in der deutschen Verfassung am besten auslegen kann. Das Thema ist rein auf Deutschland bezogen. Sie wollte einen Vergleich mit Kolumbien machen, aber der Gutachter war dagegen. Der Gutachter interessiert sich nicht für Lateinamerika, das hat sie sehr geärgert.

34 Oficina del Alto Comisionado para la Paz 2019: Víctimas de Minas Antipersonal y Municiones sin Explosionar, http://www.accioncontraminas.gov.co/estadisticas/Paginas/ victimas-minas-antipersonal.aspx. 
Es wird geschätzt, dass über 100.000 Landminen auf Feldern, in Wäldern und an Wegesrändern gelegt wurden (Caritas International 2018). ${ }^{35}$

Ein Tritt auf eine Mine führt mit hoher Wahrscheinlichkeit zu Verstümmelungen (Oficina del Alto Comisionado para la Paz 2019). Trotz der Landminenräumungen seit dem Friedensabkommen von 2016 gibt es weiterhin viele unendeckte Minen, die nach wie vor zivile Opfer fordern (NZZ 2017). ${ }^{36}$ Die Zahl der Opfer stieg sogar von 37 im Jahr 2017 auf 107 im Jahr 2018 (Caritas International 2019). ${ }^{37}$ Um die Opfer zu entschädigen, bereist die KAAD-Alumna das ganze Land, insbesondere die ländlichen Regionen, um die lokalen Verwaltungen, aber auch die Opfer direkt vor Ort über ihre Rechte aufzuklären. Dabei geht es vor allem um den kostenlosen Rechtsbeistand, der den Opfern gesetzlich zusteht, aber der aufgrund mangelden Wissens darüber von den Opfern kaum eingefordert wird. Zudem stehen den Opfern kostenlose langfristige medizinische Leistungen zu, die aber ebenfalls häufig nur gering abgerufen werden. Überhaupt ist die kolumbianische Bevölkerung nur unzureichend über die Gefahren der Minen aufgeklärt. Über ihre Arbeit sagt sie:

„Zurzeit werden in Kolumbien viele Landminen aus dem Bürgerkrieg zerstört, die von den Paramilitärs oder Guerillagruppen in den ländlichen Gebieten aufgestellt wurden, um die staatlichen Gegner zu bekämpfen, aber auch um die Landbevölkerung einzuschüchtern. Die meisten Opfer waren aber auch Kinder, Frauen und ältere Menschen, also Menschen, die mit dem Krieg nichts zu tun hatten. Sie bekommen auch kaum Unterstützung vom Staat oder von ihrer Community, sie hatten auch keine Versicherung. Aber sie haben Rechte nach der kolumbianischen Verfassung, aber auch nach bürgerlichen Gesetzen und Richtlinien. Bei der Aufarbeitung ihrer Rechte versuche ich zu helfen, und diese dann auch gegenüber staatlichen Einrichtungen zu vertreten, also sie auch bei den Korrespondenzen mit staatlichen Behörden zu unterstützen. Viele von ihnen können nicht lesen und schreiben. Dabei helfe ich. In dem Projekt geht es aber auch darum, ihnen vielleicht doch Arbeitsplatzmöglichkeiten zu schaffen, wie in der kommunalen Verwaltung, die sie trotz ihrer körperlichen Behinderung ausüben können. Erste finanzielle Entschädigungen konnten wir schon erreichen, auch wurden schon körperlich Behinderte in

35 Caritas International 2018: Kolumbien: Landminenopfer. https://www.caritas-international.de/beitraege/kolumbien-landminenopfer/149291/.

36 NZZ 2017: Das große Aufräumen. https://www.nzz.ch/international/minenraeumungin-kolumbien-das-grosse-aufraeumen-ld.137411.

37 Caritas International 2019: Kolumbien: Hilfe für Landminenopfer. https://www.caritasinternational.de/hilfeweltweit/lateinamerika/kolumbien/landminen-aufklaerung. 
den Kommunen eingestellt. Wir schlagen auch nicht nur eine Entschädigung der Opfer vor, sondern eine langfristige Invalidenrente, damit diese Opfer von etwas leben können" (Interview mit einer kolumbianischen Alumna in Bogotá, Kolumbien, 2017).

„In dem Job reise ich auch in die Dörfer der Opfer, um mir die Situation vor Ort anzusehen und um mit den Opfern und den Führern der Community zu sprechen. Wenn ich direkt mit ihnen spreche, kann ich sie auch besser über ihre Rechte aufklären und ihnen helfen, ihre Rechte gegenüber dem Staat zu vertreten. So einmal pro Monat reise ich in die Gebiete, wo die Opfer wohnen" (Interview mit einer kolumbianischen Alumna in Bogotá, Kolumbien, 2017).

Im Rahmen des Projekts, das vom norwegischen, schwedischen und schweizerischen Staat finanziert wird, werden auch entdeckte Landminen entschärft und entsorgt, damit die vertriebenen Dorfbewohner wieder in ihre Dörfer zurückkehren und Ackerbau betreiben können, zum Teil auf Feldern, die von den Paramilitärs vermint wurden. Die Alumna sagte weiter dazu:

„Es geht darum auch die aktuelle Regierung, die Oppositionsparteien und die zuständigen Behörden über die Zustände auf dem Land aufzuklären. Und auch die Rechte der Landminenopfer vor den zuständigen Behörden und Gerichten zu vertreten. Wir sollen auch Handlungsempfehlungen an die Politik abgeben, wie den Opfern besser geholfen werden kann, denn das war ja auch ein wichtiger Teil der Abmachungen des Friedensvertrags. Bisher kooperiert der kolumbianische Staat sehr gut mit uns, aber man weiß hier nie wie lange das so ist. Nächstes Jahr wird ein neuer Präsident gewählt, der kann zum Beispiel gegen die Aufarbeitung des Konflikts und gegen den Friedensprozess sein, dann war unsere Arbeit vielleicht sogar umsonst" (Interview mit einer kolumbianischen Alumna in Bogotá, Kolumbien, 2017).

Bisher kooperiert der kolumbianische Staat gut im Rahmen des Projekts, aber Entschädigung der Landminenopfer wird im Rahmen des Friedensprozesses nur langsam aufgearbeitet. Sie ergänzte:

„Vor dem Projekt hatte ich viele Bedenken mit dem kolumbianischen Staat zu kooperieren und mit der kolumbianischen Polizei zusammen zu arbeiten, ich hatte keine gute Meinung über die, weil die ja auch die Opfer nicht gut behandelt haben, aber das hat sich im Laufe des Projektes gebessert, meine Meinung ist besser geworden, weil ich erkannt habe, dass das auch nur Men- 
schen sind, die ihre Arbeit machen müssen. Mit vielen von denen kann man arbeiten. Ich glaube schon, dass sie Frieden wollen und den Opfern jetzt helfen wollen. Also nicht alle, aber viele mit denen ich gesprochen habe" (Interview mit einer kolumbianischen Alumna in Bogotá, Kolumbien, 2017).

Eine andere kolumbianische KAAD-Alumna, die im Studiengang LLM „Governance and Development" von 2014 bis 2015 an der Universität Duisburg-Essen studierte, führt im Rahmen eines UN-Projekts Aufklärungs- und Bewältigungs-Workshops für die Opfer des Konflikts in kleinen Dörfern in Westkolumbien durch (in Kooperation mit IOM und USAid). Betroffen sind vor allem indigene Frauen und Kinder, die sie über ihre Rechte aufklärt. Insbesondere Vergewaltigungsopfern erklärt sie, wie gegen die Täter juristisch vorgegangen werden kann:

"My project at the United Nations is to formulate projects how to solve the conflict in local communities in West Colombia. The work focus is on the help of traumatized women and children, who suffered from violence during the war, as I already said, and I have to teach the conflict victims to know the law and their rights, because many times they have no idea about that, they have no access to information, or even cannot read or write. We also help the community members how to receive money in the community, how to formulate development or infrastructure projects in the community, and where to get funding for that. And I'm foremost in charge of to teach them how to formulate and organize these projects. That is not always easy, because they have never done that before, and they have a very different way of thinking. Also some of them cannot read or write, or almost all of them are very bad in doing these things. So I really had to start from the beginning. [...] The central goal of the project was to help and protect the communities against war trauma and armed forces, and to teach them about their rights, and to empower them and to give them the necessary tools to protect themselves against armed forces. [...] In the communities are mestizos and indigenous people, and I tried to convince them that they can trust me and that I want to help them, but I'm not sure, if I could convince every one of them. They don't trust the Colombian government, so it helped that I don't work for the government. But it was a challenge for me, because I'm young and I'm a female, and many of them didn't believe that I'm smart and that I could help them. In the communities exists a lot of machismo attitudes. And what is also a big problem, is that most people still think in racial categories. Everyone wants to be a mestizo, even black people say that. As a blond male you would have more opportunities, even when you are from abroad. Women have to be tough to be successful in Latin America. 
People have stereotypes about women here, they have to be pretty and soft, and should take more care about household issues, and should not be involved in politics, economics, or development issues" (Interview mit einer kolumbianischen Alumna in Bogotá, Kolumbien, 2017).

"I'm done with the projects for the United Nations. Now I have to evaluate how successful the projects actually were. For this, I specially developed an evaluation method to analyze the projects in an effective way. The evaluation should end in December 2017" (Interview mit einer kolumbianischen Alumna in Bogotá, Kolumbien, 2017).

"All in all, I have to say that the time was too short to realize the projects, and to implement everything. Each project took about four months. That is too short to build trust among the community people, and to teach them about their rights and to improve their self-defense. How do you want to build trust in such a short time, and how do want to explain important rights in face to face conversations in such a short time, I mean not only in workshops and presentations in front of al community members, but really one to one conversation where you can explain things in more details, and where he or she can ask specific questions of understandings. Everyone is different and needs more or less time to understand things. That needs more time, definitely much more than just four months. Anyhow, the first results of the evaluation are that the members of the community got more guidance now. There is an overall positive feedback from the communities. The problems are still that the education and skills of the community people are not good enough to formulate their own laws and aims. To reach that goal, they would have to work more with local municipalities in these areas. A good thing is that the members have access to the community now" (Interview mit einer kolumbianischen Alumna in Bogotá, Kolumbien, 2017).

"I really like my job, because I see the results of my work that can be important in the peace process. I also talked to the victims of the conflict. No one knows about the victims, because no one talks to them. I talk to the victims about the project and the results, about everything, so that they can understand better what we are doing. I think I have good connections to them now" (Interview mit einer kolumbianischen Alumna in Bogotá, Kolumbien, 2017). 
Sie plant bereits ein weiteres Projekt:

\begin{abstract}
"Now, I'm working with a professor from the Universidad Nacional in Bogotá on a new project proposal. I already know him for a couple of years. All of the proposals have something to do with the peace process, and they have to include the peace documents that were worked out between the government and the guerrillas and paramilitaries. The proposals are to get funding by the IOM. Now I'm writing two proposals about the development plan" (Interview mit einer kolumbianischen Alumna in Bogotá, Kolumbien, 2017).
\end{abstract}

Ein anderer KAAD-Alumnus, der Jura in Deutschland studierte, arbeitet mittlerweile als Richter am Obersten Gerichtshof in Kolumbien. Dabei kann er seine Kenntnisse des deutsche Rechtssystems, das in Kolumbien als vorbildlich gilt, einbringen, die er während seines Studiums in Deutschland gesammelt hat. In seiner gegenwärtigen Richtertätigkeit kann er dabei viele Vergleiche zum deutschen und internationalen Strafgesetz ziehen und viele Punkte in das kolumbianische Strafgesetz einbringen, das zur Zeit im Rahmen des Aufarbeitungsprozesses des kolumbianischen Bürgerkrieges und der Opferentschädigung überarbeitet wird:

„Bei meiner Arbeit als Assistenzrichter im Gerichtshof musste ich ein paar Fälle der Kriegsverbrecherverurteilung mitentscheiden oder Empfehlungen abgeben, die auch mit meinem Abschlussthema in Deutschland zu tun hatten. Das ist etwas interessant, immer kann ich die akademischen Sachen mit den beruflichen Sachen verbinden. In dieser Zeit hatten wir eine Verfassungsveränderung. Es gab Verhandlungen zwischen der kolumbianischen Regierung und Mitglieder von FARC, der Guerilla. Und es gab erste Normen und Regelungen, um die Täter des Bürgerkriegs zu bestrafen. Aber dann kam das Friedensabkommen und verschiedene Gesetze wurden verabschiedet. Dann die Analyse geht weiter in die Richtung der Kompatibilität der kolumbianischen Gesetze mit dem Statut des Internationalen Strafgerichtshofs. Aber das ist jetzt immer noch ein Prozess, der noch nicht abgeschlossen ist. Die Gesetze müssen schrittweise noch ausgearbeitet werden. Deswegen arbeite ich auch als Privatdozent. Ich behalte diese Verbindung mit der Uni, weil berufliche Sachen können verbessert werden mit akademischen Diskussionen und Ergebnissen, und umgekehrt auch. Meine Magisterarbeit habe ich auf Deutsch geschrieben. Der Titel der Arbeit war der Komplimentaritätsgrundsatz des Strafgerichtshofes aufgezeigt am Beispiel Kolumbiens." „Kompetenzen im Strafrecht, sondern auch die Arbeitsweise der Juristen in Deutschland war sehr wichtig, um kennenzulernen wie ein Student ein Jurist wird in Deutschland. Ich habe diesen Prozess bei 
manchen Freunden in Deutschland verfolgt, sie haben sich in dieser Zeit für das zweite Staatsexamen vorbereitet. Das war sehr interessant und ich habe viel gelernt. Ich war immer ein Zeuge von juristischen Vorgängen, Kanzleien, Gerichtsverhandlungen. Das war immer gut zu sehen, welche Möglichkeiten der Rechtsvergleiche es gibt. Viele Leute haben mich gefragt, wieso hast Du in Deutschland Jura studiert, Du kannst diese Kenntnisse nicht direkt anwenden in Kolumbien, weil die Gesetze anders sind. Das ist wahr, aber je mehr man andere Rechtssysteme kennt, desto besser kann man verschiedene Interpretationen entwickeln und auch die Entwürfe von Gesetzen. Und ich habe auch im Internationalen Recht gearbeitet und das hilft in jedem Land" (Interview mit einem kolumbianischen Alumnus in Bogotá, Kolumbien, 2017).

Deutschland ist besonderes Vorbild aufgrund der Aufarbeitung und Bestrafung der Täter in der DDR und die Entschädigung der DDR-Opfer. Und Kolumbien als „Labor" für Konfliktaufarbeitung weltweit:

„Am Anfang, aber es gibt einige Problematiken im letzten Entwurf, die vielleicht die Zulässigkeiten des Internationalen Strafgerichtshofs aktivieren können, weil zum Beispiel der wichtigste Leiter der FARC hat die Möglichkeit, Kandidat für die Präsidentschaft im nächsten Jahr zu werden. Das kann die Rechte der Opfer verletzen. Eine Bedingung war, dass sie einen Prozess gegen ihn führen und es kamen alternative Strafen in Betracht. Es kommt in Betracht nicht die normale Strafe für ein internationales Verbrechen, dass sie begangen haben. 30, 40 Jahre Gefängnis. Diese normalen Strafen kommen nicht in Betracht, sie bleiben in bestimmten Regionen, die Mobilität ist begrenzt und sie müssten alternative Strafen haben wie soziale Arbeit, die politischen Rechte sind verkürzt, aber dieses neue Gericht funktioniert noch nicht. Deswegen haben sie keine Verurteilungen und sie können in der Politik aktiv sein und das könnte problematisch sein unter dem Blickwinkel des Internationalen Strafgerichtshofes sein. Deswegen trifft sich der Präsident heute mit der FARC. Sie diskutieren in diese Richtung. Die Verantwortlichkeit von Militär, es gibt eine Norm, die irgendwie führt zu Freilassungen von Militär von hohem Rang, die Schwerverbrecher begangen haben. Es ist ein sehr wichtiger Akteur in der Diskussion und insbesondere in der Ausgestaltung dieser neuen Justiz. Und Deutschland hat hier eine Vorbildfunktion wie die Aufklärung und Verurteilung der Verbrecher nach dem Zweiten Weltkrieg oder die Fälle nach dem Fall der Mauer, die Verbrechensaufklärung in der DDR, die Schussfälle an der Mauer und Grenze. Die wurden gut aufgearbeitet in Deutschland. Und Kolumbien ist heutzutage wie ein Labor für die Welt, weil es ist die erste Demobilisierung 
von einer sehr großen Guerilla, die für mehr als 50 Jahre gekämpft hat und jetzt kommt eine besondere Justiz für die Verurteilung dieser Verbrechen. Es kommt auch eine Wahrheitskommission, also verschiedene Mechanismen. Aber es gibt eine neue Komponente und das ist die Zuständigkeit des Internationalen Gerichtshofes von 2002" (Interview mit einer kolumbianischen Alumna in Bogotá, Kolumbien, 2017).

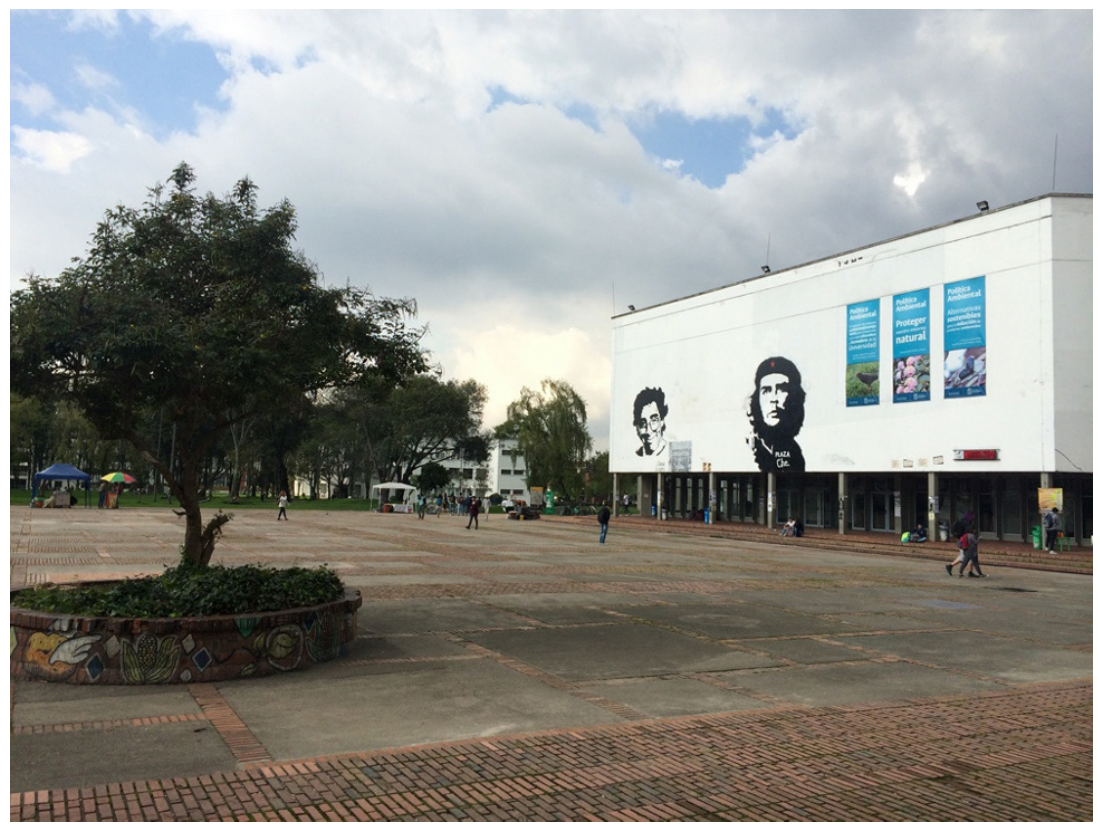

Aufnahme 4 Campus der Universidad Nacional de Colombia in Bogotá Quelle: Eigene Aufnahme.

Auch nicht Zurückgekehrte engagieren sich von Deutschland aus für den Friedens- und Demokratieprozess in Kolumbien. So organisiert ein kolumbianischer Alumnus regelmäßig Reisen mit einer Gruppe von deutschen und kolumbianischen Studierenden und Hochschullehrenden nach Kolumbien, die dort als Mediatoren im Konflikt zwischen Einheimischen und Guerillagruppen eingesetzt werden. Dabei arbeitet er eng mit anderen KAAD-Alumni in Kolumbien zusammen. 
Eine andere Alumna engagiert sich im Rahmen des oben erwähnten deutschkolumbianischen Friedens- und Konfliktforschungsnetzwerk „Instituto ColomboAlemán para la Paz" (CAPAZ) für die konkrete Umsetzung des kolumbianischen Friedensvertrages in einem kleinen Dorf in Nordkolumbien. Konkret geht es um die Frage, wie das Kommunalwahlrecht vor Ort umgesetzt wird und inwieweit sich die Dorfbevölkerung auf kommunaler Ebene repräsentiert sieht. Dabei findet ein intensiver Austausch zwischen den Mitgliedern des Forschungsnetzwerkes in Deutschland und Kolumbien statt. Trotz des vielfältigen Engagements und vereinzelter Fortschritte sehen die meisten KAAD-Alumni den Friedensprozess und die Konfliktaufarbeitung jedoch eher skeptisch. Eine KAAD-Alumna sagte dazu:

"Ich muss Optimistin sein, aber ich bin skeptisch. Meine Meinung ist, man sollte nicht über Postkonflikt sprechen, sondern über Postabkommen. Ich bin sehr skeptisch, weil es noch viele Akteure gibt, die keine Frieden in Kolumbien wollen. Und ein besonderer Faktor dabei ist der Drogenhandel. Wegen dem Drogenhandel werden wir keinen Frieden in Kolumbien haben. Die Frage ist die Legalisierung und mit den Preisen. Und ein Problem ist auch die TrumpRegierung in den USA. Die Coca-Plantagen haben sich seit dem Abkommen mit den FARC noch verdoppelt. Dieses Jahr werden hundert gepflanzt, dann nächstes Jahr 200. Und die Kokain-Exporte sind auch gewachsen. Die US-Regierung meint, dass das eine Konsequenz aus dem Friedensabkommen mit den FARC ist und wir Kolumbianer sollen eine Aggressionspolitik machen. Aber im Jahr 2000 der Plan Colombia hatte keinen Erfolg, der hatte sogar noch den Paramilitarismus verstärkt und nicht den Frieden. Das ist ein altes Rezept, das nicht funktioniert" (Interview mit einer kolumbianischen Alumna in Deutschland, Skype, 2017).

\subsection{Transformation des Rechtssystems in Georgien}

Georgien gehört zu den Schwerpunktländern des KAAD in Mittelost- und Südosteuropa. Obwohl osteuropäische Stipendiat ${ }^{*}$ innen, vorwiegend aus Polen und dem ehemaligen Jugoslawien, bereits vereinzelt in den Jahren vor 1991 gefördert wurden, sind die institutionellen Förderstrukturen für Osteuropa erst in den 1990er Jahren nach dem Zusammenbruch der Sowjetunion aufgebaut worden. Hierzu wurde für Bewerber*innen aus den Ländern Mittel-, Ost- und Südosteuropas, Kaukasus und Zentralasiens ein spezielles Osteuropaprogramm eingerichtet, das im Vergleich zu den anderen Programmen eine wesentlich kürzere Förderperiode vorsieht. 
Georgien wurde 1991 nach dem Zusammenbruch der Sowjetunion unabhängig. Seitdem unterliegt das Land einem ständigen gesellschaftlichen Wandel, der sich stark an den westlichen Ländern ausrichtet. Das kaukasische Land weist gegenwärtig ca. 4 Mio. Einwohner*innen und ein BIP/Kopf in KKP von 10.023 US-Dollar auf. Das Wirtschaftswachstum betrug 2019 2,85 Prozent. Das Universitätssystem ist stark von neueren und privaten Universitäten geprägt, die sich vor allem in der Hauptstadt Tiflis konzentrieren.

Ein Schwerpunkt der Förderung besteht hier seit vielen Jahren im Bereich der Rechtswissenschaft, der zusammen mit den Wirtschafts- und anderen Geisteswissenschaften über drei Viertel aller georgischen KAAD-Stipendiat*innen in den letzten 15 Jahren ausgemacht hat. Das Fallstudienland Georgien präsentiert dabei mit 55 Stipendiat ${ }^{*}$ innen das zweitgrößte osteuropäische Land nach Polen seit 1992. Davon waren die überwiegende Mehrheit Geistes-, Rechts- und Sozialwissenschaftler (insgesamt 45 von 55). Georgische Alumni weisen mit 88 Prozent die höchste Rückkehrquote (in den 2000er Jahren) von allen fünf Ländern in unserer Studie auf. Entsprechend hoch war auch der Anteil an Rückkehrerinnen und Rückkehrern in unserer Studie.

Der Einfluss der georgischen Alumni ist insbesondere mit Blick auf die Entwicklung des Rechtssystems groß. Laut unseren Interviewpartner*innen liegt dies vor allem daran, dass Jurist*innen als Expert*innen mit einem fundierten Rechtswissen relativ gute Berufsaussichten haben und in Georgien sehr breit nachgefragt werden, und zwar nicht nur vom georgischen Staat, sondern auch von Unternehmen und zivilgesellschaftlichen Organisationen. Viele georgische Jurastudierende gehen für ihr Studium nach Westeuropa, und insbesondere nach Deutschland. Dies hat vor allem damit zu tun, dass das georgische Recht sehr stark an die kontinentaleuropäische Rechtsentwicklung angelehnt ist. Bereits die erste demokratische Verfassung Georgiens aus dem Jahr 1918 war sehr stark an das schweizerische, französische und deutsche Recht angelehnt. ${ }^{38}$

Auch nach der Unabhängigkeit von der Sowjetunion im Jahr 1991, als sich Georgien unter dem Präsidenten Schewardnadse nach Westeuropa ausrichtete, versuchten die georgischen Gesetzesgeber*innen die neue Verfassung nach westeuropäischem Recht zu gestalten. Nach dem Ende der Schewardnadse-Ära im Jahr 2003 wurde die georgische Verfassung ebenso wie andere Gesetze abermals reformiert und auch dabei wurde viel von westeuropäischen Rechtssystemen übernommen. Hierbei ging es auch um die Etablierung demokratischer Rechtsnormen in Georgien,

38 Das Deutsche Reich war 1918 das erste Land weltweit, das die erste Verfassung Georgiens und somit Georgiens Unabhängigkeit anerkannte, auch auch geopolitischen Gründen in der Kaukasus-Region (Zürrer 1978). 
das im Gegensatz zu westeuropäischen Staaten keine demokratischen Traditionen kannte. Viele Jurist ${ }^{\star}$ innen haben in unseren Interviews darauf aufmerksam gemacht, dass sich Georgien eigentlich in den gesamten letzten 25 Jahren in einem permanenten verfassungsrechtlichen und politischen Transformationsprozess befindet. Dies kann man exemplarisch an der Transformation Georgiens von einer stark ausgeprägten Präsidialdemokratie hin zu einem parlamentarischen System (seit 2012) verdeutlichen, das die Machtstellung des Präsidenten stark einschränkt. ${ }^{39}$ Hatte der georgische Präsident in den 1990er Jahren noch fast alle politischen Entscheidungsbefugnisse in seiner Hand, wurde in den 2000er Jahren zunehmend eine semipräsidiale Demokratie nach französischem Muster etabliert - auch nach den negativen Korruptions- und Kriegserfahrungen unter Schewardnadse - und in den 2010ern wurde schließlich ein Kurs in ein reines Parlamentssystem, ähnlich wie in Deutschland, eingeschlagen. ${ }^{40}$

Aus Deutschland zurückkehrende georgische Juristinnen spielten in diesem Transformationsprozess eine wesentliche Rolle so wie auch bei der Weiterentwicklung weiterer Bereiche des georgischen Rechtssystems. So werden z. B. Merab Turava (Strafrecht), Paata Turava (Verwaltungsrecht) und Lado Chanturia (Europäisches Recht) als Pioniere der Rechtsentwicklung in Georgien angesehen. Sie studierten und forschten in den 1990er Jahren in Deutschland und brachten ihre dort erworbenen Kenntnisse des deutschen Rechtssystems nach Georgien zurück, wo sie georgische Standardwerke in ihren jeweiligen Rechtsdisziplinen verfasst und entscheidend an Gesetzesentwürfen mitgewirkt haben. Neben ihren akademischen und juristischen Tätigkeiten waren sie auch beratend für verschiedene Ministerien und Behörden tätig und haben sich für die Einführung verschiedener Regelungen des deutschen Rechts in das georgische Rechtssystem stark gemacht. Lado Chanturia ist inzwischen sogar georgischer Botschafter in Deutschland. Zudem setzen sich der heutige georgische Verteidigungsminister, Levan Izoria, der an der Universität Göttingen Jura studierte, zusammen mit dem georgischen Innenminister für eine Reform des Polizeirechts nach deutschem Vorbild ein. Georgische Professor*innen empfehlen aufgrund dieses rechtspolitischen Trends heute noch, bewusst ein Rechtsstudium in Deutschland oder in anderen westeuropäischen Ländern zu absolvieren und danach nach Georgien zurückzukommen, um ihre speziellen Kenntnisse bei der weiteren Implementierung westeuropäischen Rechts (insbesondere deutschen

39 Demnach liegen jetzt wichtige Kompetenzen beim Parlament, die vorher nur dem Präsidenten vorbehalten waren, wie z. B. die Hoheit über den Staatshaushalt oder das Militär.

40 Dabei bleibt es abzuwarten, ob diese Entwicklung des Parlamentssystems abgeschlossen ist oder in welche Richtung es sich in Zukunft entwickeln wird. 
Rechts) im georgischen Rechtssystem einzubringen (Interviews mit georgischen Alumni und Expert*innen, Tiflis, Oktober 2016). Ein georgischer Rechtswissenschaftler und KAAD-Alumnus fasst dieses Verhältnis zwischen georgischem und deutschem Recht folgendermaßen zusammen:

"Ich will besonders unterstreichen, dass der Näherung der deutschen und georgischen Juristen eine besondere Liebe und Respekt zum deutschen Recht innewohnt. [...] Hier haben viele Georgier die deutsche Sprache gründlich erlernt, was für ihre weitere Arbeit in ihrem Fach besonders wichtig war. Einer der Faktoren für die Approximation zwischen Deutschland und Georgien wurde das Rechtssystem. Das gültige Zivilgesetz Georgiens ist die Rezeption der deutschen Gesetzgebung. Bei der Reform dieses oder jenes Gebiets des Rechtes wird in Georgien immer ,das deutsche Modell" berücksichtigt (im Rahmen der Rechtshilfe). Die Reformen in Georgien werden immer von deutschen Experten unterstützt. Im Fernsehen und in der Presse können wir oft hören, dass in Deutschland jene Rechtsfrage gut entschieden ist und wir müssen den Deutschen nachfolgen. Zum Beispiel, als im Jahre 2009-2010 in Georgien umfangreiche wichtige Verfassungsreformen durchgeführt wurde, entstand in der Verfassung Georgiens das konstruktive Misstrauensvotum. Ich will sagen, dass Deutschland ist für uns in jeder Hinsicht vorbildlich" (Interview mit einem georgischen Alumnus in Tiflis, Georgien, 2016).

So waren auch viele ehemals vom KAAD geförderte Stipendiat*innen an verschiedenen rechtlichen Reformen in Georgien in den letzten Jahren beteiligt.

Ein herausragendes Beispiel ist - neben der Einführung des Parlamentarismus, worauf wir weiter unten noch eingehen - die aktuelle Reform des Jugendstrafrechts in Georgien durch ehemalige und aktuelle KAAD-Studierende. Insbesondere ein Alumnus, der zurzeit in Deutschland promoviert und bereits vor seiner Promotion in Deutschland für das Justizministerium gearbeitet hatte, macht sich für Liberalisierungen im Bereich des Jugendstrafvollzugs stark und versucht, präventive Ansätze in das georgische Recht zu integrieren. Hierfür übersetzt er regelmäßig Paragrafen und Textpassagen aus dem deutschen Jugendstrafgesetzbuch ins Georgische und schreibt an Gesetzestexten für die Neukonzipierung des georgischen Jugendstrafrechts mit. Dabei orientiert er sich sehr stark am deutschen Recht.

Ein weiterer KAAD-Alumnus setzt sich im Rahmen des georgischen Strafrechts mit Korruptionsfragen auseinander. Dabei ist es ihm wichtig, nicht nur wissenschaftlich zur Weiterentwicklung des georgischen Rechts beizutragen, sondern der Politik auch dabei zu helfen, demokratische Rechtsprinzipien und Gesetze auch im Politikalltag umzusetzen. Deswegen arbeitet er auch seit 2011 neben 
seinen Forschungsprojekten in der Vertrauensgruppe zu Korruptionsfragen des Nationalen Parlaments in Tiflis mit. Dabei beschäftigt er sich mit Korruptionsfällen von parteiübergreifenden Parlamentsmitgliedern und mit der rechtlichen Aufklärung dieser Fälle:

"Mein Vater war 28 Jahre Staatsanwalt in Georgien, auch nach der Zeit der Sowjetunion. Schon damals war Korruption unter Politikern und auch in der Gesellschaft allgemein weit verbreitet. Dies ist auch heute noch so. [...] Ich helfe dabei die Korruption unter Politikern aufzuklären, vor allem auf höchster Staatsebene. Das ist nicht leicht. Vor allem die alte Regierung war korrupt, aber Korruption tritt vereinzelt auch in der neuen Regierung auf." (Interview mit einem georgischen Alumnus in Tiflis, Georgien, 2016).

Bei dieser Arbeit profitiert er von seinen in Deutschland erworbenen Rechtskenntnissen und deren praktische Anwendung, denn auch das georgische Strafrecht und die Gesetze zur Korruptionsbekämpfung wurden größtenteils von Deutschland kopiert, so der Alumnus. Dabei helfen ihm auch seine guten Deutschkenntnisse, um in unklaren Fällen auch einmal in den deutschen Strafrechtsbüchern nachzuschlagen. Häufig bekommt er dabei auch neue Ideen, wie man einzelne Punkte im georgischen Recht noch deutlicher formulieren könnte. Im Rahmen seiner Lehrtätigkeiten an der Kaukasus-Universität Tiflis ist ihm zudem bewußt geworden, dass es kaum tiefgründige und komparative Lehrbücher auf Georgisch gibt. Deswegen hat er sich vorgenommen, ein Lehrbuch für Strafrecht zu verfassen, das das geltende Recht anhand konkreter Fallbeispiele erklärt. Solche Lehrbücher gebe es in Deutschland zuhauf, an denen er sich beim Schreiben einer georgischen Ausgabe orientieren könne. Auch seine Doktorarbeit, in der er zahlreiche Fälle sowohl anhand des deutschen als auch des georgischen Strafrechts analysiert, würden Stoff für ein Lehrbuch liefern. Trotz seiner zahlreichen akademischen Tätigkeiten kann er sich nach der Promotion eine langfristige Karriere eher im georgischen Staatsdienst als in der Wissenschaft vorstellen (Interview mit einem georgischen Alumnus, Skype, 2017).

Ein anderer georgischer KAAD-Alumnus arbeitete bereits als 23-Jähriger während seines Studiums in Tiflis als Lektor für internationales sowie georgisches Verfassungsrecht am Staatlichen Institut für ökonomische Beziehungen in Tiflis (TEUSI). Während seiner Promotion war er von 2009 bis 2013 als Mitglied im parlamentarischen Ausschuss für Kulturpflege tätig. In diesem Rahmen arbeitete er maßgeblich an einem Gesetzesentwurf zum Schutz des nationalen immateriellen Kulturerbes in Georgien mit. Dabei musste er sich insbesondere um die Recherche zu georgischen Kulturgütern kümmern sowie um den Vergleich von Gesetzen in 
anderen Ländern zu diesem Thema und um die Implementierung der UNESCOWeltkulturerbe-Richtlinien in das Gesetz. Zudem war es seine Aufgabe, Gesetzesentwürfe zu prüfen, bevor sie dem zuständigen Minister zum Unterschreiben vorgelegt wurden. Auch während seines sechsmonatigen Forschungsaufenthalts an der Juristischen Fakultät der Universität Bonn war er als Berater im georgischen Ministerium für Kultur- und Denkmalschutz tätig. Zudem unterrichtet er seit 2014 Rechtsphilosophie an der KAAD-Partneruniversität Sulkhan-Saba-Orbeliani-Universität in Tiflis. Seine in Deutschland gemachten Erfahrungen und Kontakte will er er jetzt nutzen, um ein Institut für Rechtswissenschaft nach deutschem Vorbild mit einem Forschungsschwerpunkt auf Rechtsphilosophie aufzubauen. Seine akademischen Vorbilder sind hierfür die Strukturen der Rechtswissenschaftlichen Fakultät der Universität Bonn sowie des Max-Planck-Instituts.

Dabei betont er, dass an georgischen Universitäten in den Bereichen Rechtsphilosophie und Angewandtes Recht kaum tiefer gehende Forschung betrieben wird, sondern die Professor*innen sich eher auf Lehre, das heißt auf die Vermittlung von Rechtsinhalten konzentrieren. Für ihn war es schon immer wichtig, Forschung und politische Praxis miteinander zu verbinden. In diesem Sinne, sagt er, kann Georgien noch viel von Deutschland lernen. Dabei sei auch entscheidend, dass das geschriebene Recht auch in der politischen Praxis strikt umgesetzt wird. Georgien habe damit in seiner noch jungen Demokratiegeschichte, auch aufgrund der ausgeprägten Korruption im Staatsdienst, immer Probleme gehabt. Er möchte dabei helfen, eine „Praxis des gelebten Rechts“ in Georgien zu etablieren. Deutschland habe das in seiner jüngeren Geschichte "nach vielen Jahren des Unrechts“ auch geschafft. Um die deutsche Rechtsphilosophie in Georgien bekannter zu machen, engagiert er sich neben seiner Beratungstätigkeit im Kulturministerium auch für einen politischen Austausch mit Deutschland. Hierfür lädt er auch deutsche Delegationen (mit Vertreter*innen aus Politik, Wirtschaft und Kultur) nach Georgien ein und organisiert Parlamentsbesuche und Tagesausflüge zu wichtigen nationalen Kulturstätten in Georgien, wie z. B. nach Mzcheta, Georgiens antike Hauptstadt, um den deutschen Gästen die Politik und Kultur Georgiens näher zu bringen und $\mathrm{zu}$ einem gesellschaftlichen Austausch zwischen beiden Ländern beizutragen. Zudem half er bei den Vorbereitungen für die Frankfurter Buchmesse 2018, auf der Georgien Schwerpunktland war und auch Bücher zu Georgiens Staats- und Rechtssystem vorgestellt wurden. In diesem Sinne befürwortet er auch eine stärkere Ausrichtung nach Westen und einen zeitnahen Beitritt in die EU (Interview mit einem georgischen Alumnus, Skype, 2017).

Wie bereits erwähnt, waren ehemalige KAAD-Stipendiat*innen auch an der Transformation des einst starren Präsidentialismus in ein mehr parlamentarisch geprägtes System nach deutschem Vorbild beteiligt. Ein KAAD-Alumnus, der mit 
einem dreimonatigen KAAD-Stipendium zum Thema „Perspektiven zur Implementierung eines Zweikammersystems in Georgien“ am Max-Planck-Institut für ausländisches öffentliches Recht und Völkerrecht in Heidelberg forschte und zur Zeit Juraprofessor an der East European University in Tiflis ist, berät seit mehreren Jahren den Obersten Gerichtshof Georgiens. Hierzu unterbreitete er konkrete Vorschläge, wie ein Zweikammersystem in Georgien ausgestaltet werden könnte, u. a. durch eine stärkere Einbeziehung der verschiedenen Regionen Georgiens auf nationaler Ebene nach dem Prinzip des Deutschen Bundesrates.

Auch sind die georgischen Alumni sehr aktiv in der sozialen und akademischen Netzwerkarbeit: In den letzten Jahren organisierte z. B. der „Club der ehemaligen Stipendiaten des KAAD in Georgien" zusammen mit anderen georgischen und internationalen Partner*innen verschiedene Konferenzen, bei denen es um die Entwicklung und Vernetzung in der Kaukasusregion ging. Diese fanden häufig an der KAAD-Partneruniversität Sulkhan-Saba Orbeliani Teaching University in Tiflis statt, deren Rektor ein KAAD-Alumnus ist (vgl. KAAD-Jahresbericht 2011: 89).

Obwohl also viele Stipendiat ${ }^{*}$ innen aus Georgien zurückkehren, ist auch in diesem Fall herauszustellen, dass auch Beiträge von Deutschland aus gemacht werden. Teilweise sind die Betroffenen sogar davon überzeugt, dass dies von Deutschland aus besser zu leisten sei, als wenn sie in Georgien vor Ort wären. Dazu zählen ein in Deutschland gebliebener Georgier, der von Deutschland aus ebenfalls das georgische Justizministerium berät, sowie ein aktueller Stipendiat, der neben seinem Studium für den Rechtsausschuss des georgischen Parlaments arbeitet. In seinem Fall besteht nur durch den Aufenthalt in Deutschland ein Zugang zur Fachliteratur und bei Fragen ein schneller Kontakt zu deutschen Juraprofessor*innen bzw. Richter*innen:

„Es ist wirklich so, dass Mitarbeiter aus dem Justizministerium mich regelmäßig kontaktieren und um Rat fragen, wie dies und das in Deutschland gemacht wird. Man muss sich das so vorstellen, ich gehe dann in die Bibliothek und schaue dann in den deutschen Rechtsbüchern nach und übersetze Paragraffür Paragraf. Das schicke ich dann an meine Kollegen in Georgien. Dort hätte ich nicht den Zugang zu den Gesetzestexten"(Interview mit einem georgischen Alumnus in Deutschland, Skype, 2017).

„Bei dem Verfassen von Gesetzestexten orientiert er sich sehr nah am deutschen Recht und an den bisherigen Ergebnissen seines Dissertationsprojekts. Damit leistet er einen wichtigen Beitrag zur Weiterentwicklung des georgischen Rechts. Bereits vor seinem Aufenthalt in Deutschland musste er deutsche Gesetze im Rahmen seiner Arbeit für das Justizministerium analysieren und überprüfen, inwieweit sie auch in das georgische Rechtssystem implementiert werden 
könnten. Bakuradze betonte, dass man ihn damals nur aufgrund seiner guten Deutschkenntnisse eingestellt habe, weil man händeringend einen Übersetzer mit Rechtskenntnissen suchte. Dabei bemerkte er, dass das sehr gut klappt, weil das georgische Rechtssystem bereits große Ähnlichkeiten mit dem deutschen Rechtssystem aufweist, weil es seit den 1990er Jahren, wie oben erwähnt, in Anlehnung an das deutsche Recht reformiert wird. Bakuradze ist stolz darauf, dass ganze Passagen im georgischen Jugendstrafgesetzbuch aus seiner Feder stammen. In Bezug auf das Jugendstrafrecht plädiert er für mildere Strafen und mehr Präventionsarbeit zur Bekämpfung von Jugendkriminalität. Seiner Meinung nach, hat der georgische Staat über Jahrzehnte hinweg Jugendliche bei kleineren Delikten zu hart bestraft, wie z. B. durch die Verhängung einer Gefängnisstrafe bei Marihuana-Konsum. Nach seiner Promotion in Deutschland würde er gerne wieder als fester Mitarbeiter in der Jugendstrafabteilung im Justizministerium arbeiten"(Interview mit einem georgischen Alumnus in Deutschland, Skype, 2017).

Eine andere KAAD-Alumna wurde nach einem einjährigen Masterstudium „Deutsches und Europäisches Recht und Rechtspraxis“ an der Humboldt-Universität in Berlin nach ihrer Rückkehr bereits wieder als Rechtsberaterin in der Nationalagentur für das staatliche Eigentum (AdöR) in Tiflis eingestellt, wo sie schon vor ihrem Deutschlandaufenthalt arbeitete. Für dieses einjährige Weiterbildungs-Studium - das sie mit dem internationalen Master of Laws (LL.M.) abschloß - musste sie ihren Beruf nicht kündigen, sondern wurde dafür beurlaubt. Dabei wurde sie vom CIM-Programm für georgische Rückkehrer ${ }^{\star}$ innen $^{41}$ unterstützt. Ihre Arbeitsschwerpunkte in der AdöR sind Themen wie die Verwaltung staatlichen Eigentums (Privatisierung staatlicher Unternehmen, Übertragung des Nutzungsrechts etc.) sowie die Organisation von Investitionsprojekten unter der Leitung des Ministeriums für Wirtschaft und nachhaltige Entwicklung. In Zukunft soll sie bei der Implementierung europäischer Richtlinien im Rahmen des Assoziierungsabkommens zwischen Georgien und der EU (bilaterales Freihandelsabkommen) auf Behördenebene helfen (insbesondere die die Art. 141-150 AA zur Verwaltung staatlichen Eigentums betreffen direkt die Arbeit des AdöR). Bei ihrer Arbeit, insbesondere bei der Interpretation europäischen und deutschen Rechts sowie beim Austausch mit deutschen Behörden profitiert sie direkt von ihren Deutschkenntnissen und ihrer juristischen Spezialausbildung in Deutschland. Auch um

41 Ähnlich wie in den anderen Ländern gibt es auch in Georgien das CIM-Programm der GIZ, das Rückkehrern aus Deutschland die Re-Integration in Georgien erleichtern soll, v. a. durch informelle und finanzielle Unterstützung bei der Arbeitsplatzsuche. 
diesen innereuropäischen Austausch zu unterstützen, wird diese Stelle vom CIM mitbetreut und mitfinanziert. Der gesamte Vorgang dieser zirkulären Migration - zunächst Arbeiten in Georgien, dann für ein Jahr zum Studium nach Deutschland und dann wieder zurück zum Arbeiten nach Georgien - wurde vom CIM in enger Kooperation mit der AdöR organisiert. Die Idee dahinter ist, die georgische Fachkraft im Rahmen eines längerfristigen Studienaufenthalts in Deutschland weiterzuqualifizieren, ohne dass dabei der Arbeitsplatz in Georgien verloren geht oder es zu größeren zeitlichen oder finanziellen Problemen kommt. Die zweite Hälfte des Studiums wurde vom KAAD finanziert.

Georgische Jurist*innen, die in Deutschland studiert oder geforscht haben, aber kein Stipendium vom KAAD bekommen haben, haben nach ihrer Rückkehr ebenfalls eine Funktion im georgischen Staat übernommen. So berät z. B. der Jura-Professor und Dekan der juristischen Fakultät an der Sulkhan-Saba-Orbeliani-Universität, der vor sieben Jahren ohne Stipendium sein Jura-Examen an der Universität Bremen absolvierte, neben seiner Universitätstätigkeit gleichzeitig das Justizministerium und andere staatliche Einrichtungen. Dabei hat er seinen Schwerpunkt auf das Zivilrecht gelegt und engagiert sich sehr stark dafür, dass das Eigentumsvorbehaltsprinzip, das es grundsätzlich im georgischen Zivilrecht gibt, auch häufiger in Rechtsstreitigkeiten angewandt wird. ${ }^{42}$ Andere ehemalige georgische Studierende in Deutschland machten eine politische Karriere und haben hohe Leitungspositionen in georgischen Ministerien und Behörden übernommen. Dazu gehören der oben angesprochene Botschafter in Deutschland, Lado Chanturia, und der georgische Verteidigungsminister, Levan Izoria. Ein KAS-Alumnus, der vor 10 Jahren zum Thema „Parteienrecht in Georgien und Deutschland“ an der Universität Hamburg promovierte und zurzeit als Staatssekretär im georgischen Diasporaministerium arbeitet, ist ein weiteres Erfolgsbeispiel. ${ }^{43}$ Im Diasporaministerium ist er für die Organisation internationaler Studierendenmigration zuständig. ${ }^{44}$

42 Zurzeit promoviert er auch an der Staatlichen Universität Tiflis zum Thema „Eigentumsvorbehalt im deutschen und georgischen Zivilrecht“.

43 Die Konrad-Adenauer-Stiftung (KAS) fördert im Schnitt nur einen Stipendiaten pro Jahr aus der Kaukasusregion (Georgien, Armenien und Aserbaidschan) (Interview mit einem Vertreter der KAS, Tiflis, Georgien, 2016).

44 Das georgische Diasporaministerium, das eigens für die im Ausland lebenden Georgier*innen ins Leben gerufen wurde, ist auch für die Kooperation mit den „Jungen Botschaftern Georgiens“ im Ausland verantwortlich. Der Status „Junger Botschafter“ geht auf eine Idee des Alumnus zurück, die er während seiner Tätigkeit im AStA der Universität Saarbrücken hatte. Er wollte, dass georgische Studierende einen „direkten Draht“"zum georgischen Staat bekommen und gleichzeitig auch offizielle Vertreterinnen des georgischen Staates im Ausland sind. Als er nach seiner Rückkehr anfing für die 
In seinen Arbeitsbereich fällt auch die Verwaltung des staatlichen Stipendienprogramms IEC (International Education Center) ${ }^{45}$, das eine Masterstudium und eine Promotion von georgischen Studierenden im Ausland fördert. Ungefähr 80 georgische Studierende werden jährlich über dieses Programm gefördert (Interview mit einem georgischen KAS-Alumus in Tiflis, Georgien, 2016). Dabei ist es auch möglich nur zu einem Teil von diesem Programm gefördert zu werden und zu einem anderen Teil von einem anderen Stipendiengeber*innen. Dies ist auch bei einer KAAD-Stipendiatin aus Georgien der Fall. ${ }^{46}$

Demgegenüber sollte angemerkt sein, dass ehemalige georgische Studierende, die nicht in Deutschland oder in anderen europäischen Ländern, sondern in den USA studiert haben, zumeist noch höhere Leitungsfunktionen im georgischen Staat übernommen haben. Dazu gehören z. B. der ehemalige Präsident Micheil Saakaschwili (2004 bis 2013), der Jura an Columbia University in New York studierte, der aktuelle Ministerpräsident Giorgi Kvirikashvili, der Finanzwesen an der University of Illinois studierte, oder auch einer seiner Amtsvorgänger Nika Gilauri, der einen Business Master von der Temple University in Philadelphia erlangte. Interessanterweise hat keiner der bisherigen georgischen Präsidenten, Ministerpräsidenten sowie

georgische Regierung zu arbeiten, wollte er diese Idee in die Praxis umsetzen und baute ein Netzwerk unter georgischen Studierenden im Ausland auf. Georgische Studierende können sich an der Wahl eines „Jungen Botschafters“ in sieben Ländern beteiligen, der sowohl die Interessen der georgischen Studierenden gegenüber dem georgischen Staat vertritt als auch den georgischen Staat im Ausland (Interview mit einem georgischen KAS-Alumus in Tiflis, Georgien, 2016).

45 Das Stipendienprogramms IEC (International Education Center) wurde 2014 vom georgischen Staat ins Leben gerufen, um die internationale Mobilität von georgischen Studierenden insbesondere in der EU und Nordamerika anzukurbeln und damit zu einer besseren internationalen Ausbildung für zukünftige Beamt*innen beizutragen. Im Jahr 2015 haben sich über 500 Studierende beworben, wobei 80 eine Zusage bekommen haben. Die Hauptzielländer der Stipendiat*innen sind neben den USA und Großbritannien Deutschland und Frankreich. Das Programm wird hauptsächlich vom georgischen Staat und ferner auch von der Bank of Georgia sowie internationaler Geldgeber*innen finanziert. Ausländische Studierende in Georgien werden nicht gefördert (Interview mit einem georgischen KAS-Alumus in Tiflis, Georgien, 2016).

46 Im Rahmen des Förderprogramms IEC müssen sich die Stipendiat*innen dazu verpflichten nach ihrem Studium im Ausland nach Georgien zurückzukehren und für mindestens zwei Jahre eine Position in einer staatlichen Einrichtung oder einer zivilgesellschaftlichen Organisation in Georgien einzunehmen. Die Rückkehr*innenquote liegt bei fast 100 Prozent und die meisten von ihnen gehen danach in den Staatsdienst. In diesem Sinne fungiert das IEC als eine Art staatliche Elitenrekrutierung, um international geschulte Führungskräfte für den Aufbau Georgiens zu gewinnen. 
der Justizminister in Deutschland studiert (die im Ausland studiert haben waren zumeist in Russland oder in den USA, vereinzelt auch in Frankreich).

Andere KAAD-Alumni, die keine direkten Tätigkeiten im Staatsdienst ausüben, engagieren sich ebenfalls für (demokratische) Reformen in Georgien. Dies tun sie vor allem in der Wissenschaft. In diesem Sinne tritt ein Religionswissenschaftler an der Staatlichen Universität Tiflis - der vom KAAD bereits mehrmals für seine Forschungen in Deutschland (Universität Tübingen und Ludwig-MaximiliansUniversität München) gefördert wurde - in seinen Schriften und öffentlichen Stellungnahmen immer wieder für eine klare Trennung von Kirche und Staat in der georgischen Verfassung sowie in der politischen Praxis ein. Dabei macht er deutlich, dass es eine Trennung zwischen Staat und Kirche zwar grundsätzlich in der Verfassung bereits angelegt sei, aber die privilegierte Stellung der georgisch-orthodoxen Kirche im Staate, im Gegensatz zu anderen Religionen und Konfessionen, immer noch faktisch vorherrsche. Damit ist die georgisch-orthodoxe Kirche in Georgien gegenüber anderen Kirchengruppen, wie z. B. der katholischen Kirche, sowie anderen Religionen verfassungsrechtlich höhergestellt. Zudem weisen seines Erachtens die Vertreter der orthodoxen Kirche eine (zu) enge Beziehung zur georgischen Regierung auf und üben großen Einfluss mit ihren Stellungnahmen und Politikempfehlungen auf georgische Wahlen aus. Er beschreibt das Verhältnis von Staat und Kirche in Georgien folgendermaßen:

„Das Hauptproblem hier in der Sphäre von „Religion und Staat" oder „Kirche und Gesellschaft" ist immer noch der kirchlich-orthodoxe Nationalismus und Fundamentalismus. Das heißt, die Gleichsetzung der Konfession und Nation oder Organisierung der Ortskirche nach dem Nationalprinzipien, die nach der kirchlich-theologischen Sprache Phyletismus heißt, ist ein Merkmal der Tätigkeit der gegenwärtigen georgisch-orthodoxen Kirche und des Bewusstseins der Mehrheit der heutigen georgischen Gesellschaft. Über dieses Thema schreibe ich viel. [...] Der Einfluss der orthodoxen Kirche ist manchmal so stark, dass die Regierung gezwungen ist, selbst die Entscheidungen zu verändern, die völkerrechtliche Bedeutungen haben, wenn das von den so genannten orthodoxen Georgiern gefordert wird." (Interview mit einem georgischen Alumnus in Tiflis, Georgien, 2016).

Die starke Verwobenheit zwischen georgisch-orthodoxer Kirche und Staat macht auch der erste georgische "Junior-Botschafter" in Deutschland, der im Fach Politikwissenschaft in Köln promoviert, deutlich: 
„Die georgische Kirche hat zu viel Macht. [...] Wenn man für den Staat arbeiten möchte, dann darf man nichts Kritisches gegen die orthodoxe Kirche sagen" (Interview mit dem georgischen ,Junior-Botschafter“ in Deutschland, Köln, 2016).

Der KAAD-Alumnus an der Staatlichen Universität Tiflis plädiert deswegen für eine verfassungsrechtliche Gleichstellung der religiösen Gruppierungen in Georgien und eine politische Entflechtung zwischen Vertretern der georgisch-orthodoxen Kirche und der georgischen Regierung. Dabei verweist er auch auf die deutsche Verfassung und die politische Praxis in Deutschland, in der religiöse Gruppierungen keinen direkten Einfluss auf politische Entscheidungen nehmen können (Interview mit einem georgischen Alumnus in Tiflis, Georgien, 2016).

Ein weiterer KAAD-Alumnus, der versucht durch seine wissenschaftlichen Arbeiten einen Beitrag zur gesellschaftlichen Entwicklung in Georgien zu leisten, beschäftigte sich bereits im Rahmen seiner Doktorarbeit mit Theorien der Wirtschaftsethik und dem Modell der sozialen Marktwirtschaft in Deutschland (vgl. Khizanishvili 2016). ${ }^{47}$ Die praktische Ausgestaltung der sozialen Marktwirtschaft in Deutschland studierte er während eines von der EKD geförderten Forschungsaufenthalts an der Universität Tübingen im Jahr 2010 und später noch einmal mit einem KAAD-Stipendium an der Ludwig-Maximilian-Universität im Jahr 2015. Dabei entwickelte er die Idee, dass man einzelne Aspekte der deutschen sozialen Marktwirtschaft auch auf die Wirtschaftspolitik Georgiens übertragen könne. Er sieht eine soziale Marktwirtschaft als möglichen Lösungsansatz für die wirtschaftlichen Probleme in Georgien an, die er in Verbindung mit einem „Turbokapitalismus nach amerikanischer Art" bringt, der sich rasant nach dem Zusammenbruch der Sowjetunion in Georgien ausbreitete und schnell in eine Krise mit hoher Arbeitslosigkeit und enormer Staatsverschuldung Mitte der 1990er Jahre führte. Die georgische Wirtschaft stehe seiner Ansicht nach heute zwar besser dar als in den 1990er Jahren, dennoch gibt es immer noch krasse Einkommensunterschiede und weit verbreitete Armut - insbesondere in ländlichen Gegenden. Dabei plädiert er für mehr soziale Gerechtigkeit in Georgien und macht dies am Beispiel der Weinbauern deutlich ${ }^{48}$ :

47 Die Veröffentlichung seiner Doktorarbeit wurde mit finanzieller Unterstützung des KAAD von einem georgischen Verlag in Tiflis publiziert (vgl. Khizanishvili 2016).

48 Georgien ist ein traditionsreiches Weinland, in dem seit über 4000 Jahren mehr als 500 verschiedene Weinsorten hergestellt werden. Der Weinanbau spielt eine große Rolle in der georgischen Wirtschaft und macht dabei fast zehn Prozent des georgischen BIP aus und wird zunehmend auch für den georgischen Export wichtig (NZZ 2019). 
„Georgien braucht mehr soziale Gerechtigkeit. Zum Beispiel verdienen die Weinbauern weniger als 100 Euro pro Monat, obwohl die großen Weinunternehmen, die viele kleine Anbaugebiete von Bauern in den letzten Jahren aufgekauft haben, mehrere Millionen durch Exporte ins Ausland, auch in die Europäische Union, verdienen" (Interview mit einem georgischen Alumnus in Telawi, Georgien, 2016).

Interessanterweise merkt er an, dass Grundsätze der sozialen Marktwirtschaft bereits in der georgischen Verfassung verankert sind (dazu zählen u. a. Arbeitnehmer*innenschutz und ein stabiles Sozialversicherungssystem), diese aber von der Politik nicht umgesetzt würden. Das hat ihn auch dazu motiviert, ein Lehrbuch über die Grundzüge der sozialen Marktwirtschaft und wie sie in der georgischen Wirtschaftspolitik umgesetzt werden können in georgischer Sprache zu verfassen. Das Buch soll sich nicht nur an Studierende und Forschende richten, sondern auch an die Politik. Er sieht in der sozialen Marktwirtschaft eine Erfolgsgeschichte und bezieht sich dabei auf die wirtschaftstheoretischen Schriften angefangen bei Alfred Müller-Armack und Walter Eucken, ${ }^{49}$ deren praktische Umsetzung von den 1950er Jahren unter dem früheren deutschen Wirtschaftsminister Ludwig Erhard, bis zu den wirtschaftspolitischen Schriften der Gegenwart. Konkrete Themen wie Arbeitnehmer*innenschutz, Kartellbestimmungen, Umweltschutz, Richtlinien für Außenhandel etc. werden in dem Buch behandelt. Der Alumnus ist davon überzeugt, dass eine an der sozialen Marktwirtschaft ausgerichtete Wirtschaftspolitik - die er auch den „sozialdemokratischen Weg“ nennt - auch mehr Vorteile für Georgien im Rahmen des Freihandelsabkommens mit der EU bringt - das seit Sommer 2016 in Kraft getreten ist - und Georgien schneller als volles Mitglied in die EU führen wird. ${ }^{50}$ Dies begründet er u.a. mit der Verhinderung von Lohndumping und besseren sozialen Absicherungen der Arbeitnehmer*innen. Als Wirtschaftswissenschaftler an der Staatlichen Universität Telawi (in Ostgeorgien) bietet er auch $\mathrm{zu}$ diesem Thema Vorlesungen und Seminare an (Interview mit einem georgischen Alumnus in Telawi, Georgien, 2016).

Zudem haben wir noch andere georgische KAAD-Alumni sowie Alumni anderer deutscher Stipendienwerke interviewt. Dazu gehören auch drei Germanist*innen an der Staatlichen Universität und Ilia Universität in Tiflis (vom KAAD und DAAD gefördert wurden), die sich neben ihrer wissenschaftlichen Tätigkeit auch für die

49 Beide gelten als theoretische Begründer der sozialen Marktwirtschaft in Deutschland.

50 Die Ziele der sozialen Marktwirtschaft sind auch im Vertrag von Lissabon fixiert. In Artikel 3 heißt es, dass die Europäische Union eine „wettbewerbsfähige soziale Marktwirtschaft“ mit Vollbeschäftigung und sozialem Fortschritt anstrebt (Lissaboner Vertrag 2007). 
Verbreitung der deutschen Sprache durch Vorträge, Vorlesungen und Deutschunterricht für ein breites Publikum in Georgien einsetzen (Interviews mit KAAD- und DAAD-Alumni in Tiflis, Georgien, 2016).

Viele der interviewten Alumni haben sich also bereits in ihren Master-, Doktor- und Forschungsarbeiten in Deutschland bzw. teilweise bereits schon in ihren Abschlussarbeiten bzw. Forschungstätigkeiten im Herkunftsland mit (entwicklungsrelevanten) Themen beschäftigt, die sie später in ihrem Beruf zum Zentrum ihrer Tätigkeit gemacht haben. So schrieben z. B. die beiden Juristen, die wesentlich an der Reform des Jugendstrafrechts in Georgien mitwirken, ihre Doktorarbeiten zu dem Thema „Deutsches und georgisches Jugendstrafrecht im Vergleich“ bzw. „Strafrecht für Minderjährige. Ein Vergleich zwischen Deutschland und Georgien“. Zwei andere georgische Alumni setzten sich in ihren Forschungsarbeiten mit der Implementierung eines Zweikammernsystems in Georgien auseinander. Dazu gehört die Forschungsarbeit eines älteren Wissenschaftlers mit dem Titel „Perspektiven der Implementation des Zweikammersystems in Georgien (Standarten des Bikameralismus - Theorie und Praxis)" und eines jüngeren Doktoranden, der zum Thema „Perspektiven zur Implementierung eines Zweikammernsystems in Georgien nach deutschem Vorbild" promovierte. In einer anderen Doktorarbeit eines georgischen Alumnus mit dem Titel „Elementare Grundsätze im deutschen und US-amerikanischen Rechtssystem" werden die Rechtssysteme in beiden Ländern grundsätzlich verglichen. Auch dabei wurde überlegt, inwieweit Elemente aus dem angelsächsischen und dem kontinentaleuropäischen Recht kombiniert auf das georgische Recht zu übertragen werden könnten. Ein weiterer Alumnus arbeitete zum Thema „Die rechtsvergleichende Analyse der Mechanismen einer staatlichen Kontrolle gegen Korruption zwischen Georgien und Deutschland“.

Auch nicht vom KAAD geförderte Studierende und Forschende aus Georgien beschäftigten sich mit rechtlichen Themen in Bezug auf Georgien. So z. B. eine ehemalige DAAD-Stipendiatin, die zum Thema „Versammlungsrecht in Georgien“ promovierte. Dabei kommt sie zu dem Ergebnis, dass das Versammlungsrecht in Georgien bereits seit Bestehen Georgiens schrittweise nach dem deutschen Versammlungsrecht reformiert wird und wahrscheinlich auch in den nächsten Jahren weiter nach deutschem Vorbild reformiert werden wird. Sie betont aber auch, dass es noch viele Lücken gibt und dass das Versammlungsrecht noch so weit eingeschränkt ist, dass es noch nicht vollständig westeuropäischen Normen entspricht.

$\mathrm{Zu}$ erwähnen ist schließlich ein weiterer KAAD-Alumnus, der katholischer Theologe und Rektor der KAAD-Partneruniversität Sulkhan-Saba-OrbelianiUniversität Tiflis ist, einer Universität, die vor kurzem erst unter seiner Schirmherrschaft gegründet worden ist und als erste katholische Universität in Georgien eine besondere Rolle einnimmt. Er ist zugleich er Vorsitzender des KAAD-Part- 
nergremiums in Georgien und unterstützt den KAAD bei der Auswahl geeigneter Stipendiat ${ }^{\star}$ innen und bei der Betreuung zurückgekehrter Alumni in Georgien. Für seine Arbeit bekam er 2014 den Preis der „KAAD-Stiftung Peter Hünermann“ in Bonn verliehen. Neben seinem Amt als Universitätsrektor forscht er zu Themen der christlichen Fundamentaltheologie und arbeitet an neuen didaktischen Methoden in der Religionswissenschaft in Georgien. Auf seine besonderen Verdienste soll, im nachfolgenden, den Ergebnisteil abschließenden Kapitel eingegangen werden.

\section{6 Übergreifende Aspekte}

\subsubsection{Beiträge zu den Wissenschaftssystemen}

In allen Fallstudienländern konnten übergreifende Aspekte des Wissens- und Informationstransfers beobachtet werden, unabhängig von den jeweiligen Besonderheiten eines jeden Landes. Hierzu gehört, dass wir in jedem Land einen Einfluss ehemaliger KAAD-Stipendiat ${ }^{*}$ innen auch auf die jeweiligen Wissenschaftssysteme beobachten konnten, da unter den Geförderten auch viele Wissenschaftler*innen sind bzw. ein Teil der Geförderten nach seinem Studium in der Wissenschaft geblieben ist. Insofern haben wir auch mit vielen Alumni gesprochen, die nach ihrem Studien- oder Forschungsaufenthalt neue Lehr- und Forschungsmethoden mit in ihre Herkunftsländer gebracht haben und nun an ihre Studierenden weitergeben. Die Beispiele hierfür sind vielfältig. Ein kolumbianischer KAAD-Alumnus etwa, der im Bereich Bankrecht in Deutschland promovierte und kurz danach auf eine Professur an der juristischen Fakultät der renommierten Universidad Nacional in Bogotá berufen wurde, führte in Kolumbien „Kapitalmarktrecht in Lateinamerika“ als neuen Lehrschwerpunkt ein.

Der oben erwähnte KAAD-Alumnus aus Ghana, der an der Universität Kumasi neue Untersuchungsmethoden der Wasserqualität in Flüssen und Seen entwickelt, lernte die Grundlagen hierfür während seines Studiums in Deutschland kennen. Eine andere ghanaische Alumna des KAAD an der Legon Universität in Accra begründete den in Ghana bis dato unbekannten Forschungsschwerpunkt „Landwirtschaft und Gender", auf den sie während ihrer Promotion in Deutschland stieß und zu dem sie seit ihrer Rückkehr regelmäßig Seminare anbietet.

Andere Alumni haben Netzwerke zwischen ihren Herkunftsländern und Deutschland aufgebaut, die inzwischen teilweise auch weit über Deutschland und das Herkunftsland hinausgehen. Die oben erwähnte indonesische Juristin etwa, die in Deutschland mit einem KAAD-Stipendium promovierte und jetzt Vizedekanin der 
Juristischen Fakultät an der KAAD-Partneruniversität Atma Jaya in Indonesien ist, hat ein dichtes Forschungsnetzwerk zwischen Europa und Asien aufgebaut. Hierfür ist sie noch regelmäßig in Europa, zuletzt für einen zweijährigen PostdocAufenthalt in Belgien, wo sie sich mit dem Wettbewerbsrecht in Westeuropa beschäftigt hat. Zurzeit arbeitet sie mit japanischen und koreanischen Kolleg*innen an einer vergleichenden Studie zum Wettbewerbsrecht in asiatischen Staaten. Ein Alumnus aus Palästina, der mittlerweile Professor für Klinische Psychologie mit Schwerpunkt Therapieforschung an der Hochschule Göttingen ist und im Bereich der Angsttherapie und Behandlung von Traumata bei Geflüchteten forscht, versucht, ein Forschungsnetzwerk mit Universitäten im Nahen Osten aufzubauen. Dabei soll vor allem der im Nahen Osten noch junge Zweig der psychologischen Therapieforschung gestärkt werden, der bisher noch in den Kinderschuhen steckt und aufgrund der politischen und sozialen Lage vor Ort schwierig ist.

Auch deutsche Universitäten oder Forschungszentren nutzen die internationalen Studierenden und Forschenden, um neue Partnerschaften aufzubauen, neue Forschungsfelder zu erschließen oder um internationale Forschungsprojekte durchzuführen. Ein Beispiel hierfür ist eine kolumbianische KAAD-Alumna, der während ihrer Promotion in Deutschland ein Angebot von der Helmholtz-Gemeinschaft Deutscher Forschungszentren (HGF) über ein Forschungsprojekt zur Pestizidnutzung in landwirtschaftlich genutzten Böden in Kolumbien unterbreitet wurde. Die HGF wurde nicht nur deswegen auf sie aufmerksam, weil sie in diesem Bereich promovierte, sondern weil sie auch die Forschungsbedingungen in Kolumbien gut kannte. Im Rahmen des Projekts werden heute Bodenproben in Kolumbien entnommen und im HGF-Forschungszentrum in Deutschland ausgewertet. Dabei entstand eine enge Kooperation mit der Partneruniversität in Medellin. Ähnlich war es auch bei einem kolumbianischen KAAD-Alumnus, der eine Partnerschaft zwischen einer deutschen Universität und der Universidad del Rosario in Bogotá initiierte. Ein KAAD-Alumnus aus Palästina war maßgeblich an einem Partnerschaftsabkommen zwischen dem Biologie-Institut der Bethlehem Universität und der Universität Leipzig beteiligt. Ein weiterer Alumnus hat an der Universidad Javeriana, einer Partneruniversität des KAAD in Bogotá, ein Chemielabor aufgebaut, das zu den besten in Kolumbien gehört. Hierfür warb er Drittmittel beim kolumbianischen Bildungsministerium und privaten Fördereinrichtungen ein und stattete das Labor mit Forschungsgeräten aus Deutschland aus. Während seines vom KAAD geförderten Forschungsaufenthalts in Deutschland hatte er intensiv mit diesen Geräten vertraut gemacht. Auch das oben erwähnte deutsch-kolumbianische Friedens- und Konfliktforschungsnetzwerk CAPAZ (Instituto Colombo-Alemán para la Paz) wurde u. a. mit Forschungsgeldern aus Deutschland mitfinanziert (vom DAAD). Ihre internationale Erfahrung und ihre transnationalen Netzwerke 
bedeuten daher für viele KAAD-Alumni gegenüber anderen (nicht international ausgerichteten) Mitbewerber*innen um Forschungsgeld einen Wettbewerbsvorteil.

Das herausragendste Beispiel ist aber sicher in Georgien zu finden, wo der eben erwähnte ehemalige KAAD-Stipendiat maßgeblich an der Gründung einer Universität beteiligt war, nämlich der oben schon erwähnten katholischen Sulkhan-Saba Orbeliani Universität in Tiflis. Seit 2008 fungiert der Alumnus auch als Rektor der Universität. In dieser Funktion lässt er sich stark von den Erfahrungen seiner Studien- und Promotionszeit in Deutschland leiten. So versucht er, Elemente des Theologiestudiums in Deutschland in Georgien einzuführen (zunächst an der Orbeliani Universität) und neben klassischen Vorlesungen auch Kolloquien und Seminare zur Vertiefung des Lehrstoffes und aktiven Teilnahme der Studierenden anzubieten. Inzwischen sind auch andere KAAD-Alumni als Professor ${ }^{*}$ innen an die Orbeliani-Universität berufen worden bzw. als Lehrbeauftragte tätig, die entsprechende Curricula für ihre Fächer entwickeln. Zudem werden zentrale theologische Schriften und Lehrbücher (vor allem aus dem Deutschen und Englischen) ins Georgische übersetzt. Der erste von drei geplanten Bänden zur Fundamentaltheologie in georgischer Sprache ist bereits erschienen. Dies wird in der Fachwelt als Pionierleistung für die theologische Lehre in Georgien angesehen (KAAD 2013).

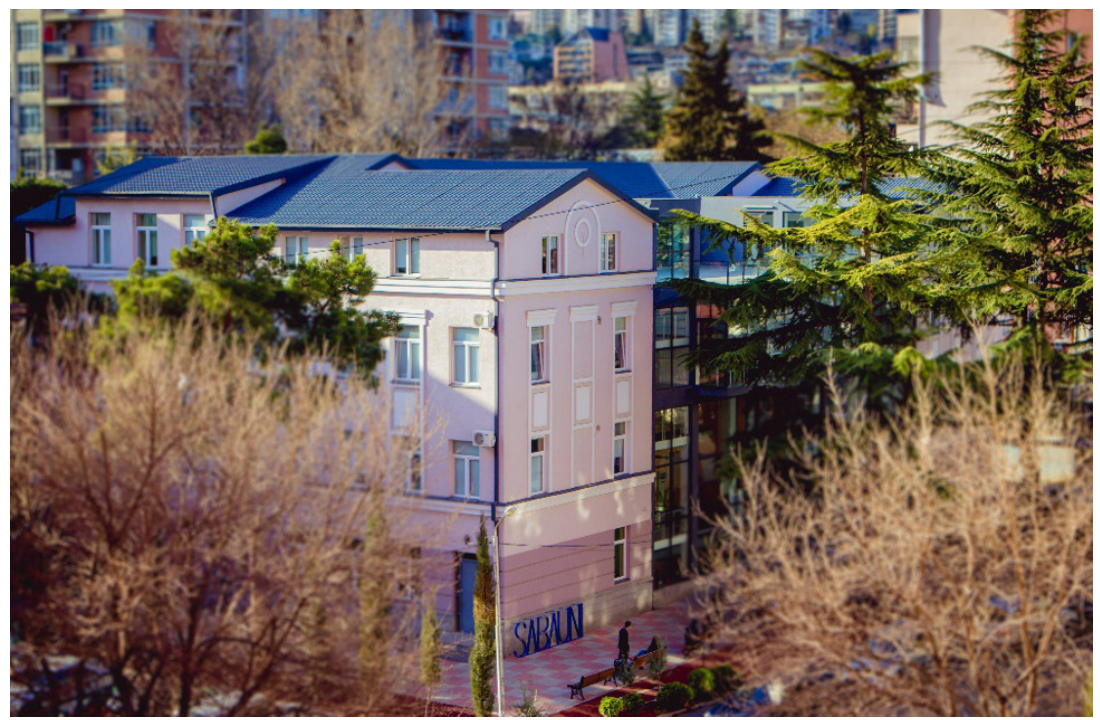

Aufnahme 5 Sulkhan-Saba Orbeliani Universität in Tiflis

Quelle: Sulkhan-Saba Orbeliani Universität in Tiflis 


\subsubsection{Schwierigkeiten bei der Re-Integration}

Ein zweiter, wichtiger, übergreifender Befund der Studie ist, dass vielen Alumni die Rückkehr und Re-Integration in ihr Herkunftsland trotz aller Erfolgsgeschichten nicht immer leicht gefallen ist und viele sogar sagten, dass ihnen die Wieder-Eingewöhnung nach der Rückkehr im Herkunftsland sogar schwerer fiel als die Eingewöhnung in Deutschland zu Beginn des Studiums. Oftmals wurde die Rückkehr in die Heimat als „zweiter Kulturschock“ beschrieben. In unserer Online-Umfrage waren es fast 60 Prozent, die angaben, solche oder ähnliche Probleme nach der Rückkehr gehabt zu haben. Ein ghanaischer Alumnus sagte dazu:

„Es ist hart für die Rückkehrer, sich wieder in Ghana einzufinden. Es ist sehr anstrengend und frustrierend, dass nichts funktioniert. Das sind sie nicht mehr gewöhnt. In Deutschland funktionieren die meisten Dinge. In Ghana kommen alle zu spät und es passiert lange nichts, bevor es endlich losgeht. Das ist frustrierend, aber langsam gewöhnen wir uns wieder daran" (Interview mit einem ghanaischen Alumnus in Accra, Ghana, 2018).

Als große Probleme bei der Reintegration wurden zudem Luftverschmutzung, Staus in den Großstädten und lange Wege zum Arbeitsplatz genannt. Ein Alumnus aus Indonesien äußerte sich folgendermaßen dazu:

„Es war wirklich ein Kulturschock am Anfang, nach mehreren Jahren in Deutschland wieder zurück in Jakarta zu sein. Für mich war alles viel zu laut am Anfang, die Stadt war so dreckig und der Verkehr war für mich am Anfang auch unerträglich. Das war ich nicht mehr gewöhnt. Ich wollte eigentlich sofort wieder zurück in mein kleines und ruhiges Karlsruhe. Ich war komplett überfordert am Anfang und wusste erst einmal gar nicht, wie ich mich auf die Umstellung einstellen sollte. Das hat sich erst nach mehreren Monaten gelegt" (Interview mit einem indonesischen Alumnus in Jakarta, Indonesien, 2017).

Eine Alumna aus Ghana äußerte sich ähnlich:

„Es hat sehr lange gedauert bis ich mich an das langsame Leben in Ghana gewöhnt habe, und vor allem daran, dass die Reisewege in Ghana so lange dauern und anstrengend sind. In dieser Hinsicht vermisste ich Deutschland am Anfang schon sehr. Es hat einige Monate gedauert bis ich mich wieder daran gewöhnt habe" (Interview mit einer ghanaischen Alumna in Accra, Ghana, 2018). 
Zudem stellte aber auch der Umgang mit sozialer Ungleichheit in den Herkunftsländern eine große Herausforderung dar. Viele Alumni haben während ihres Studiums in Deutschland Werte wie der Schutz von religiösen und sozialen Minderheiten und die soziale Gleichstellung von Mann und Frau zu schätzen gelernt. Eine kolumbianische Alumna äußerte sich folgendermaßen dazu:

"Als ich wieder nach Kolumbien gekommen bin, war es am Anfang schwierig mich wieder einzugewöhnen. Es war schwierig. [...] Das größte Problem hier, und das habe ich vor meiner Zeit in Deutschland nicht so stark wahrgenommen, ist das Frauenbild. Hier gibt es viel Machismo. Und das kann es auch sehr schwer machen, hier als Professorin oder Anwältin oder Richterin $z u$ arbeiten, weil die Männer einen nicht voll ernst nehmen. Das kann sehr schwierig werden. Ich muss noch lernen damit umzugehen. Es ist schwieriger als Frau hier Karriere zu machen" (Interview mit einer kolumbianischen Alumna in Bogotá, Kolumbien, 2017).

Knapp 30 Prozent der Befragten in unserer Umfrage gaben zudem an, sehr lange gebraucht zu haben, einen Beruf zu finden, der ihrer Qualifikation entspricht. Einige haben sich deswegen selbstständig gemacht (rund $5 \%$ in unserer Onlinebefragung). Dies betrifft z. B. die oben genannten Ärzt*innen in Palästina wie Unternehmer*innen in Indonesien. Eine indonesische Alumna, die Veterinärwissenschaft in Deutschland studierte, hatte fast zwei Jahre nach ihrer Rückkehr eine Stelle gesucht. Danach fand sie auch nur einen Job als Verkäuferin in einem Tierladen auf Sumatra, wo sie ungefähr drei Jahre arbeitete, bevor sie wieder entlassen wurde. Heute ist sie wieder arbeitslos. Eine palästinensische Alumna, die Gesundheitsmanagement in Heidelberg studierte, suchte fast ein Jahr nach einem Arbeitsplatz nach der Rückkehr in Israel, bis sie einen Arbeitsplatz als Krankenschwester in einem jüdischen Krankenhaus in Jerusalem fand. Ein kolumbianischer Alumnus schilderte seine Probleme bei der Jobsuche folgendermaßen:

"Ich hatte mich schon von Deutschland aus für verschiedene Jobs an Universitäten in Kolumbien beworben, aber leider keinen bekommen. Als ich und meine Familie im September 2011 zurückgekommen sind, hatte ich mehrere Monate keinen Job gefunden. Erst im Januar 2012 habe ich meine Stelle als Assistenzprofessor an der Rosario Universität in Bogotá bekommen. Dort arbeite ich jetzt schon fast sechs Jahre"(Interview mit einem kolumbianischen Alumnus in Bogotá, Kolumbien, 2017). 
Fast drei Viertel der Befragten gaben in unserer Onlineumfrage jedoch an, dass sie heute mit ihrem Beruf zufrieden sind. Gleichzeitig waren aber auch 63 Prozent der Befragten mit ihrer Bezahlung unzufrieden. Das betrifft insbesondere diejenigen, die im akademischen Bereich arbeiten. Ein indonesischer Alumnus beklagte:

"I work full time, sometimes more than 50 hours in a week, but I earn too little to manage my life. Here at the university I only earn a little bit more than 300 Euros. This is not enough for me and my two little children. My wife has a small job, and earns about 150 Euros. We can not afford a car, so I have to take the public transport system here in Yogyakarta. This takes a lot of time, and sometimes I feel I spend more time on the bus than at the university, or with my family. I don't see that this situation will change in the future time, or that I will earn more money. It is really difficult" (Interview mit einem indonesischen Alumnus in Jakarta, Indonesien, 2017).

Auch die geringen Forschungsgelder sind ein großes Problem für die wissenschaftliche Arbeit der Alumni. Ein Alumnus in Kolumbien bemängelte:

„Die größte Herausforderung für mich ist es, ein gutes Forschungsteam aufzubauen und Forschungsgelder für meine Projekte zu bekommen. In Kolumbien ist das nicht wie in Deutschland. Man kann nicht einfach Geld bei der Uni oder bei Fördereinrichtungen in Kolumbien beantragen. Hier gibt es nicht so viel Geld für Forschung. Eine der wenigen Möglichkeiten, Geld zu bekommen ist, wenn man mit internationalen Forschern aus Deutschland oder den USA zusammenarbeitet. Die können leichter Geld in ihren Ländern beantragen und davon können auch wir im Forschungsteam profitieren, aber leider konnte ich noch nicht in so einem internationalen Forschungsteam mitarbeiten. [...] Es ist auch schwierig, gute Forscher in Kolumbien zu finden, mit denen man gut arbeiten kann und die gelernt haben, wie man gute Forschung macht" (Interview mit einem kolumbianischen Alumnus in Bogotá, Kolumbien, 2017).

Bürokratie und Korruption stellen weitere Herausforderungen dar. Das wurde besonders häufig von den ghanaischen Alumni erwähnt:

„In Ghana zu arbeiten ist jeden Tag eine Herausforderung, besonders weil die staatlichen Behörden immer misstrauisch sind gegenüber neuen Ideen und einem erst einmal Steine in den Weg legen müssen" (Interview mit einem ghanaischen Alumnus in Tamale, Ghana, 2018). 
Ein sehr wichtiges Projekt, das den Beruf einer KAAD-Alumna in Ghana sichern sollte, scheiterte fast komplett aufgrund der ghanaischen Bürokratie. Sie sagte:

„Wir mussten wir viele Unterlagen ausfüllen. Und alleine um unser Flugzeug nach Ghana zu bekommen und in Ghana zu nutzen, brauchten wir drei Zusagen, nämlich von der Zivilen Flugbehörde (civil aviation), vom National Security Office und vom Außenministerium. Es dauerte insgesamt über drei Monate, um alle Zusagen zu bekommen. Das war sehr frustrierend [...] Ein großes Problem der Bürokratie hier in Ghana sind auch die langen Behördengänge, vor allem muss man zuerst von einem Vorbüro in das andere, anstatt direkt einen Termin bei der Person zu bekommen, die für die Bearbeitung direkt verantwortlich ist. Dabei braucht man auch bei jeder Person einen Termin. Das kann lange dauern und einem Unternehmen auch viel Geld kosten" (Interview mit einer ghanaischen Alumna in Accra, Ghana, 2018).

Auch anderen ghanaischen Alumni macht die ausufernde Bürokratie zu schaffen:
"It is really difficult to get projects done on time. Because of bureaucracy. You need papers for everything, and it can take a long time until the responsible agents make a final decision. That's true for business, but also for academia. If I get funding for a research project from an international research foundation, $I$ need also written agreements from the government and from my university. That can take a long time" (Interview mit einem ghanaischen Alumnus in Kumasi, Ghana, 2018).

Zudem war auch die institutionelle Diskriminierung von religiösen Minderheiten ein Problem für Alumni. Das gilt für alle Herkunftsländer in der Fallstudie, wurde aber insbesondere von den indonesischen Alumni erwähnt. In Indonesien, wo sich die muslimische Mehrheitsgesellschaft in den letzten Jahren zunehmend radikalisiert, sieht man auch die wachsende Intoleranz von politischen und juristischen Institutionen gegenüber religiösen Minderheiten im Land. Ein KAAD-Alumnus, der Katholik ist, stellte fest:

„Joko Widodo [Präsident Indonesiens] ist ein Hoffnungsträger für mich. Er ist zwar auch Muslim, aber er ist nicht für die Radikalisierung der Muslime in Indonesien verantwortlich. Sondern es sind eher die lokalen Politiker und Gerichte. Die Einflüsse von Widodo sind dabei sehr begrenzt, wegen der Gewaltenteilung hier in Indonesien. Das ist gut, aber die Gerichte treffen'manchmal falsche Entscheidungen, die Christen oder andere Gruppen diskriminieren 
können. Das sind schwere Entscheidungen und Joko findet das bestimmt nicht gut. Ich glaube aber, er gibt sein bestes" (Interview mit einem indonesischen Alumnus in Pontianak, Indonesien, 2017).

Für über 42 Prozent der befragten Alumni in der Online-Studie stellt zudem die fehlende Zuverlässigkeit oder Unpünktlichkeit anderer ein Problem dar ( $\mathrm{n}=212)$. Fast 36 Prozent der Befragten gaben darüber hinaus an, dass die unterschiedliche Arbeitsweise der Kolleginnen und Kollegen ein Problem für sie darstelle. Ein Kolumbianer wies folgendermaßen darauf hin:

„Die Leute wollen hier viele Dinge gleichzeitig machen. Es ist schwer sich hier auf eine Sache zu konzentrieren. Am Ende werden viele Dinge gleichzeitig gemacht, und dafür aber nichts richtig gut. Häufig werden die Dinge auch überhaupt nicht zu Ende gebracht" (Interview mit einem kolumbianischen Alumnus in Bogotá, Kolumbien, 2017).

In Kolumbien werden Probleme zwischen Mitarbeiter*innen häufig nicht direkt angesprochen, sondern es wird erst einmal versucht, sich ohne größere Konflikte miteinander zu arrangieren. Eine kolumbianische Alumna sagte dazu:

"Ich habe keine Probleme mit Kolumbianern zusammen zu arbeiten, generell gibt es keine Probleme. Mein Vorteil ist, dass ich sehr direkt bin, das war ich schon immer. Ich sage, wenn mir was nicht passt. Das kann vielen Problemen bei der Arbeit vorbeugen. In Kolumbien ist man das nicht so gewöhnt. Man spricht hier Probleme nicht direkt an, sondern versucht, miteinander irgendwie still auszukommen. Aber ich finde, das verursacht noch weitere Probleme. Deswegen spreche ich das direkt an. Nicht immer leicht, vor allem als Frau in diesem Macho-Land" (Interview mit einer kolumbianischen Alumna in Bogotá, Kolumbien, 2017).

An den unterschiedlichen Arbeitsweisen können Alumni auch scheitern, die positive Veränderungen nach ihrer Rückkehr anstoßen wollen. Ein Beispiel aus Kolumbien:

"Ich habe viele Herausforderungen hier. Mein Leben besteht aus Herausforderungen, das habe ich sehr gerne. Es ist Folgendes: Ich habe zunächst an der Uni eine gute akademische Herausforderung gehabt. Ich wollte in Kolumbien, das heißt meine Herausforderung bestand darin, meine Professur so auszuüben, wie es in Deutschland üblich ist. Das heißt, dass ich eine gute Forschung als Professor machen kann, und dass die Studenten wirklich wissenschaftlich 
arbeiten können, zu denken beginnen und wissenschaftlich arbeiten. Das war meine Herausforderung. Es ist mir leider nicht gelungen. Ich war sehr alleine da und das ist nicht so einfach hier in Kolumbien. Meine Herausforderung im beruflichen Leben besteht darin, die ausgezeichnete Kanzlei aufzubauen und zu leiten. Die Leitung werde ich bald an einen der Mitarbeiter abgeben. Aber eine richtig gute Kanzlei aufzubauen, die auf Dauer halten kann. Ich hoffe, dass diese Kanzlei immer besteht, auch in 100 Jahren" (Interview mit einem kolumbianischen Alumnus in Bogotá, Kolumbien, 2017).

Über 90 Prozent der befragten Alumni sind insgesamt trotzdem zufrieden mit der Entscheidung, in ihr Herkunftsland zurückgekehrt zu sein.

\subsubsection{Veränderte Sicht auf die Welt}

Wie schon angedeutet, haben wir in unserer Studie die internationalen Studierenden und Alumni auch gefragt, was für sie „globale Gerechtigkeit“ bedeutet und wie sich durch ihr Studium in Deutschland und die generelle Erfahrung der Migration ihre grundsätzliche „Sicht auf die Welt“ verändert hat. Die zentrale, übergreifende Antwort auf diese Frage war, dass sie durch den Studienaufenthalt im Ausland eine neue, globale und umfassendere „Sicht auf die Welt" bekommen hätten. So wurden durch das Studium im Ausland nicht nur ihre akademischen und beruflichen Fähigkeiten ausgebildet (s. o.), sondern sie wurden auch für globale Zusammenhänge und Herausforderungen sensibilisiert, insbesondere in Bezug auf das Verhältnis zwischen Globalen Norden und Globalen Süden, die Entwicklung des Globalen Südens sowie ihr persönliches Verständnis von "Gerechtigkeit“, „Entwicklung“" und „Glaube“.

Interessanterweise sahen viele Alumni dabei die größere Verantwortung für die Entwicklung bei den Ländern des Globalen Südens. Der Norden sollte ihnen aber mehr Freiraum und Partizipationschancen einräumen. Die Initiative müsse aber von den Ländern des Globalen Südens selbst kommen. Dabei nehmen sie in der Mehrheit ihre Rolle als „Entwicklungsmotoren“, „Vermittler zwischen dem Süden und Norden“, „Brückenbauer" oder "Change Agents" durchaus an. Ein Stipendiat sagte in diesem Zusammenhang:

"Ausbildung von Leadership. Afrika fehlen lokale Leader wie ein Martin Luther einst in Europa oder Martin Luther King in den USA, die unsere Kommunen mitnehmen und Menschen positiv verändern können. Ich möchte mich nicht mit den Großen vergleichen, aber wir müssen in diese Richtung denken. Wir 
haben die Bildung und das Potenzial, und wir kennen die Geschichte. Und wir haben Erfahrungen in Deutschland gemacht. Wir müssen im Kleinen anfangen und die Kommunen verändern, wir haben es eigentlich in den Händen. Und dadurch werden wir auch selbstständiger und unabhängiger" (Interview mit einem ghanaischen Stipendiat, Skype, 2017).

In Bezug auf die konkreten Lösungsansätze unterscheiden sich die Antworten sehr stark in Abhängigkeit von den Entwicklungsschwerpunkten der einzelnen Länder. Ghanaer*innen wiesen auf die Bedeutung der Umwelt und der Entwicklung der Landwirtschaft in ihrem Land hin. Palästinenser*innen sorgten sich um den Frieden und die gesundheitliche Versorgung. Indonesier*innen verwiesen vor allem auf die Chancen einer wirtschaftlichen Entwicklung, gerade im Technologiesektor, mahnten gleichzeitig aber auch Reformen mit Blick auf den Umweltschutz an. Georgier*innen war die demokratische und rechtliche Entwicklung des Landes wichtig und für Kolumbianer*innen war der Friedensprozess im eigenen Land zentral. Ein kolumbianischer Alumnus sagte dazu:

„Das Wichtigste für Kolumbien ist jetzt, dass sich der Friedensprozess stabilisiert [...]. Ohne den Frieden und das freie Zusammenleben in den stark geschädigten Dörfern wird es keine Entwicklung Kolumbiens geben. Erst wenn der Frieden sicher ist, wird sich Kolumbien gut entwickeln können"(Interview mit einem kolumbianischen Alumnus in Bogotá, Kolumbien, 2017).

Dabei wurde auch deutlich, dass nicht nur der Süden durch das gesammelte Wissen der Alumni profitiert - wie oben im Detail geschildert - sondern auch der Norden vom Süden durch die Stipendiat ${ }^{\star}$ innen und Alumni lernen kann. Dazu gehören laut der Alumni und Stipendiat*innen u. a. mehr Spontanität, Gelassenheit, Freundlichkeit und eine stärkere Betonung der Familie und des gesellschaftlichen Miteinanders insgesamt. Ein Alumnus aus Ghana erklärte dazu:

"Es gibt auch Dinge, die Deutschland von Ghana lernen kann. So könnten sich die Deutschen mehr Zeit für Freizeit und ihre Freunde nehmen. Nicht immer nur zu arbeiten, sondern auch einmal Dinge gemeinsam zu machen. Das würde das soziale System im Privaten stärken, nicht nur in der gesellschaftlichen Öffentlichkeit. Wir waren auch erschrocken, wie wenig man sich privat um alte Menschen in Deutschland kümmert. In Ghana kümmern sich die jungen Familienmitglieder um die älteren Familienmitglieder. Man lebt solange mit den Großeltern zusammen bis sie sterben. [...] Die Deutschen haben keine Ahnung von Kunst, das könnten sie von uns lernen. Wir Ghanaer wissen, wie 
man Musik macht, tanzt und schöne Kleidung, Figuren und Masken herstell “ (Interview mit einem Alumnus in Accra, Ghana, 2018).

Eine KAAD-Stipendiatin aus Georgien machte deutlich, dass die kulturelle Diversität in den Ländern des Globalen Südens einen Mehrwert für den Norden haben kann:

\begin{abstract}
„Unsere Kultur ist sehr vielfältig, wir sind das zweitälteste christliche Land nach Armenien. Wir haben eine sehr alte Wissens- und Schriftkultur und haben eine sehr lange Tradition der Architektur. Und wir haben die älteste Weinkultur der Welt. Aber im Westen wissen das nicht viele Menschen. Georgien ist immer noch ein unbekanntes Land für sie. In Deutschland erzähle ich viel von Georgien, und die Leute sind dann erstaunt, wie wichtig Georgien auch für die europäische Kultur ist und dass es da immer einen regen Austausch über Jahrtausende gab. Diese Traditionen und das Wissen müssen wir jetzt wiederentdecken und untereinander austauschen, auch auf akademischer Ebene" (Interview mit einer georgischen Stipendiatin, Berlin, 2016).
\end{abstract}

Open Access Dieses Kapitel wird unter der Creative Commons Namensnennung 4.0 International Lizenz (http://creativecommons.org/licenses/by/4.0/deed.de) veröffentlicht, welche die Nutzung, Vervielfältigung, Bearbeitung, Verbreitung und Wiedergabe in jeglichem Medium und Format erlaubt, sofern Sie den/die ursprünglichen Autor(en) und die Quelle ordnungsgemäß nennen, einen Link zur Creative Commons Lizenz beifügen und angeben, ob Änderungen vorgenommen wurden.

Die in diesem Kapitel enthaltenen Bilder und sonstiges Drittmaterial unterliegen ebenfalls der genannten Creative Commons Lizenz, sofern sich aus der Abbildungslegende nichts anderes ergibt. Sofern das betreffende Material nicht unter der genannten Creative Commons Lizenz steht und die betreffende Handlung nicht nach gesetzlichen Vorschriften erlaubt ist, ist für die oben aufgeführten Weiterverwendungen des Materials die Einwilligung des jeweiligen Rechteinhabers einzuholen. 